\title{
Border Crossings:
}

The Cultural Brokerage and Artistic Practice of David Ruben Piqtoukun

By

Krystina Marie Mierins, B.A. Hons.

A Thesis submitted to the Faculty of Graduate Studies and Research in partial fulfilment of the requirements for the degree of

Master of Arts

in Art History: Art and Its Institutions

Carleton University

OTTAWA, Ontario

August 10, 2008

(C) 2008, Krystina Marie Mierins 


$\begin{array}{ll}\begin{array}{l}\text { Library and } \\ \text { Archives Canada }\end{array} & \begin{array}{l}\text { Bibliothèque et } \\ \text { Archives Canada }\end{array} \\ \begin{array}{l}\text { Published Heritage } \\ \text { Branch }\end{array} & \begin{array}{l}\text { Direction du } \\ \text { Patrimoine de l'édition }\end{array} \\ \begin{array}{l}\text { 395 Wellington Street } \\ \text { Ottawa ON K1A 0N4 } \\ \text { Canada }\end{array} & \begin{array}{l}\text { 395, rue Wellington } \\ \text { Ottawa ON K1A 0N4 } \\ \text { Canada }\end{array}\end{array}$

Your file Votre référence ISBN: 978-0-494-43480-2

Our file Notre référence

ISBN: 978-0-494-43480-2

NOTICE:

The author has granted a nonexclusive license allowing Library and Archives Canada to reproduce, publish, archive, preserve, conserve, communicate to the public by telecommunication or on the Internet, loan, distribute and sell theses worldwide, for commercial or noncommercial purposes, in microform, paper, electronic and/or any other formats.

The author retains copyright ownership and moral rights in this thesis. Neither the thesis nor substantial extracts from it may be printed or otherwise reproduced without the author's permission.
AVIS:

L'auteur a accordé une licence non exclusive permettant à la Bibliothèque et Archives Canada de reproduire, publier, archiver, sauvegarder, conserver, transmettre au public par télécommunication ou par l'Internet, prêter, distribuer et vendre des thèses partout dans le monde, à des fins commerciales ou autres, sur support microforme, papier, électronique et/ou autres formats.

L'auteur conserve la propriété du droit d'auteur et des droits moraux qui protège cette thèse. $\mathrm{Ni}$ la thèse ni des extraits substantiels de celle-ci ne doivent être imprimés ou autrement reproduits sans son autorisation.
In compliance with the Canadian Privacy Act some supporting forms may have been removed from this thesis.

While these forms may be included in the document page count, their removal does not represent any loss of content from the thesis.
Conformément à la loi canadienne sur la protection de la vie privée, quelques formulaires secondaires ont été enlevés de cette thèse.

Bien que ces formulaires aient inclus dans la pagination, il n'y aura aucun contenu manquant.

\section{Canada}




\begin{abstract}
This thesis examines contemporary Inuit artist David Ruben Piqtoukun's selfpositioning as a cultural intermediary. By looking at Ruben's interactions with the art world in two different fora - exhibition and the web, I trace how his role as a "culture broker" transformed from its genesis within a colonial power structure to its current existence in a transnational context. Ruben initially worked in an art community that was part of a hierarchical nation-state structure, but globalizing factors have lead to a dispersal of power. Ruben collaborated with curator Darlene Wight and art dealer Harold Seidelman for the 1996 solo exhibit Between Two Worlds, and had an unprecedented degree of participation as an Inuit artist. Transnational tools, such as the internet, have provided Ruben with the means to gain control over his career. Various art world participants, such as museums and patrons, continue to play a role in Ruben's career, but no longer have as much influence.
\end{abstract}




\section{Table of Contents}

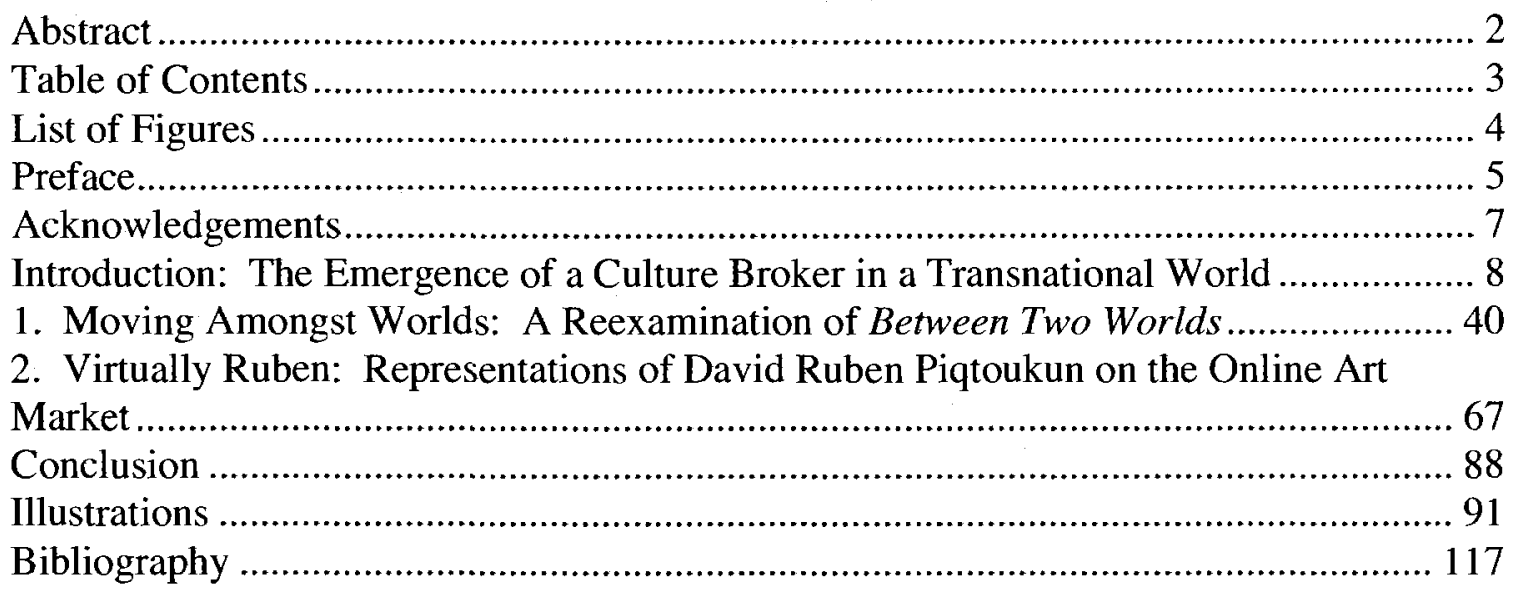




\section{List of Figures}

\section{Introduction}

Figure i.1

Figure i.2

Figure i.3

Figure i.4

Figure i.5

Figure i.6

\section{Chapter One}

Figure 1.1

Figure 1.2

Figure 1.3

Figure 1.4

Figure 1.5

Figure 1.6

Figure 1.7

Figure 1.8

Figure 1.9

Figure 1.10

Chapter Two

Figure 2.1

Figure 2.2

Figure 2.3

Figure 2.4

Figure 2.5

Figure 2.6

Figure 2.7

Figure 2.8

Figure 2.9
Absorbing the African Way, 1982

Like Father, Like Son, 2004

Aura, 1996

Division of Meat, 1996

Airplane, 1995

Our Spirits: They Soar High, 2007

Installation Shot, Between Two Worlds, Canadian Museum of Civilization

Installation Shot, Between Two Worlds, Canadian Museum of Civilization

Installation Shot, Between Two Worlds, Canadian Museum of Civilization

Installation Shot, Between Two Worlds, Canadian Museum of Civilization

Guidepost, 1995

The Choice, 1995

Spirits of My Ancestors, 1995

Priest and Nun, 1995

Sedna Lives, 1995

Journey to the Great Woman, 1995

Screenshot, Gallery d'Art Vincent website, virtual gallery of David Ruben Piqtoukun's work

Screenshot, Galerie Elca London website, virtual gallery of David Ruben Piqtoukun's work

Screenshot, Galerie Elca London website, David Ruben

Piqtoukun's biography

Screenshot, Home and Away Gallery website, virtual gallery of David Ruben Piqtoukun's work

Screenshot, Home and Away Gallery website, David Ruben

Piqtoukun's biography

Screenshot, David Ruben Piqtoukun: Artist Romancing the Stone, www.davidruben.com

Screenshot, www.davidruben.com virtual gallery

Screenshot, www.davidruben.com virtual gallery of contemporary work

Screenshot, www.davidruben.com coming events 


\section{Preface}

I completed my undergraduate degree in Art History and Peace Studies at McMaster University. While completing the Peace Studies component of the degree, I had the opportunity to develop creative skills for the process of conflict transformation and thought that art might have a role to play in this dynamic process. I wondered if artworks could be understood as a means for telling one's personal truths, whether they are absolute or unique to that individual. Several years ago, when I first saw Ruben's work in the Between Two Worlds catalogue, I thought it could be useful to understand his work in terms of conflict transformation. I had planned to examine Ruben's work in light of the concept of truth as used by a Truth and Reconciliation Commission or TRC. In a TRC the main goal is not to prosecute perpetrators but rather to document people's accounts of their experiences.

I was intrigued by the very personal narratives that emerged in the sculptures and text that Ruben had created. Initially, I wanted my thesis research to focus on how Ruben used his art as a tool to communicate his individual stories. However, my project changed and instead of focusing on one person's message and how it is conveyed to an audience, it came to focus on a cross-cultural dialogic process. The cultural brokerage aspect of my research began to develop when I took a class with Norman Vorano in which we examined cultural consumption. For that class I wrote the first draft of "Virtually Ruben." At that time I knew I wanted my thesis to examine both the exhibit Between Two Worlds and Ruben's current engagement with the online art market, but I was uncertain as to what connected the two. After reading Aaron Glass's work on 
Mungo Martin, I realized that the exhibit and davidruben.com were both examples of Ruben's interactions with audiences across cultural borders.

Although this thesis moved away from my initial plan to examine art as a form of truth-telling or witnessing, a parallel has been maintained in a study of Ruben's use of his personal stories to move amongst cultures and to convey his own narratives to a broad audience. As this project is nearing its end, so begins a momentous event for Canada. A Truth and Reconciliation Commission is being established with the purpose of creating a safe and culturally appropriate forum in which people may share their individual experiences in residential schools. 


\section{Acknowledgements}

Thank you to my supervisors Ruth Phillips and Norman Vorano for their knowledgeable guidance and tireless editing.

I wish to convey my thanks to all the people who have been with me through this struggle. My parents, Carole Mierins and Egils Mierins, have consistently supported my academic pursuits. Thank you to my mother for encouraging my interest in the arts ever since I was finger painting in a highchair. Loving thanks to my Uncle Michael Lanctôt and Aunt Marie Lanctôt who have always been proud of me. I lovingly acknowledge my fellow students Nicole Neufeld, Caroline Vanderloo and Rhiannon Vogl, who gave me the strength and support to persevere in finishing this degree. Love and gratitude to my friend and mentor Alison McQueen who has supported this endeavour since before it began, and to Eugenia de Montijo who reminds me why I love art history. Love and thanks to James Beals who was a constant source of care, love and support while I completed my thesis.

I must express my deepest gratitude to Ian Manion who taught me the skills I needed to complete this thesis. 
Introduction: The Emergence of a Culture Broker in a Transnational World

"I wanted to create inukshuks all over my travels. That desire is coming to fruition,"" said David Ruben Piqtoukun in an interview published in 1994. Ruben ${ }^{2}$ is an artist who has been able to travel and interact with people of other cultures due to opportunities related to his career. As part of these interactions he has constructed sculptures known as Inuksuit (plural of Inukshuk), synecdoches standing for all of Inuit culture to mark these meeting places. At the same time he has incorporated knowledge attained from these interactions into his own work. The wish to create Inuksuit in the places to which he has travelled is indicative of Ruben's interest in establishing connections with peoples who have previously been inaccessible to him. Through these and other efforts Ruben has become a "culture broker," or cultural intermediary linking the North to the South, the Inuit and the white world, even Canada and Africa. Amongst these realms, Ruben transmits information about the experience of his generation of residential school survivors. This thesis looks at the evolution of his positioning as a culture broker through an examination of his career and sculptural works and his ongoing engagement with various institutions such as museums, the art market, critics and patrons.

Artistic production has often been used as a strategy to convey information among cultural groups. According to art historian Sally Hyer,

The visual arts have become one of the main forms of intercultural communication between Native Americans and the non-native world... outsiders sometimes assume that noted artists represent their tribes or even are tribal

\footnotetext{
' John Ayre, "David Ruben Piqtoukun," Inuit Art Quarterly 9, no.3 (Fall 1994): 20.

${ }^{2}$ Piqtoukun is the artist's formal name, which he chooses to use solely for special occasions. For this thesis I will use the name Ruben when discussing the artist, however, some scholarly work continues to use Piqtoukun and this name will occasionally appear in quotations. Sonia Gunderson, "David Ruben Piqtoukun: In Search of a Softer Wind," $I A Q$ vol. 22, no. 1 (Spring 2007): 29.
} 
spokespeople. The role of cultural intermediary has been embraced by some artists, forced on others, and rejected by still others. ${ }^{3}$

In this thesis I examine how Ruben has moved beyond the traditional role of 'artist as author' to position himself as an intermediary. I look at Ruben's engagements with the art world in two different historical and institutional 'nodes' - exhibition and the web. I trace how his role as a "culture broker" transformed from its genesis within a colonial power structure to its current existence in a transnational context. Ruben initially worked in an art community that was part of a hierarchical nation-state structure, but globalizing factors have lead to a dispersal of power. The web has created favourable circumstances for Ruben to gain greater control over his career and to develop a new cultural community. Various art world participants, such as museums and patrons, continue to play a role in his career, but no longer have as much influence. In this introduction I outline Ruben's biography and then provide definitions for the terms culture broker, culture, discourse and transnationalism, which are key to the theoretical framework of this thesis.

\section{Biography}

Ruben was born in the Western Arctic community of Paulatuk on 10 May 1950. As a young child Piqtoukun was removed from his community and placed in a residential school in Aklavik, where Inuktitut was forbidden. In 1967, having lost the ability to speak Inuktitut, he left school and spent the next few years working at various jobs, such as construction worker, janitor at the DEW (Distant Early Warning) line station and

\footnotetext{
${ }^{3}$ Sally Hyer, "Pablita Velarde: The Pueblo Artist As Cultural Broker," in Between Indian and White Worlds: The Cultural Broker, Edited by Margaret Connell Szasz (Norman, OK: University of Oklahoma Press, 1994), 273.
} 
roughneck on oil rigs in southern Canada. ${ }^{4}$ As he explains, it was only after he moved

to Vancouver in 1972 that he began carving.

I began carving at age 22, with original instructions from my brother Abraham Apakark Anghik Ruben in 1972. At first I found the carving process very difficult and tedious. My images were crude with little detailing... I copied images from Eskimo books on stone carving for ideas. To be original I stopped looking through books for 5 years. My first carving I made, I sold for the money aspect. In 1975ish, I realized there was more to the art of carving. I started exploring my native roots, and collected stories from my travels home in Canada's Western Arctic. I found better stone material for carving and was fascinated by my own culture. ${ }^{5}$

Since the mid-1970s Ruben has used carving as a means to "rediscover" Inuit culture.

During trips to the North he has listened to elders' narratives, which he then incorporates into his sculptural works. ${ }^{6}$

Ruben took part in his first exhibition in 1973, only one year after he had begun carving, and, as he realized that he could earn a living as an artist, he became more involved in the Canadian art community. ${ }^{7}$ In 1980 he was appointed to the now defunct Canadian Eskimo Arts Council, which advised Inuit Cooperatives on their annual print releases, and served until 1983. His involvement in this committee helped establish him in the Inuit art community. ${ }^{8}$

Ruben's interactions with the art market have developed significantly since he sold his first carvings of animals in relief to Edith Clark of the Gallery of British Columbia Arts in $1973 .{ }^{9}$ Ruben produced work for devoted patrons in Vancouver until

\footnotetext{
${ }^{4}$ Gunderson, 30 .

${ }^{5}$ Artist's Statement, Artist file, Indian Art Centre, Indian and Northern Affairs Canada, Accessed November 2005.

${ }^{6}$ Laura Eggertson, “Arctic Images Provide Inspiration in Inuit Sculptor's Toronto Studio," The Globe and Mail (29 December 1987): C7.

${ }^{7}$ Symbols of Survival (Toronto: Paulatuk Fine Art, 1987) np.

${ }^{8}$ Symbols of Survival, np.

${ }^{9}$ Wight, Out of Tradition, 41.
} 
he moved to Toronto in 1981 and began working with Harold Seidelman, owner of Images Art Gallery. ${ }^{10}$ Seidelman supported Ruben's exploration of materials and subject matter and was instrumental in the artist's success. The working relationship that developed between the artist and dealer would later give Ruben unique access to exhibiting opportunities not available to most artists. His financial success at Images Art Gallery has ultimately led to the artist being able to work independently of art dealers. In 2001 Ruben said,

I've spent a long time - many years - establishing myself to the point where I can go on my own much further. I've developed a home gallery. I deal directly with the market, but I'm in control of my work, my work schedule, my design and my presentation and I have my choice of materials. ${ }^{11}$

Ruben's commercial success will be discussed in greater depth in chapter two.

In 1982 Ruben was chosen by the Department of External Affairs to represent artists at Canada week in Abidjan, Ivory Coast. During this trip he created a sculpture incorporating imagery that was symbolic of both Inuit and Ivory Coast culture. The soapstone carving, Absorbing the African Way (Fig. i.1) depicts a figure dressed in a parka holding a large mask in front of himself. The mask has stylized facial markings resembling African scarification, and originally had feathers. These two features are reminiscent of images Ruben saw while visiting the Ivory Coast. He commented on the sculpture, "The African influence is quite evident in this carving. I felt very excited about this work." Ruben's interest in the stylized facial markings, which may also be a reference to traditional Inuit facial tattooing, would continue and can still be seen in his

\footnotetext{
${ }^{10}$ Wight, Out of Tradition, 41.

${ }^{11}$ David Ruben Piqtoukun in Heather Campbell "Urban Inuit Artists," Inuit Art Quarterly vol. 6, no 2 (Summer 2001): 6.

${ }^{12}$ Piqtoukin, David Ruben. "Trip to Abidjan, Ivory Coast, Africa." Inuktitut. (January 1983):29.
} 
contemporary work. ${ }^{13}$ The amalgamation of cultural references, seen in both subject matter and materials, is a recurrent component of Ruben's oeuvre. He has used his audience's perception of him as a representative of Inuit culture to further his work as a cultural intermediary and artist. ${ }^{14}$

While travelling to Abidjan, Ruben documented his trip in a journal that was then published in English, French and Inuktitut. He presents the reader with a sense of the geographical distance he is crossing when he mentions the desert he is flying over. He goes on to state, "I was aware of the distance I was from my village on the Arctic Coast."

As an indigenous person Ruben's access to African culture in Abidjan positioned him to publicize views about the people and place visited. Most other travellers would not have had access to the same forum or authority to express such perceptions and to create innovative artworks that incorporated influences from both cultures. For a brief period of time Ruben was able to act as a broker for Abidjan culture, bringing it back to North America through his writing and sculpture. His access to one relatively exotic culture granted him access to another and his position as artist provided a means for him to express viewpoints on both cultures.

In the 1980s Ruben also had opportunities to travel to the North on two occasions for the purpose of exhibiting his work. He traveled to Paulatuk in 1987 to take part in the exhibition Paulatuk: Mythology in Stone and Photographs. Thirteen of Ruben's

\footnotetext{
${ }^{13}$ Ingo Hessel, Inuit Art: An Introduction (Toronto: Douglas and McIntyre, 1998) 137.

${ }^{14}$ Hyer suggests that some Native American artists adopt the role of cultural intermediary after outsiders have applied it to them. Sally Hyer, "Pablita Velarde: The Pueblo Artist As Cultural Broker," in Between Indian and White Worlds: The Cultural Broker, Edited by Margaret Connell Szasz (Norman, OK: University of Oklahoma Press, 1994), 273.
} 
sculptures were shown alongside photographs taken by photojournalist Tom Skudra. ${ }^{15}$

While this exhibition was created primarily for the people of Paulatuk, it was later shown

in Toronto and was accompanied by a publication, The Storytellers. The sculptures are

Ruben's interpretation of narratives told to him by people of his parent's generation. The accompanying photographs depict the storytellers and their community. In the

introduction Brian Shein states that Skudra's photographs

...meticulously document the details that compose Paulatuk. This is a place of television screens and snow, of wooden crosses in the graveyard, of wolverine parkas, of telephones, of dogs, of hide and bone, of airplanes, of meat. With clear-eyed realism, Skudra's images also imply a place that was here for time out of mind before there was a town of Paulatuk, a place of vast expanses of cloud and water. The silence is immense. ${ }^{16}$

This description is at odds with Skudra's images that focus on community members in their daily lives. Instead, this introduction focuses on the non-human elements creating the impression of a desolate un-populated place. The reference to the area of Paulatuk as "a place that was here for time out of mind before there was a town of Paulatuk," implies timelessness and gives the reader a romanticized sense of the location and people.

In contrast, Ruben's introduction positions himself and his work in relation to a vibrant community:

For the past seven years, I have been collecting the oral mythology of my village town of Paulatuk - stories from my parents and my older uncles and aunts. Some folks have since passed away, but their stories live on and I am grateful to be able to present these legends in stone carvings... In our society a storyteller holds the same esteem as a great hunter. Hopefully, my work will justify the enthusiasm of the storytellers, and my sculptures, in their own way, will also become the storytellers. ${ }^{17}$

\footnotetext{
${ }^{15}$ Martha Devine, "Paulatuk Exhibition Shows Spirit, Power," Native Press, 24 July 1987, 22.

${ }^{16}$ Brian Shein in The Storytellers: Sculptures by David Ruben Piqtoukun and Photographs by Tom Skudra. (Toronto: The Koffler Gallery, 1988) n.p.5.

${ }^{17}$ Ruben in Shein, n.p. 2
} 
After asserting the importance of the storyteller in Paulatuk society, Ruben situates his work, and by extrapolation himself, in relation to the art of storytelling. He presents his audience with tangible objects that capture the narratives. The introduction refers to the sculptures and states,

These objects testify to the force and weight of culture, a language, a mythology. They are evidence of a world of humans, animals and spirits in constant transformation, and proof of a place of sky, water, snow and stone. This place is now here, wherever these objects are. Standing amongst them, we have travelled there. ${ }^{18}$

He suggests to non-Inuit readers that they can cross into another culture by means of this exhibition. Ruben's sculptures are presented as a synecdoche for Paulatuk. The audience is told that through the work and perspective of one person they can "travel" to the culture. Shein defers to the authority of Ruben as culture broker, and then re-enforces this authority by interpreting the artist's work as a synecdoche of an entire community.

In 1989, the exhibition Out of Tradition, featuring Ruben and his brother Abraham Anghik, opened at the Winnipeg Art Gallery (WAG). This exhibition, part of which was shown in Northern communities, provided Ruben with the opportunity to familiarize himself with various Arctic communities. Ruben's strategic methods of engaging with the WAG positioned him not only as one who could successfully negotiate a Southern art institution but also as an artist who was established in the North.

Out of Tradition marked a significant intervention into the dominant discourses used by museums and galleries in its presentation of Inuit art. In most previous exhibitions of Inuit art the curator had decided which works and interpretations would be displayed for viewers. Working collaboratively with curator Darlene Wight and

\footnotetext{
${ }^{18}$ Shein, n.p. 5.
} 
Seidelman, Ruben positioned himself as an artist who could both successfully

negotiate Southern art institutions and was also well-established in the North. This work with the WAG was a precursor to the 1996 follow-up exhibition featuring Ruben alone, Between Two Worlds, which even more clearly and convincingly reinforced Ruben as a negotiator between the Inuit and Southern worlds. Both of these exhibitions will be addressed in depth in chapter one.

1989 was an important year for Ruben, now an articulate spokesperson for Inuit culture. He was appointed to the UNESCO Canadian Committee for the World Decade of Development and was appointed Inuit art ambassador at the United Nations opening of the exhibition "Masters of the Arctic," which had been organized by the Amway Corporation. He attended openings for this exhibit in Washington DC, Tokyo, Gatineau and Buenos Aires.

Ruben has been endorsed by both cultural and governmental institutions, which have invited him to participate in events nationally and internationally. International events have given him the opportunity to travel to the Cote d'Ivoire (1982), Mexico (1989), China (2000), and most recently Zimbabwe (2006), among others. In 1998, Ruben married a Korean woman, Katherine Lee, with whom he travelled to Korea. ${ }^{19}$ Two years later he received the honour of an appointment to the Sculptors Society of Canada. $^{20}$ In 2003, the Canadian government commissioned Ruben to carve an Inukshuk

\footnotetext{
${ }^{19}$ davidruben.com archived pages in the author's files, last modified 7 May 2006.

${ }^{20}$ Sculptors Society of Canada: David Ruben Piqtoukun, http://www.cansculpt.org/memberDetails.php?id=106\&fn=David\%20Ruben\&ln=Piqtoukun, accessed 24 July 2000 .
} 
to be presented to the city of St. Petersburg for its $300^{\text {th }}$ anniversary. It was the first Inukshuk to ever be erected in Russia. ${ }^{21}$

Recently Ruben has received attention from several prestigious Southern art institutions. The exhibition About Face at The Wheelwright Museum of the American Indian in 2005-2006 included a work by Ruben. Co-curator Zena Pearlstone wrote "What distinguishes Native American self-portraits from those of the dominant culture is that these speak to identity through the negotiation of cultural conflict."22 The term conflict implies the presence of incompatible views that cannot easily be reconciled. It is precisely this "cultural conflict" that Ruben overcomes as a culture broker. In 2003 he said

The "resolution" of conflict of identity has taken shape in the form of artistic expression and attitude. To be able to carve stone has given many people the ability to better understand the gap between the "older" and "modern" societies, and the knowledge of our customs and traditions. We have to grasp the wisdom of old and introduce it into our present way of seeing and perceiving this new way of living. ${ }^{23}$

His work does not fit into a concept of conflict as it is through his work that he has been able to bridge, or reconcile, the various cultures in his life experience.

In emails to co-curator, Allan Ryan, Ruben wrote of his work, Like Father, Like Son, 2004 (Fig. i.2):

I see myself in the face of the carving. I am the one with one eye over the other. Many things I am confused about, such as: which culture I belong to; what are my cultural priorities; my hunting skills for survival, and most important, who am I and what type of Eskimo have I become? This carving is symbolic of being 'Torn

${ }^{21}$ James Sinclair, "David Ruben Piqtoukun: Between Two Worlds," Inuit Art Quarterly, vol. 19, no. 3 (Fall/Winter 2004): 30.

${ }^{22}$ Zena Pearlstone, The Wheelwright Museum of the American Indian, Past Exhibitions, About Face: SelfPortraits by Native American, First Nations, and Inuit Artists, November 13, 2005 - April 23, 2006, http://www.wheelwright.org/exhibitions/AboutFace/aboutface.html, Accessed 12 October 2007. ${ }^{23}$ Courtright, 59. 
Between Two Worlds' and trying to face the reality of such. I have great respect for the hunter's skills; I see myself as a different type and make of hunter. I practice the same learning skills for survival but I utilize the skills in a different manner. I have to realize that I am who I am and what I am. I still have great respect for the animals, the land and most important, the people; and the legends and mythology which we as individuals interpret in a unique manner. ${ }^{24}$

This statement indicates that Ruben continues to grapple with his position amongst various cultures. A year earlier Ruben spoke about the ways he and other Inuit artists attempt to reconcile the different cultures:

Our old customs, traditions and mythologies have been well documented and preserved. We are an adaptive new society and we have accepted the responsibility of change; we take the wisdom and knowledge of our old culture and re-introduce them into our present ways and in all our aspects of living. We have to "recycle" all this knowledge in order to deal with all the changes that have been brought to our doorsteps. It's like having to redesign tools of antiquity: they still do the same job. We have to maintain the ingenuity of our ancestors. ${ }^{25}$

This statement indicates that Ruben's worlds include both the North and South, as well as the old and new.

The National Gallery of Canada (NGC) showed three of his works in the exhibition Inuit Sculpture Now, which was curated by Christine Lalonde. ${ }^{26}$ Two of the sculptures were initially created for the 1996 exhibition Between Two Worlds at the WAG. Aura, 1996 (Fig. i.3) is one of three works that the gallery visitor first sees upon entering the exhibition space. The work features a mask-like face made of Brazilian soapstone on a base of welded steel. The stylized mask is reminiscent of the faces influenced by the artist's time in Africa. However, rather than the parallel lines in the cheeks this mask has rows of dots that bring to mind the Inuit practice of facial tattooing.

\footnotetext{
${ }^{24}$ Quoted in Allan Ryan and Zena Pearlstone, curators, About Face: Native American, First Nations and Inuit Self-Portraits (Santa Fe, New Mexico: Wheelwright Museum of the American Indian, 2006): 17.

${ }^{25}$ Courtright, 60.

${ }^{26}$ Inuit Sculpture Now ran from 30 June - 18 November 2007. Christine Lalonde, Inuit Sculpture Now (Ottawa: National Gallery of Canada, 2005).
} 
Above the face is a second mask that looks as though it might be lowered to cover the first. Ruben has used steel to create a circle that surrounds the face. The curator of Inuit Sculpture Now chose to show this work with the text Ruben originally wrote for Between Two Worlds:

The metal circle represents the technology of the outside world and the aura of the spirit world. An abstract owl's mask hovers over the shaman's mask. Can the old knowledge find a place among the new ways? Can the shaman and his spirit helper break out from the new circle of understanding $?^{27}$

As in most contemporary art exhibitions, the curator has sought to include the words of the artist. By incorporating Ruben's text the curator is encouraging his role as culture broker, particularly with this quotation in which the artist has raised questions that explicitly position him amongst cultures. Ruben's words written more than a decade ago continue to have resonance for an audience interested in information from across contact zones.

The curator wrote the text that accompanies Sharing the Good Food: "In his minimalist version of a piece of meat cut into equal portions with the traditional woman's knife, or ulu, Piqtoukun distills to its essence the value of sharing, a fundamental pillar of past and contemporary Inuit society." ${ }^{28}$ This work, which was completed in 1999, is a continued exploration of the subject matter depicted in Division of Meat, 1996 (Fig. i.4) for Between Two Worlds. Ruben wrote text to accompany the 1996 work: "We have always shared our food. Even though we have gone through many changes, we will always take care of each other."29 The importance of sharing and supporting the

\footnotetext{
${ }^{27}$ Ruben on text panel, Inuit Sculpture Now.

${ }^{28}$ Text panel, Inuit Sculpture Now.

${ }^{29}$ Darlene Coward Wight, Between Two Worlds: Sculpture by David Ruben Piqtoukun (Winnipeg: Winnipeg Art Gallery, 1996) 34.
} 
members of one's community continues to be important, but the significant change in the work is seen in the instrument being used to cut the meat. In Division of Meat the ulu is used, whereas the meat in Sharing the Good Food has been cut by a piece from one of Ruben's old saw blades. The change in cutting utensil is also a reference to the relatively recent introduction of trade goods in the North, which led to ulus being made from saw blades rather than chiseled stone. ${ }^{30}$ The third sculpture by Piqtoukun is Airplane, 1996 (Fig. i.5), which is exhibited without the text he wrote for it when it was shown in Between Two Worlds. This work demonstrates a clash between Northern and Southern life and is discussed in detail in chapter one. The texts included in Inuit Sculpture Now continue to portray Ruben as though he is positioned between, rather than amongst cultural values and ideas.

Ruben has also recently received extensive attention from Inuit Art Quarterly. In the Spring 2007 feature article, Sonia Gunderson situates Ruben's current practice in relation to biographical details, much like earlier articles, then goes on to discuss his more recent artistic production. He no longer deals with the psychologically draining issues that were the focus of Between Two Worlds, but rather develops his use of new materials and narratives from Inuit culture.

Unlike earlier articles this one draws attention to the fact that Ruben lives near Toronto, thereby destabilizing both the conceptual and real distance between the Inuit artist and the south. His upcoming move and plans to "live mortgage-free on a... tract of land that will accommodate a larger studio"31 creates additional connections with the

\footnotetext{
${ }^{30}$ David Ruben Piqtoukun, Sharing the Good Food, 1999, in cybermuse, http://gallery.ca/cybermuse/search/artwork e.jsp?mkey=97186, Accessed 13 October 2007.

${ }^{31}$ Gunderson, 32.
} 
reader through the mention of the banal everyday issue of a mortgage. However, these connections are mediated by the theme throughout David Ruben Piqtoukun: In Search of A Softer Wind, which is based on the meaning of Ruben's name, something that has received surprisingly little attention. In the 1970s Ruben began using his childhood name, Piqtou meaning "gusty wind", and extending it to Piqtoukun meaning "soft wind," as a way of indicating that his work was Inuit. The article briefly addresses his upcoming work, which will be based on a wind motif. Gunderson writes that "Ruben plans to make a series of 12 massive metal works on the wind theme, partnering with Redbone, a Los Angeles band, to create an avant-garde performance exhibit. ${ }^{, 32}$ Both the materials and partnership further demonstrate Ruben's departure from his earlier artistic practice.

The article shows Ruben's market consciousness with a quotation from the artist in the introduction of Gunderson's article: "This week 15 collectors passed through here after Waddington's [Inuit art auction]... and no one bought anything. ${ }^{{ }^{33} 3}$ She describes Ruben as fuming and clenching his fist as he said this. She goes on to describe Ruben's successes in both the museum and art market worlds and the artist's perplexity at the current lack of sales.

The images reproduced in Gunderson's article led Viviane Gray, of Indian and Northern Affairs Canada (INAC), to purchase a work by Ruben for the lobby of the Terrasse de la Chaudiére government building. ${ }^{34}$ In May 2007 Ruben visited Ottawa to install Our Spirits: They Soar High, 2007 (Fig. i.6). The sculpture, which was created with steel, paint, field stones, granite and dolomite, is a departure from Ruben's

\footnotetext{
${ }^{32}$ Gunderson, 34.

${ }^{33}$ Gunderson, 29.

34 "Provocative Inuksuk Installed in Government Building," IAQ vol. 22, no.3 (Fall 2007): 33.
} 
recognizable stylized forms and lines that distinguish the majority of his oeuvre. The most notable change is the incorporation of colour into the abstract Inukshuk. Ruben states that he has begun using colour with symbolic meaning:

The red base of the installation is symbolic of fire and rebirth, like the Phoenix that rises from the ashes and fire of despair and eventual death... The middle stone is painted black, to represent the Heart of Life that recalls clearly the darkness and doubt that we have all had to endure... The very top stone is symbolic of the human mind. It is painted blue to represent the search for wisdom that enables us to pursue the most rational choices that are presented to us all on a daily basis. ${ }^{35}$

The organic forms of rocks and the curvature of the uppermost piece of steel contrast the strong horizontal and vertical lines. The arced form at the top gives the impression that the Inukshuk is reaching upwards, an idea that would be difficult to convey in stone alone. The minimal mass of steel creates a sense of airy lightness that is stabilized by the heavy rocks. Since the sculpture can be identified as an abstract Inukshuk it can be connected to Ruben's specific cultural background. However, the artist's statement situates the work in a broader discourse in terms that can connect with a much broader audience: "This sculpture depicts my thoughts on the resilience of the human spirit as people of all races have had to battle with the demoralization of self and possible genocide of their whole lot." ${ }^{36}$ Ruben has refrained from verbally specifying Inuit culture, and instead discusses an experience to which people of different backgrounds can relate.

\footnotetext{
${ }^{35}$ David Ruben Piqtoukun in "Provocative Inuksuk Installed in Government Building," IAQ vol. 22 , no. 3 (Fall 2007): 33.

${ }^{36}$ Ruben in "Provocative Inuksuk Installed in Government Building." 33.
} 
Theorizing the Culture Broker

In this thesis, I shall mainly draw from anthropological approaches to the "culture broker,' which I outline briefly in this introduction. In the 1950 s anthropologist Clifford Geertz explored the concept of the culture broker in relation to Javanese political leaders who negotiated between their constituents and local religious leaders. Geertz recorded how political elites struggled to bridge the gap between the national and the local by working cooperatively with religious leaders, who had the respect of their communities. ${ }^{37}$ Geertz argues that the religious leader's prestigious role as a community insider enabled him to assuage the uncertainties of the outsiders, while his community's confidence in him enabled him to be a cultural middleman between peasant and urban life and culture. ${ }^{38}$ Contemporaneous to Geertz's work on culture brokerage, anthropologist Eric R. Wolf described some of the necessary characteristics of a political and economic broker. "He must learn to operate in an arena of continuously changing friendships and alliances," wrote Wolf, "which form and dissolve with the appearance or disappearance of new economic or political opportunities." ${ }^{39}$ The majority of later definitions of culture brokerage encompass these features described by Wolf. Integral to the role is the fluidity that enables the person to function successfully in a variety of situations with various members of society.

Anthropologist Irving Hallowell delved into the topic of culture brokerage in the 1960s when he proposed the term "transculturation" to describe

\footnotetext{
${ }^{37}$ Clifford Geertz, "The Javanese Kijaji: The Changing Role of a Cultural Broker," Comparative Studies in Society and History vol. 2, no. 2 (January 1960): 228-249.

${ }^{38}$ Geertz, 229.

${ }^{39}$ Eric R. Wolf, "Aspects of Group Relations in a Complex Society: Mexico," American Anthropologist vol. 58, no. 6 (December 1956): 1071-1072.
} 
the process whereby individuals under a variety of circumstances are temporarily or permanently detached from one group, enter the web of social relations that constitute another society, and come under the influence of its customs, ideas, and values to a greater or lesser degree. A correlative term, transculterite, can then be used to designate those individuals who have undergone transculturation. ${ }^{40}$

Although Hallowell's term is no longer used with the same meaning, it has continued to be part of the culture brokerage discourse. "Transculturation" has been used by cultural critic and linguist Mary Louise Pratt to describe how subjugated peoples choose and use materials and practices from a dominant culture to meet their own political, social and cultural needs. While individuals cannot readily determine what comes from the dominant culture, they do control, to some degree, what they take from it. ${ }^{41}$ Pratt's use of the term endows the "transculturite" with greater agency than does Hallowell, but it too does not allow the transculturite to have full access to the "dominant" culture.

In 1969 anthropologist Irwin Press described the culture broker as an innovator. "If the acts of an innovator are accepted," said Press, "he must necessarily have some form of structural permission to innovate. Otherwise, he is likely to be viewed as deviant or intrusive. $" 42$ This figure must have the respect of both his peers and other members of the cultures with which he interacts. He must be able to move from participating in the subjugated group to being a temporary member of the dominant group.

Common to these views, culture brokers develop ways to strategically move through what James Clifford called "contact zones" in order to attain recognition for their work. Within the contact zone are borders that cannot be easily traversed, but culture

\footnotetext{
${ }^{40}$ Hallowell, 523.

${ }^{4]}$ Mary Louise Pratt, Imperial Eyes: Travel Writing and Transculturation (New York: Routledge, 1992$) 6$.

${ }^{42}$ Irwin Press, "Ambiguity and Innovation: Implications for the Genesis of the Culture Broker," American Anthropologist vol. 71, no. 2 (April 1969): 205.
} 
brokers have skills that give them a unique point of access to cross cultural boundaries. Historian Margaret Connell Szasz writes, "For intermediaries... borders have become pathways that link peoples rather than barriers that separate them." ${ }^{43}$ The contact zone can only be accessed and crossed if one has an understanding of various worldviews and 'other' cultural values. As this understanding develops, according to Szasz, the culture broker strategically incorporates aspects of various cultures into his behaviours and choices. Pratt proposes the term "autoethnography" to describe the representations that subjugated peoples create for themselves using the dominant culture's terms. This term implies a high degree of self-reflexivity in self-representations.

By using an autoethnographic approach in their work, culture brokers document both their personal experiences, as well as traces of the 'other' cultures to whom they are translating. Szasz, Pratt and Clifford show how non-western individuals often employ Western discourses and practices when conveying their cultural identities. As culture brokers develop their understandings of the cultures they traverse, they, to some degree, "see" themselves through the eyes of others.

A broker's efforts bring together aspects of the cultures bordering the contact zones, but his actions must also be considered in light of the complex social or economic relationships that are negotiated around these zones. In the 1970 s, anthropologist Robert Paine presented four structural roles within contact zones: client, broker, go-between and patron. The go-between conveys information with no expectation of remuneration. ${ }^{44}$ Paine's concept of broker is of one who transmits information but who may alter the

\footnotetext{
${ }^{43}$ Margaret Connell Szasz, ed., Between Indian and White Worlds: The Cultural Broker (Norman, Oklahoma: University of Oklahoma Press, 1994), 3.

${ }^{44}$ Robert Paine, ed., Patrons and Brokers in the East Arctic. Memorial University of Newfoundland Social and Economic Papers 2 (Toronto: University of Toronto Press, 1971).
} 
emphasis or content to serve self-interests defined as economic or cultural prestige. ${ }^{45}$ The patron spends assets to have access to resources presented by the client. ${ }^{46}$ The client conveys information based on the values and beliefs of the patron and, by catering and adhering to the patron's belief system, secures a position in the relationship. ${ }^{47}$ Culture brokers make strategic choices driven by self-interest, based on the beliefs and values of the dominant players in and around the contact zones.

Paine writes that while it is wrong to immediately identify the patron as the "big man," the patron is usually the person with more power. ${ }^{48}$ While the relationship is one of reciprocity as it depends on the involvement of both parties, the broker ultimately has greater control over the terms of the relationship. The patron initially sets the parameters for the interactions, but the broker is able to control information to meet his or her needs within the relationship.

Building on the work of Pratt, Paine, Clifford and others, anthropologist and artist Aaron Glass characterizes the culture broker as one "forging relationships between disparate communities and negotiating cultural knowledge through facilitating the movement and transformation of objects, values and information." 49 Traditionally, artists were thought of as 'clients' according to Paine's strucure. I am proposing, like Glass, to see the artist as a culture broker. Glass develops this concept by exploring the culture broker's function in stylizing his own role. In his article "From Cultural Salvage to Brokerage: The Mythologization of Mungo Martin and the Emergence of Northwest

\footnotetext{
${ }^{45}$ Paine, 19

${ }^{46}$ Paine, 17.

${ }^{47}$ Paine, 15.

${ }^{48}$ Paine, 10.

${ }^{49}$ Aaron Glass, "From Cultural Salvage to Brokerage: The Mythologization of Mungo Martin and the Emergence of Northwest Coast Art," Museum Anthropology vol. 29, no. 1 (2006): 22.
} 
Coast Art," Glass examines the work of Kwakwaka'wakw artist, museum employee and cultural intermediary Mungo Martin during the mid-twentieth century. The author suggests that Martin was cognizant of the significance of his role in facilitating the movement of information and objects from small rural communities to metropolitan museums. In this process he developed an understanding of how to mediate the knowledge and interactions to maintain and develop relationships with various parties. ${ }^{50}$

The power to control the information, and even the patrons, is connected with the ability to assume different roles in the various interactions involved in culture brokering. Szasz compares culture brokers to actors who retain different identities that are used strategically to negotiate across borders. These various identities are informed by an understanding of the worldviews of the "other side." S1 Szasz concludes that a significant motivating factor for brokers is the power the position presents. ${ }^{52}$ The patron is manipulated by the broker who provides information based on the wishes of the patron in the anticipation of payment. Beyond the power and material reward is an element of personal satisfaction. The broker attains recognition for both himself and his culture through the conveyance of cultural information.

A conceptual distance between the patron and the broker is significant to the positioning of brokers as it provides them with an authoritative position. When that distance begins to shrink, it is imperative to reinforce the cultural 'otherness' of the broker. Hal Foster writes that the "assumption that if the invoked artist is not perceived as socially and/or culturally other, he or she has but limited access to this transformative

\footnotetext{
${ }^{50}$ Glass, 25.

${ }^{51}$ Szasz, 6.

${ }^{52}$ Szasz, 298.
} 
alterity, and that if he or she is perceived as other, he or she has automatic access to it." ${ }^{53}$ This perceived distance is necessary as it upholds the exclusivity of the broker's role.

Although the pecuniary aspect of culture brokerage has often been acknowledged, it has not been given extensive consideration until recently. In 2001 curator Bennet Simpson addressed the issue in his essay "Pushing an Open Door: The Artist as Culture Broker" in the catalogue for the Americans. new art. In his discussion of culture brokerage he examines the necessary market savvy approach taken by many American artists in the mid to late $1990 \mathrm{~s}$ :

This figure of the culturepreneur (also variously called a 'culture-broker' or a 'pro-sumer') is a kind of ancillary or post-yBa, ${ }^{54}$ who has left behind the relatively circumscribed economy of simply making artwork and enters more literally the realm of cultural - economic mediation. ${ }^{55}$

After the recession of the early 1990s American artists had to find new ways to meet market demands and pragmatic business-oriented ways of interacting with other parties involved in the art market. The tools necessary to negotiating these connections was discussed by the self-titled culturepreneurs Anthony Davies and Simon Ford. They described the culture broker as having the ability:

...to follow capital wherever it goes, tapping into local networks, setting up partnerships, and identifying trends from a variety of clients. Their bridging role, between business and communities that work on the cutting edge of culture, provides the knowledge, information, and 'association' that is vital to companies requiring local association for competitive global strategies, ${ }^{, 56}$

\footnotetext{
${ }^{53} \mathrm{Hal}$ Foster, "Artist as Ethnographer," in The Return of the Real (Cambridge, Massachusetts: The MIT Press, 1996), 173.

${ }^{54}$ The yBas, or young British artists, are a group of conceptual artists based in the United Kingdom. Their shock art received significant media and patron attention during the 1990s.

${ }^{55}$ Bennett Simpson, "Pushing an Open Door: the Artist as Culture Broker," in The Americans. New Art, curated by Mark Sladen (London: Booth-Clibborn Editions, 2001): 297.

${ }^{56}$ Anthony Davies and Simon Ford, “Art Futures," Art Monthly vol. 9, no. 223 (February 1999): n.p., 10.
} 
Davies and Ford recognized the necessary attributes of artists who wished to take on the role of culture broker: "Their key skills were communication-based and included the ability to process large amounts of information and think strategically. $" 57$

Christopher B. Steiner addresses the economic facet of culture brokerage in the disparate context of the African art market. He writes

...the study of the African art trade uncovers not only a complex economic system with its own internal structure, logic, and rules, it reveals also an elaborate process of cross-cultural exchange in which the image of Africa and its arts are continually being negotiated and redefined by a plurality of market participants spread out across the world. ${ }^{58}$

In his work he examines the multitude of institutions and participants that engage in the process of culture brokerage. Steiner focuses on the role of culture broker as taken on by the middlemen or art dealers rather than artists. He focuses on how art dealers influence the public perception of artists as cultural intermediaries. Although the traders are the focus of Steiner's work, the cultural interactions they control could be taken on by a variety of other parties, such as the artists or patrons.

\section{Defining 'Culture'}

As the word 'culture' will be used throughout this thesis, it is imperative to provide a working definition of my approaches. The word culture evokes a variety of meanings to anthropologists, social scientists and art historians, which I use in different ways throughout this thesis, dependent upon circumstance and disciplinary context. In the nineteenth century British literary critic Matthew Arnold defined culture as "the best that

\footnotetext{
${ }^{57}$ Davies and Ford, n.p., 11.

${ }^{58}$ Christopher B. Steiner, African Art in Transit (Cambridge: Cambridge University Press, 1994): 10.
} 
has been thought and said in the world," 59 a formulation that had traction in the modern discipline of art history in the early and mid $20^{\text {th }}$ century. Subsequent philosophers and social critics, such as Dwight Macdonald, have divided Western culture into two categories: high and mass culture. ${ }^{60}$ Sociologist Pierre Bourdieu refined Macdonald's categories into a multitude of finer "distinctions," theorizing that culture is composed of shared symbols and practices that reflect and re-produce class distinctions. ${ }^{61}$ His approach argues that cultural tastes are informed by a habitus, one's home background and education, which is the tacit knowledge of how to reinforce social class through strategic consumption. ${ }^{62}$ For Bourdieu, consumers draw upon their economic, cultural and social capital. Economic capital is one's financial resources. Social capital is one's relationships and affiliations. Cultural capital is one's set of distinctive taste, skills, resources, knowledge and practices. Culture, then, is defined by one's access to symbolic capital, which enables individuals to validate certain interpretations of the world. ${ }^{63}$ Bourdieu's work is useful to an understanding of why one may choose to foster specific and strategic relationships through acts of consumption. For the purpose of this thesis, Bourdieu's concept of culture is useful for understanding the motivational character of consumption, and the intended and unintended social meanings of art as it circulates on the commercial market.

\footnotetext{
${ }^{59}$ Matthew Arnold, "Culture and Anarchy," in Cultural Theory and Popular Culture, $2^{\text {nd }}$ ed., John Storey, ed. (Athens, Georgia: The University of Georgia Press, 1998): 7.

${ }^{60}$ Dwight Macdonald, “A Theory of Mass Culture," in Cultural Theory and Popular Culture, $2^{\text {nd }}$ ed., John Storey, ed. (Athens, Georgia: The University of Georgia Press, 1998): 22.

${ }^{61}$ Pierre Bourdieu, Distinctions: A Social Critique of the Judgment of Taste, Richard Nice, trans., (Cambridge: Harvard University Press, 1984).

${ }^{62}$ Bourdieu, 1.

${ }^{63}$ Bourdieu, 282.
} 
In the context of the discipline of anthropology, Wolf had written of the changing concept of culture in the $1960 \mathrm{~s}$. The category no longer clearly denoted an incontrovertible, bounded set of symbols shared by a particular 'native' group. He wrote that Anthropologists "have moved on to emphasize interrelationships, and to visualize chains of systems within systems, rather than isolated phenomena with impermeable boundaries." 64 According to Wolf, anthropologists of the 1960 s were recognizing the dynamism and contexts of cultures, as well as the role and effect of the observer. ${ }^{65}$

Geertz discusses a similar shift in the meaning of culture in After the Fact: Two Countries, Four Decades, One Anthropologist in which he looks back on his experiences in the discipline. ${ }^{66}$ The early concept "marked the West, rational, historical, progressive, devotional, off from the Non-West, superstitious, static, archaic, magical."67 According to Geertz, the sense of the word altered due to the need for a more positive portrayal of the "other" and came to mean the "life-way-of-a-people." 68 In a description of the anthropologist's role in studying cultures, Geertz writes "Understanding a form of life... involves more than the assembly of telling particulars or the imposition of general narratives. It involves bringing figure and ground, the passing occasion and the long story, into coincident view. ${ }^{99}$ Similar to Wolf he recognizes the importance of contextualizing the dynamism of the cultural practices observed.

\footnotetext{
${ }^{64}$ Eric Wolf, Anthropology (Englewood Cliffs, New Jersey: Prentice-Hall, 1964): 53.

${ }^{65}$ Wolf, Anthropology, 53.

${ }^{66}$ Clifford Geertz, After the Fact: Two Countries, Four Decades, One Anthropologist (Cambridge, Massachusetts: Harvard University Press, 1995): 42.

${ }^{67}$ Geertz, After the Fact, 42.

${ }^{68}$ Geertz, After the Fact, 42.

${ }^{69}$ Geertz, After the Fact 51.
} 
The anthropological definitions of culture proposed by Williams, Wolf and Geertz are useful to an understanding of the types of information conveyed by culture brokers. While both these definitions, and Bourdieu's focus on shared social symbols and practices, the former is concerned with these shared characteristics as they contribute to unique group identities, while the latter is focused on how they reproduce class.

\section{Discourse}

Central to this thesis is a critical understanding of the 'Art world' and its related discourses. 'Discourse' is described by philosopher Michel Foucault as the systems of thought that converge to form an episteme, which is an "open and doubtless indefinitely describable field of relationships. ${ }^{, 70}$ Foucault describes an individual discourse as having its own set of rules that apply to all aspects of it and determine what can and cannot be said. ${ }^{11}$ However, discourses are undergoing continuous change as new utterances are included. ${ }^{72}$ Literary theorist and cultural critic Edward Said, who was influenced by Foucault, believed that all discourse, particularly as it pertains to culture, is ideological and must be understood within an ideological framework that is related to power between different social/cultural groups. He believed that discourse creates, rather than enables an examination of, the divisions and hierarchies amongst cultures. ${ }^{73}$

According to Foucault and Said, discourses are dynamic, but at the same time create the stability necessary for what can and cannot be said. Words are assigned meanings that are stable for only a brief period of time:

\footnotetext{
${ }^{70}$ Michel Foucault, in The Foucault Effect, Graham Bell et al, eds (Chicago: University of Chicago Press, 1991): 55.

${ }^{71}$ Foucault, 61.

${ }^{72}$ Foucault, 54.

${ }^{73}$ Edward Said, The World The Text and The Critic (Cambridge, Massachusetts: The Harvard University Press, 1983): 249-267.
} 
It is only when a word is located in a discourse and read in a context that there is a temporary halt to the play of signifier to signifier. But even discourses and contexts cannot fully control the play of meaning; 'traces' will always be carried from other discourses and from other contexts. ${ }^{74}$

This thesis draws primarily on the discourses of art history and anthropology as they have predominantly been used in the discussion of Inuit art. As anthropology and the study of art continue to overlap in a variety of ways the discourses of both areas of study become less certain. Anthropologists George E. Marcus and Fred R. Myers's edited volume The Traffic in Culture, examines the relationship between the two disciplines. The essays it contains are not concerned with defining culture, but rather how artistic practices and discourses produce culture. ${ }^{75}$ In their introduction, Marcus and Myers state "In contemporary cultural life, art is becoming one of the main sites of cultural production for transforming difference into discourse, for making it meaningful for action and thought." ${ }^{.76}$ Fred Myers discusses anthropologists' struggle to interpret and translate between non-Western and Western concepts of culture. He addresses the problem posed by art discourses that have traditionally interpreted non-Western cultural objects according to Western values. ${ }^{77}$ According to Marcus and Myers

Navigating the translation between art-world discourse and that of anthropology, therefore, is particularly challenging, demanding a genuinely dialogical stance and a recognition that the boundary between "art" and "anthropology" has never been very clear. ${ }^{78}$

\footnotetext{
${ }^{74}$ John Storey, "Part Three Introduction," in Cultural Theory and Popular Culture, $2^{\text {nd }}$ ed., John Storey, ed. (Athens, Georgia: The University of Georgia Press, 1998): 96.

${ }^{75}$ George E. Marcus and Fred R. Myers, eds. The Traffic in Culture: Refiguring Art and Anthropology (Berkeley and Los Angeles, California: University of California Press, 1995): 10

${ }^{76}$ Marcus and Myers, 34-35.

${ }^{77}$ Fred Myers "Representing Culture," in The Traffic in Culture, Fred R. Myers and George E. Marcus, eds. (Berkeley and Los Angeles: University of California Press, 1995): 80.

${ }^{78}$ Marcus and Myers, 5.
} 
In addition to the lack of a boundary between the disciplines, there are also traits unique to each. Fields of inquiry are characterized by their objects of study, methods of research and the histories of the disciplines themselves. ${ }^{79}$ Each of these factors affects the formation of a discipline's discourse and must be re-negotiated to successfully translate cultural concepts and values.

In the introduction to Unpacking Culture, art historian Ruth B. Phillips and anthropologist Christopher B. Steiner recognize the difficulty of representing indigenous objects as "art" since this requires that they be transposed into Western systems of classification, in which they are often understood as either artifact or art. ${ }^{80}$ These categories cannot take the context and meaning of the object into account. For an interpretation of such objects, the categories should be understood as informing each other and efforts must be made "to unpack the baggage of transcultural encounter with which they travel and search for the meanings and memories stored inside. ${ }^{{ }^{81}}$ Phillips and Steiner acknowledge the need to contextualize objects by using information not traditionally a part of art historical discourse since the Western frame of reference is inadequate for an understanding of non-Western objects. This is a project that would require the inclusion of indigenous perspectives. Until recently the discourse about native art has not easily afforded space for native people to speak. ${ }^{82}$

\footnotetext{
${ }^{79}$ John Storey, "Introduction: The Study of Popular Culture and Cultural Studies," in Cultural Theory and Popular Culture, $2^{\text {nd }}$ ed., John Storey, ed. (Athens, Georgia: The University of Georgia Press, 1998): x.

${ }^{80}$ Ruth B. Phillips and Christopher B. Steiner, "Art, Authenticity, and the Baggage of Cultural Encounter," in Unpacking Culture, Ruth B. Phillips and Christopher B. Steiner, eds. (Berkely and Los Angeles: University of California Press, 1999): 15.

${ }^{81}$ Phillips and Steiner, 19.

${ }^{82}$ Fred Myers in Marcus and Myers, 81 .
} 
Transnationalism

Globalization describes the increasing movement of information, objects and people across and within national borders as a result of technological developments, political orientations and economic policies. The globalizing factors in contemporary society are creating new fora in which artistic communities can form and develop. These factors will be addressed in this thesis since they affect the power balance of the art world.

World systems, such as those proposed by Geertz, have presented a split between centre and periphery. Comparative literary theorists Françoise Lionnet and Shu-mei Shih distinguish between the power structures of globalization and transnationalism, writing that globalization is central, assumes a norm and produces a hierarchy. ${ }^{83}$ It is "defined vis-à-vis a homogenous and dominant set of criteria, [whereas] the transnational designates spaces and practices acted upon by border-crossing agents, be they dominant or marginal." 84 Furthermore "The transnational... can be conceived as a space of exchange and participation wherever processes of hybridization occur and where it is still possible for cultures to be produced and performed without necessary mediation by the center." ${ }^{\circledR 5}$ This concept of transnationalism recognizes it as part of globalization, but also that it creates space for fluidity and dynamism. ${ }^{86}$ Globalization causes the minor to always seem mediated by the major and does not facilitate international minority alliances, whereas the transnational is not bound by the binary of the global and the local

\footnotetext{
${ }^{83}$ Françoise Lionnet and Shu-mei Shih, eds., Minor Transnationalisms (Durham and London: Duke University Press, 2005).

${ }^{84}$ Lionnet and Shih, 5.

${ }^{85}$ Lionnet and Shih, 5.

${ }^{86}$ Lionnet and Shih, 5.
} 
and enables us to consider the relationships formed among different margins. ${ }^{87}$ The binary model assumes a power-relationship in which the minor is either in opposition to the major, or assimilated into it. ${ }^{88}$ According to Lionnet and Shih the minor can form productive relationships with the major, as well as minor-to-minor connections that exclude the major. ${ }^{89}$

For Lionnet and Shih, the attribution of authenticity asserts the norm or dominance. They write

Once authenticity is evoked or normalized, a politics of inclusion and exclusion sets in, where arbitrarily fixed categories of identity in the form of identity politics can police cultural expressions and practices. Differences within a given minority group are suppressed in the interest of forming a cultural unified front against domination. However, minor cultures as we know them are the productions of transmigrations and multiple encounters, which imply that they are always already mixed, hybrid and relational. ${ }^{90}$

According to Lionnet and Shih, it is now necessary that we reconsider authenticity from a transnational perspective because of the "increased speed, frequency, and expansion of cultural conjunctures and disjunctures in the formation of various spaces of contact, physical and virtual." 91 The minority is often constituted in the physical sense by migration and travel between West and non-West, but the authors note that very little has been written about multidirectional travels beyond immigration studies. ${ }^{92}$ They further acknowledge that "The nonwhite Western person who traverses the forces of globalization to the non-West presents [a] subject position fraught with ambivalence." 93

\footnotetext{
${ }^{87}$ Lionnet and Shih, 6.

${ }^{88}$ Lionnet and Shih, 7.

${ }^{89}$ Lionnet and Shih, 8.

${ }^{90}$ Lionnet and Shih, 10.

${ }^{91}$ Lionnet and Shih, 10.

${ }^{92}$ Lionnet and Shih, 13.

${ }^{93}$ Lionnet and Shih 13.
} 
In anthropologist and linguist Arjun Appadurai's book Modernity at Large ${ }^{94}$ he examines the movement of people and information and argues that new possibilities are made possible as

...mass mediation becomes increasingly dominated by electronic media (and thus delinked from the capacity to read and write), and as such media increasingly link producers and audiences across national boundaries, and as these audiences themselves start new conversations between those who move and those who stay, we find a growing number of diasporic public spheres. ${ }^{95}$

Like Lionnet and Shih, Appadurai argues "The new global cultural economy has to be seen as a complex, overlapping, disjunctive order that cannot any longer be understood in terms of existing center-periphery models." ${ }^{96}$ To account for the more complex movement of information and people, Appadurai proposes that there has been a break, or rupture, primarily due to media and migration, from the past. ${ }^{97}$

Since this thesis is concerned with the art world it is useful to include art historian and anthropologist Aldona Jonaitis' perspective on the movement of First Nations art in a transnational world. In her essay "First Nations and Art Museums" she writes

Although much First Nations art has remained with its creators, many artworks have been exhibited internationally, and thus have assumed a place within the sphere of global culture... Too many exhibits present First Nations work in isolation from the globalized world, creating a false image of separation and expressing a historicity that does not exist. Displays of First Nations art in art museums will certainly contribute to ongoing efforts to enhance viewers' understanding and appreciation of these works, and will also acknowledge the forces of globalism. ${ }^{98}$

\footnotetext{
${ }^{94}$ Arjun Appadurai, Modernity at Large, (Minneapolis: University of Minnesota Press, 1996).

${ }^{95}$ Appadurai, 22.

${ }^{96}$ Appadurai, 32.

${ }^{97}$ Appadurai, 9

${ }^{98}$ Aldona Jonaitis, "First Nations and Att Museums," in On Aboriginal Representation in the Gallery, ed Lynda Jessup and Shannon Bagg (Hull, Quebec: Canadian Museum of Civilization, 2002), 21.
} 


\section{Chapter Breakdown}

To date, the most significant scholarly contributions about Ruben's work have been the catalogues for the shows Between Two Worlds ${ }^{99}$ and Out of Tradition, ${ }^{100}$ both curated by Darlene Wight at the Winnipeg Art Gallery. These two sources have been invaluable for my research. The artist was involved in the writing of both catalogues, and, accordingly, they document his perspectives apart from the wider debates about discourse, institutions, and globalization. Other brief reviews and entries in books dating from the early 1970s onward have primarily focused on Ruben's biography, often recapitulating the information from both catalogues, rather than developing a critical study of his work. A key resource has been Inuit Art Quarterly (IAQ), which has published interviews with Ruben and reviews of his exhibits. I contacted Ruben, but unfortunately was unable to conduct an interview with him and had to rely on these alternative sources for the artist's perspective. ${ }^{101}$

Chapters one and two present two case studies, an exhibition and website, respectively. The first focuses on the unique situation that led to the development of Ruben's role as a culture broker as revealed in his solo exhibition Between Two Worlds. This chapter traces the artist's agency in a developing collaborative curatorial process that enabled him to move from what Paine would describe as a 'client' to that of a

\footnotetext{
${ }^{99}$ Darlene Coward Wight, Between Two Worlds: Sculpture by David Ruben Piqtoukun (Winnipeg: Winnipeg Art Gallery, 1996).

${ }^{100}$ Darlene Wight, Out of Tradition: Abraham Anghik/David Ruben Piqtoukun (Winnipeg: Winnipeg Art Gallery, 1989).

${ }^{101}$ I initially contacted Ruben in August 2006. At that point he expressed interest in an interview and we agreed to stay in contact. When $I$ attempted to make an appointment in March 2007 Ruben was very busy but he still seemed interested in meeting with me. I emailed him three more times to schedule an interview during the summer but did not receive any response. I regret that $I$ have therefore had to base this discussion on interviews conducted by others, and hope that in the future $I$ may be able to develop this work further through direct conversation between us.
} 
'broker,' a self-conscious intermediary between the 'Inuit world' and the 'southern world.' I examine the exhibition within a trajectory of Canadian museum politics regarding curatorial process and the representation of Aboriginal Peoples, including the 1992 Report of the Task Force on Museums and First Peoples, which provided recommendations for collaborative relationships between museums and aboriginal peoples. ${ }^{102}$ I also look at two catalogues to enhance our understanding of the relevant cultural politics during Ruben's solo exhibit, arguing that Women Artists: Voices From Cape Dorset ${ }^{103}$ (which accompanied Isumavut: The Artistic Expression of Nine Cape Dorset Women) and Pudlo: Thirty Years of Drawing ${ }^{104}$ helped to establish the trajectory of museological practices in the Inuit art world that led to Between Two Worlds. Critical reviews of Isumavut published in popular and specialized sources will situate the range of debates about curatorial methods that this exhibition stimulated. This chapter will also address the important role played by Seidelman, who provided key economic support for Ruben during the creation of a new body of work. The developments in the curatorial processes, in tandem with the financial support from Ruben's dealer, enabled the artist to produce a coherent body of carvings specifically for the exhibition, and allowed him to help determine the work and text that would be used in the exhibit. The aim of this chapter is to disentangle the complex linkages between the market, dealers, curators, artist and the public.

\footnotetext{
${ }^{102}$ Task Force on Museums and First Peoples (Ottawa: Assembly of First Nations and Canadian Museums Association, 1992).

${ }^{103}$ Odette Leroux, Marion E. Jackson and Minnie Aodla Freeman, eds., Inuit Women Artists: Voices from Cape Dorset (Vancouver and Toronto: Douglas and McIntyre: 1994).

${ }^{104}$ Marie Routledge and Marion E. Jackson, Pudlo: Thirty Years of Drawing (Ottawa: National Gallery of Canada, 1990).
} 
Chapter two will examine Ruben's current engagement with the commercial art market as seen in his website, www.davidruben.com. ${ }^{105}$ I argue that in this transnational forum the artist takes a more subtle approach to culture brokerage than in his prior work. The site demonstrates that he is not conveying cultural information to a broad audience, but is developing refined relationships with other artists and patrons who are rich in cultural and economic capital. ${ }^{106}$ Against the trend found in other galleries and dealers, Ruben's own website focuses on his current artistic practice and his role as a culture broker.

At the centre of this project lies Ruben's interest in crossing cultural borders and his ongoing desire to present himself as a 'border crosser.' Although he has previously relied on mainstream art institutions to advance his culture brokerage, the tools of transnationalism are now providing him with new means of moving across previously impenetrable boundaries.

\footnotetext{
${ }^{105}$ David Ruben Piqtoukun: Artist Romancing the Stone, http://davidruben.com/, last modified on 8 March 2007, Accessed 15 March 2007.

${ }^{106}$ Bourdieu, Distinctions: A Social Critique of the Judgment of Taste.
} 


\section{Moving Amongst Worlds: A Reexamination of Between Two Worlds}

This chapter explores the politics and role of a curatorial project that expedited Ruben's development as a culture broker. The Winnipeg Art Gallery's (WAG) 1996 solo exhibition Between Two Worlds involved a unique collaboration between David Ruben Piqtoukun and the Associate Curator of Inuit Art, Darlene Wight. The process was facilitated by the extensive financial support of Ruben's dealer, Harold Seidelman, which allowed the artist to produce a new body of work for the show. As I will show in this chapter, the roles fulfilled by Seidelman and Wight were crucial to the success of Ruben's art world positioning as a cultural intermediary, enabling the artist to produce a cumulative body of focused work appropriate for exhibition, and, from the curator's perspective, giving him greater access and control over self-representations in a new contact zone, the museum. Since the show was also exhibited at a national institution, the Canadian Museum of Civilization, Ruben's work as an artist and a culture broker could meet a broader audience. This chapter examines the three-way negotiations between artist, dealer and curator that were central to Ruben's positioning as a culture broker.

In order to understand the issues that were in the minds of these three players, Between Two Worlds must be contextualized in the museum world politics of the 1980s and 1990s. First, the curatorial methodology of the show can be related to a concatenation of events dating back to Wight's earlier work for the Canadian Arctic Producers (CAP) in the 1980s. Second, although on the surface of things, the exhibit seems not to have been directly related to the 1992 Task Force on Museums and First Peoples, I argue that it should nevertheless be considered in light of the recommendations set forth in the report. Because the Task Force presented an important model for a new 
collaborative curatorial method, it tacitly reinforced the collaborative method that was simultaneously being developed by Seidelman, Wight and Ruben. These changes may also reflect a parallel evolution that had been taking place in the Inuit art world since the late 1970 s, most notably an increased focus on the artists' perspectives and biographies.

The success of the process used by Wight can be seen in the enthusiastic response of both the general audience and other museum professionals. The show presented a new and welcome framework for looking at Inuit art and enabled the audience to move past stereotypical expectations. Ruben was not a silent producer of saleable work, but took on the role of a broker of culture between the North and the South: the exhibition included recognizbly "Inuit" cultural references, in addition to more cosmopolitan layers of meaning through the addition of new imagery explained in text panels which channeled the audience's response to the works. Visitors were presented with narratives constructed by both Ruben, through his text and sculpture, and Wight, through her organization of the show. It is important to inquire as to how nuanced meanings of the show were altered when it moved from the first venue, a provincial art gallery to the second, a national social history museum. ${ }^{107}$

\section{Genesis of the Exhibition}

When Wight began working as Associate Curator of Inuit art at the WAG she had already incorporated into her curatorial practice the method of working directly with artists, which had become the norm for curators of Inuit art. During the 1980s, when she was working for CAP she had repeatedly travelled to the North to interview artists. At this time few Inuit art curators worked with artists during the curatorial process, but

${ }^{107}$ This thesis will focus on the show as it was presented at the CMC due to the availability of photographic documentation for that venue. 
Wight believed this was a necessary part of her work. She has said, "what I wanted to do was to work directly with artists and to figure out what was in their minds, what their objectives were, what their aesthetic interests were." ${ }^{108}$ It was this goal that made the collaborative effort with Ruben possible.

Shortly after Wight began working at the WAG, she curated the exhibit Out of Tradition in 1989. She developed a curatorial methodology in this exhibition that would be used later in Between Two Worlds. Out of Tradition featured the work of Ruben and his brother Abraham Anghik, who both lived in the South, and their relative geographical proximity facilitated collaboration between Wight and the artists. The propinquity of the artists to the gallery also enabled them to have greater involvement in all stages of the curatorial process. Wight repeatedly interviewed the artists, who were involved in the selection and locating of works for the show. It was during the work for Out of Tradition that Wight was able to complete much of the research that would later contribute to Between Two Worlds. ${ }^{109}$

While both of the shows featuring Ruben's work travelled, Out of Tradition was unique in that it travelled in the North and was shown in Cape Dorset, Pangnirtung and Iqaluit. Wight discussed the process and purpose of the show:

We packed it up and took it north and David actually came with me to Cape Dorset, Pangnirtung and Iqaluit... we installed it in the co-op in Cape Dorset and I had it sitting on these pedestals that didn't have tops on them and the idea was to allow artists in the north to see work that was made out of Brazilian soapstone and $[\ldots]$ other materials. Because my idea was to encourage other artists to work in materials that weren't necessarily considered to be "authentic." 110

\footnotetext{
${ }^{108}$ Darlene Wight, Interview by author, 27 April 2007, Audio recording, Carleton University, Ottawa.

${ }^{109}$ Wight, Interview by author.

${ }^{110}$ Wight, Interview by author.
} 
This effort happened spontaneously and received little attention. Importantly, it directly involved Ruben, the artist, as well as many other Inuit artists in the exhibition process. Taking the show to northern communities expanded Ruben's capacity to foster relationships between his southern and northern communities, allowing him to translate information across the seemingly fluid border separating the two contact zones. Since Ruben was featured in a significant show at a well-established art institution, his work was validated in both the southern and northern communities.

At the time that these innovative and collaborative efforts in Out of Tradition were taking place, the broader Canadian museum world was engaging in a complex debate about the relationship between museums and aboriginal peoples. Although this disputed issue was most strongly and explicitly connected to First Nation peoples rather than Inuit, the timing indicates that it did have an impact on the methods used to display Inuit art. Accordingly, the curatorial practice used to show Ruben's work in 1996 needs to be considered in relation to Inuit art shows that took place in the early 1990s, following a series of events that had highlighted the need to include the perspectives of Native artists. Knowledge of this context is imperative to an understanding of Between Two Worlds.

The controversy surrounding the 1988 show The Spirit Sings at the Glenbow Museum sparked discussions about the roles and responsibilities of museums to First Peoples. ${ }^{111}$ The controversy ultimately led to the Assembly of First Nations and the Canadian Museums Association jointly appointing a task force to investigate issues that were relevant to museums and First Peoples, a process which led to significant changes

${ }^{111}$ Marie Routledge, "North South: Inuit Art at the National Gallery of Canada: Changing Times," Inuit Art Quarterly, vol. 5, no. 4 (Fall/Winter, 1990/1991): 89. 
on many levels of museum practice. ${ }^{12}$ The Task Force's recommendations, released in 1992, identified a central imperative that the "desire and authority of First Peoples to speak for themselves should be recognized and affirmed by museums."113 Since then, both anthropology and history museums as well as art galleries have used a variety of methods in response to the Task Force. ${ }^{114}$

For Wight, the practice of direct collaboration with Inuit artists does not seem to have been influenced by the Task Force:

I had a sense that [The Task Force] was more to do with Native art rather than Inuit... I didn't really think about that at all. It [working directly with artists] was just something that I had done since I started working in this field. I always wanted to, whenever I had the opportunity to talk to artists I did and it just so happened that the opportunity for this show existed and was right... I guess my point is that this is just something I do and I've always done it and always will do it. $^{115}$

Working with artists was an established part of Wight's curatorial practice and a practice that was clearly articulated in the Task Force, ${ }^{116}$ Between Two Worlds reflects developing methods employed by other curators of Inuit art.

Shortly after The Spirit Sings there were several Inuit art exhibits that demonstrated significant changes in Inuit art curatorial practices. None of them explicitly addressed issues related to the Task Force but the curators were certainly cognizant of the politics in the changing museum world. In the 1980 s, the Inuit art world was engaging

\footnotetext{
${ }^{112}$ Routledge, 89.

113 "Turning the Page: Forging New Partnerships Between Museums and First Peoples." A Report jointly sponsored by the Assembly of First Nations and the Canadian Museums Association, Ottawa, 1992. See also Trudy Nicks, "Partnerships in Developing Cultural Resources: Lessons from the Task Force on Museums and First Peoples," Culture, vol. 12, no. 1 (1992): 87-94.

114 "North South: Current Issues Facing Museums," Inuit Art Quarterly, vol. 5, no. 4 (Fall/Winter, 1990/1991): 88

${ }^{115}$ Wight, Interview by author.

${ }^{116}$ Under Section B, "Specific Recommendations to Establish Partnerships between First Peoples and Canadian Museums," sub-section 2e specifies "Canadian art museums should work with artists of First Nations ancestry to enhance their collection of contemporary art." "Turning the Page."
} 
with its own concerns that paralleled those faced by the Canadian museum world. In 1982, the Conference for Curators and Specialists who Work with Inuit Art was held in Ottawa. It is clearly evident that Inuit art scholars, artists and dealers were attending to some of the issues that would later become pertinent to the Task Force in 1990, although in a less overtly politicized form. The panel entitled Methods for the Interpretation of Inuit Art emphasized the importance of interviewing artists and including their perspectives in the interpretation of their work, but recognized the difficulties encountered when working with Northern artists. The primary challenges, they surmised, were due to physical distance, language barriers and associated costs of northern travel and translation. An additional problem was posed by language when a translator had to be included in the process as he or she might unintentionally alter nuanced meanings. When a second translation was proposed as part of the process Mame Jackson responded:

It's not a matter of simply translating words - and with languages that are so different that's a difficulty anyway - it's also communicating the "spirit" of what's intended. I don't know that even a second translation of the same tape is as much an answer as really finding a compatible relationship among an interviewer, an interpreter-collaborator and an artist... I think the "chemistry" itself is such an important aspect of a successful interview that if that isn't there in the interview, a second translation of the tape, though it may be clearer, doesn't help. ${ }^{117}$

Although translation would not be an issue for work done with Ruben, these comments indicate the increasing significance placed on the perspectives of the Inuit artist, and indeed the importance of language itself in the interpretation of Native art.

Most conference participants emphasized the importance of developing the relationship between the artist and the scholar. Jackson aptly surmised that

\footnotetext{
${ }^{117}$ Mame Jackson in Conference for Curators and Specialists who Work with Inuit Art, Canadian Government Conference Centre, September 15 and 16, 1982, Ottawa: Indian Affairs and Northern Development, 1983, 178.
} 
“interviewing is not just a matter of collecting information. It's not just a one-way

street, but it's a dialogue - part of a continuing dialogue between individuals." 118 At a point when discussion was focused on the needs of the scholar, Jackson re-focused the issue on the importance of recognizing the artist's goals and needs, and how these should be included in ongoing relationships. Jackson stated that

one of the primary purposes of interviewing is to understand the works of art and to enable or make possible opportunities for the artists to be understood on their own terms, as they want to be understood, rather than as we try - through cultural differences sometimes - to understand them. ${ }^{119}$

The 1982 conference, and in particular this panel, drew attention to the necessity of incorporating the artist's views into interpretations of art works as a two-way street between scholar and artist. Although it can still be difficult to interview Northern artists, the expectation of incorporating the artist's views was set as a standard goal rather than an exception within the Inuit art scholarly community.

Exhibitions of Inuit art curated by Jackson and colleagues in the early 1990s put this theory into practice by including Inuit artists' voices and establishing a new trajectory for thematic approaches to the works. Exhibitions such as Pudlo: Thirty Years of Drawing (from hereon to be referred to as Pudlo), curated in 1990 by Marion Jackson and Marie Routledge, and Isumavut: Contemporary Expressions of Nine Cape Dorset Women Aritsts (from here on to be referred to as Isumavut), curated in 1993 by Odette Leroux, Marion Jackson and Minnie Aodla Freeman, included the life stories of Inuit artists, written in first-person. Although the one person show or retrospective biographical approach had been used for understanding Western art and has a long and

\footnotetext{
${ }^{118}$ Mame Jackson in Conference for Curators and Specialists who Work with Inuit Art, 174.

${ }^{119}$ Mame Jackson in Conference for Curators and Specialists who Work with Inuit Art, 174.
} 
well-established history that can be dated back to Giorgio Vasari, the inclusion of Inuit artists' perspectives or biographical information had not been typical in the curatorial work for Inuit art shows prior to the 1990s. As acknowledged earlier, factors that had led to the exclusion of Inuit voices were the distance and obstacles to communication, but even as these difficulties became manageable, historians remained resistant to collaborate with artists. After the 1982 Carleton Conference, scholars became aware of and began to use new and alternative curatorial paradigms with success.

A clear example of this can be seen in curators Routledge and Jackson's National Gallery of Canada retrospective, Pudlo. The show focused on the artist's biography to contextualize the work. ${ }^{120}$ Since Pudlo Pudlat worked within the West Baffin Eskimo Cooperative, his well-known prints are evidence of the collaborative efforts between himself, the printmakers who interpret his drawings and physically cut the print stone, and the Coop directors who select his drawings to be printed. In her capacity as curator, Routledge sought out those of Pudlo's drawings that "bring us closest to the hand and the eye of the artist."121 His works, which have incorporated depictions of modern technology for subject matter since the 1970s, have been controversial for their departure from "traditional" depictions that typically represent Inuit living before the present. A new level of understanding is brought to the works, said the curator, if they are contextualized by the artist's words and experiences. Through numerous interviews and collaborative efforts with several interpreters, Routledge was able to bring her own perspective together with the artworks and the artist's voice.

\footnotetext{
${ }^{120}$ Pudlo, 14.

${ }^{121}$ Pudlo, 13.
} 
In a review of this show, Dorothy Speak drew attention to the fact that Pudlo was the first solo exhibition of an Inuit artist's work at the National Gallery of Canada. ${ }^{122}$ She pointed out that this was a watershed exhibit taking place at a National institution indicating that it was setting a precedent for future shows. Overall her response was positive and her main criticism was that there was not more information on the labels for individual works, which may reflect the curatorial paradigm of the art museum, its hyperfocus upon the artwork itself rather than on its social or cultural context. Speak ultimately heralds the show as one that demonstrates Inuit art's place in the mainstream art world: "For shortsighted critics who claim that Inuit art does not belong in our art institutions, let exhibitions such as Pudlo: Thirty Years of Drawing open their eyes to the validity and immense talent of native artists such as Pudlo Pudlat."

For its part, the Gallery readily acknowledged that the logistics of this show were influenced by the then recent controversy surrounding The Spirit Sings, which also included the imperative to increase the representation of Aboriginal peoples in museums. In response to the politics and concerns of the time, the NGC published all text related to the show in Inuktitut, as well as English and French to "strengthen the partnership with Inuit artists." ${ }^{\prime 24}$ After the opening of the show the Gallery had additional programming to facilitate engagement between artists and curators from the North and South, as well as to educate the general public. ${ }^{125}$

\footnotetext{
${ }^{122}$ Dorothy Speak, "Pudlo: Thirty Years of Drawing: The First Solo exhibition of an Inuit artist's work at the National Gallery of Canada, July 6 to September 3, 1990," Inuit Art Quarterly, vol. 5, no. 4 (Fall/Winter, 1990/1991): 80.

${ }^{123}$ Speak, 84.

${ }^{124}$ Inuit Art Quarterly, vol. 5, no. 4 (Fall/Winter, 1990/1991): 88.

125 "North South: Current Issues Facing Museums," 88.
} 
In a public lecture prior to the opening of Pudlo, Routledge acknowledged several current issues that were influencing the Canadian museum world. She discussed the then in-progress Task Force and the transfer of the federal Department of Indian and Northern Affairs' collection to cultural institutions across the country. ${ }^{126}$ Of relevance to the process used for Pudlo is Routledge's reference to Jo-Anne Birnie Danzker's paper presented at the Canadian Museum Association in 1990, "Cultural Apartheid". ${ }^{227}$

Danzker argued that the portrayal of Native art in Canadian museums and galleries could not be legislated, and for new methods of representation to be successful they must be put into practice. Routledge countered that by including all text for Pudlo in Inuktitut the NGC was responding to this concern and putting the new needs into practice. Her lecture positioned the exhibit as a success within the art world politics of the time. Although other curators using a collaborative approach to exhibiting Inuit art may not explicitly connect their work to the politics of the early 1990s as did Routledge, their shows should nonetheless be understood in relation to the trajectory set by Pudlo and the earlier Carleton Conference.

The next major show to utilize a collaborative framework raised more controversy. Isumavut, which was initially shown at the CMC in 1993, featured the work of senior women artists from Cape Dorset. By collaborating with interpreters to conduct extensive interviews, the co-curators, Odette Leroux and Marion Jackson, ensured that the artists had a strong voice in the interpretation and presentation of their work. They participated in choosing works to be exhibited, and the writing of texts for both the show and catalogue. In a review of the show published in The Globe and Mail, critic Ray

\footnotetext{
${ }^{126}$ Routledge, 89.

${ }^{127}$ Routledge, 89.
} 
Conlogue responded to the curatorial method by writing, "All of this is heart-warming, but it highlights the growing gap between traditional curating and the emerging politically correct notion of what a curator does." ${ }^{128}$ The author implies that the consultation with artists is unique and, ultimately, detrimental to this show. Conlogue cited the views of Norman Zepp, former curator of Inuit art at the Art Gallery of Ontario, to support his own views. Zepp was highly critical of Leroux's choice to let the artists select some of the works to be shown, believing that this led to the inclusion of works lacking in quality. This view assumes that there is an objective method to deciding the merit of a work, and that the curators were abrogating their professional responsibilities by allowing the artists to make selections. This review ended with Zepp's negative comment "This exhibition was largely curated by the artists themselves... Artists are not the best judges of their work." 129 Both Zepp and Conlogue seem unable to acknowledge the artists' cultural authority, and instead, maintain a stagnant view and framework for understanding and exhibiting Inuit art.

In response to this decidedly negative review, art historian Janet Berlo wrote a lengthy response incorporating some of the issues that became central to the Task Force. ${ }^{130}$ She began her article, which is divided into three sections, with a review of the exhibit and raised some criticisms, in particular about the paucity of text panels. Ultimately her review is positive and she writes "Despite these minor criticisms, I found the show beautifully installed, most of the selections well chosen, and the overall effect

\footnotetext{
${ }^{128}$ Ray Conlogue, “A curatorial square-off," The Globe and Mail, 22 October 1994, C17.

129 Zepp cited in Conlogue, "A curatorial square-off."

${ }^{130}$ Janet Catherine Berlo, "An Exhibition, a Book and an Exaggerated Reaction," Inuit Art Quarterly, vol. 10, no. 1 (Spring 1995): 26-36.
} 
eloquent and impressive." ${ }^{\prime 13}$ Berlo continued her review with a discussion of the catalogue, published by the CMC. This section opens:

While the exhibition is a beautiful one, it is really the accompanying book, Inuit Women Artists: Voices From Cape Dorset, that is the landmark achievement. For it is here that the voices of these women emerge as a strong complement to their artistic visions. ${ }^{132}$

Moving beyond the Pudlo catalogue, which presented a biography, this catalogue documented primarily autobiographical information. ${ }^{133}$

This important aspect of the show, which Berlo identifies as "a pathbreaking collaborative effort, "134 is not referenced in Conlogue's review. In the final section of the article, Berlo responds to specific criticisms raised in The Globe and Mail review of the show. She identifies Zepp's main concern as the close involvement of the artists in the curatorial process and goes on to identify the ironic fact that this is "practised daily in shows of $20^{\text {th }}$ century art made by non-Aboriginal artists. It is routine practice in every art gallery and museum in Europe and North America for a living artist to be consulted when a retrospective exhibit is hung." ${ }^{135}$ In response to Conlogue and Zepp's concern that the show demonstrates a lack of 'quality', Berlo points out that there is no universal standard by which the works can be judged. ${ }^{136}$ Unfortunately, the review in The Globe and Mail would have reached a much larger audience than the response published by Inuit Art Quarterly. Berlo's review in turn sparked a major debate that raged in

\footnotetext{
${ }^{131}$ Berlo, 30.

132 Berlo, 32.

${ }^{133}$ Shannon Bagg, "The Anthropology of Inuit Art: A Problem for Art Historians" in On Aborignal

Representation in the Gallery (Hull, Quebec: Canadian Museum of Civilization, 2002), 187.

${ }^{134}$ Berlo, 32.

${ }^{135}$ Berlo, 33.

${ }^{136}$ Berlo, 36.
} 
subsequent issues of $I A Q$ and polarized the Inuit art community. ${ }^{137}$ Nevertheless, the controversial response to this show seems not to have had a negative impact as the show continued to tour through 2008 , proving the curatorial approach a success.

Against this context, I return to look more closely at the collaborative effort used by Wight for Between Two Worlds, which finds its precedents in the curatorial methods used by Routledge for Pudlo and by Jackson, Leroux and Freeman for Isumavut. Several factors enabled Wight to meet, and in some aspects surpass, the standards set by the other two curators. As mentioned earlier, the collaborative effort between Ruben and the WAG was facilitated by the fact that the artist lived in the South and already had a working relationship with the gallery. Focus on the debated issue of incorporating the artist's voice into exhibits had led to this practice becoming more entrenched and accepted, which would have strengthened Wight's curatorial approach when conceptualizing the exhibition. This approach permitted Ruben to take a strong role in the production of text for the exhibit. Unlike other Inuit artists, including Pudlo and the Cape Dorset women artists, Ruben also had financial backing from his dealer.

The show, which would have also served Seidelman's commercial interests as an art dealer, enabled Ruben to create a new body of work with the intent of keeping the work together as a unified collection for an exhibition. ${ }^{138}$ Seidelman was also instrumental in documenting Ruben's comments about each object, which were confirmed by Wight at a later stage in the curatorial process. ${ }^{139}$ Thus, through his

\footnotetext{
${ }^{137}$ See Cynthia Cook, "No Thanks for the Isumavut review," and rejoinder by Janet Catherine Berlo, Inuit Art Quarterly, vol. 10, no. 3 (Fall 1995): 68-69.

${ }^{138}$ Wight, Interview by author.

${ }^{139}$ Wight, Interview by author.
} 
financial support and participation, Seidelman became an integral part of the network that facilitated Ruben's work as a culture broker.

The theme of the show developed over the two-year period prior to the exhibition. As the body of work grew, Wight developed eight sub-sections for the exhibition.

According to Wight the creation of a theme for the exhibit seemed to encourage the artist as he continued to produce works for the exhibition:

We came up with a title part way along. And I guess once I realized that a lot of the works dealt with his feelings of being torn between North and South and between the cultures, and it seems that definitely became part of the thinking, and once he realized that then he really went with it. He realized that that was what was interesting and he really worked towards that theme once we had it figured out. But it was part way along that this emerged and I think it really helped him a lot. It really energized him to work on that theme and sort of exorcise some of his demons. It had a very cathartic affect on him, I think. Afterwards he collapsed [emotionally] unfortunately, but while he was working on the show I think it was very beneficial for him. ${ }^{140}$

The "Between Two Worlds" theme enabled Ruben to develop and express coherentlyfocused ideas relating to various aspects of his life, seen divided between the North and South. It was in the work for this show that he moved beyond simply conveying Northern cultural narratives for a Southern audience and became invested, instead, in the physical, geographic and psychological conditions of the North and South divide. In preparation for Between Two Worlds, Ruben was able to bring together information from various contact zones: the crossing of numerous borders can be seen in the eight sub-sections of the show, which were entitled: Two Worlds, The Shaman, Sedna, Government, Christianity, Helping Spirits, Stories and Hope. Each section can be understood as a sub-

\footnotetext{
${ }^{140}$ Wight, Interview by author.
} 
narrative within the overall theme indicating that Ruben lives not 'between two worlds' but rather among many worlds.

It is no surprise, given the wealth of museum theory that posits the museum space, following Clifford, as a "contact zone,"141 that the articulation of Ruben's multiple identities occurred within the walls of an art gallery. Museums, according to Aaron Glass, are concrete and limited spaces in which the concept of the contact zone, as proposed by Pratt, is made manifest. Museums are unique loci, he points out, which emerge as sites of such articulation, as 'contact zones' in which and through which people, objects and knowledge travel; in which culture is collected, recollected, revalued and displayed; in which identities and values are formed, negotiated and represented. ${ }^{142}$

What has historically and geographically been separated is brought together within the museum; the new relationships established between these objects and representations can be seen and internalized by museum visitors. The WAG and CMC served as the loci through which the sculptures, and inherently their meanings as ascribed by Ruben, are brought together and presented to an audience. Although the relationships between the objects and the visitors continue to re-define identities, the audience's understanding of an exhibit, according to museum theorist Eilean Hooper- Greenhill, "depends on prior knowledge, and on beliefs and values. We [the audience] see according to what we know, and we make sense of meaning according to what we see." ${ }^{\text {143 }}$ Ruben was able to relate to the audience as a Southerner while presenting a select view of Inuit culture.

\footnotetext{
${ }^{141}$ James Clifford, Routes: Travel and Translation in the Late Twentieth Century (Cambridge, Massachusetts: Harvard University Press, 1997).

142 Glass, 36.

${ }^{143}$ Eilean Hooper- Greenhill, "Education, communication and interpretation: Towards a Critical Pedagogy in Museums," In The Educational Role of the Museum, $2^{\text {nd }}$ ed. Eilean Hooper-Greenhill, ed. New York: Routledge, 1999, 12.
} 
The CMC exhibited Between Two Worlds from April 18, 1996-February 15, 1997 (Fig. 1.1-1.4). ${ }^{144}$ The audience's experience and understanding of the exhibit must be considered in the context of the specific host museums because, as acknowledged by Eileen Hooper-Greenhill, "In museums, meaning is constructed from objects, and from the sites themselves." 145 Visitors to Between Two Worlds at the CMC entered the exhibition space with a somewhat different perspective from those seeing the show at the WAG, I suggest. As a national museum of social history the CMC is imbued with meanings that differ significantly from those of an art gallery. The audience expects both a different experience and, due to its stature as a national museum, to learn different types of information. Even though the actual exhibit was not physically altered significantly from the former to the latter venue, we may sense a shift in meaning due to the context in which it was presented. While the settings provided by the two institutions varied significantly, this show nonetheless enabled audiences to question expectations of Inuit culture, whether it be in relation to art or to social history.

The differences between the museums are amplified by the particularly distinct architecture and layout of the CMC. To gain access to the show, visitors first descended into an exhibition of a Pacific Coast Indian village in the Grand Hall, and thus the exhibition may have been seen within a trajectory of Native ethnology or Native history, rather than western art-history. Within the Grand Hall, aspects of the historical environments of Native peoples are replicated with the intention of influencing the

\footnotetext{
${ }^{144}$ Although this show was organized by the WAG the primary object of study for the purposes of this thesis is the exhibit as it was shown at the CMC. While there were minor changes in the lay-out due to the floor plan nothing was changed substantially (Wight).

Project Brief, CMC file, Acq 2005-1-0009 - Fonds Sylvie Morel.

${ }^{145}$ Hooper-Greenhill, "education, communication and interpretation" in The educational role of the museum 12-13.
} 
visitors" senses and emotions, offering various levels of "in-situ" experience. ${ }^{146}$ The large open space of the Grand Hall both dwarfs and overwhelms the visitor. It is a beautiful and dramatic setting, which incorporates sound and pulls the viewer into a highly staged setting. Ruth Phillips writes that

museums today function as interactive theatres where spectacles are produced and staged for increasingly diverse audiences. Here practice refers to the honing of representational skills through repeated application and has significations of preparation, rehearsal, and performance. ${ }^{147}$

At the CMC, the spectacle has been created to capture the attention of a broad audience.

The experience of entering the Between Two Worlds Exhibition space was a stark contrast to the Grand Hall but maintained a sense of drama. Gray walls, carpets and pedestals could have created a stagnant and sterile environment, but the use of theatrical lighting, combined with the CMC's distinct curvilinear architectural forms, generally evocative of a Native view of nature as implied by the Aboriginal architect Douglas Cardinal, also created a powerful sense of movement. As is evident in the installation photos, light filtering down over the forest-like arrangement of plinths created an ethereal quality in the exhibition space.

The planned path through the exhibit first brought the visitor to the work Guidepost (Fig. 1.5), which was part of the Christianity sub-section of the show. This work depicts a smooth, masked figure who appears to be emerging upwards out of a long horizontal platform. Ruben writes "The Christian cross merges here with the inukshuk, the 'likeness of a person' that was used as a navigational marker on the land. The base

\footnotetext{
${ }^{146}$ George F. Macdonald, "Change and Challenge: Museums in the Information Society," In Museums and Communities (Washington and London: Smithsonian, 1992) 166.

${ }^{147}$ Ruth B. Phillips, "Re-placing Objects: Historical Practices for the Second Museum Age," Canadian Historical Review vol. 86, no. 1 (March 2005): 88.
} 
suggests the clothing of the Grey Nuns. The new beacons have led many people away from the old signposts." 148 This work symbolically oriented visitors as they entered the exhibit. This sculpture, which is large in comparison to the other works in the show, establishes a visual representation of the cultures that are being negotiated by Ruben. However, this is not necessarily clear to the viewer unless s/he reads the text. Like both Pudlo and Isumavut this show was criticized because the texts were not easily and immediately accessible to the viewer. Instead of including labels and extended captions, works were numbered and an accompanying pamphlet contained Ruben's descriptions.

In Alison Gillmor's review of the show she notes that:

The smooth and unified viewing experience normally orchestrated by art institutions is broken up here by the sudden shift between perceiving a threedimensional object and then riffling through the accompanying pages in search of its name. This set-up certainly challenges the passivity of the standard gallery/museum process, making the search for meaning more personal and active. At times, however, the juncture between Piqtoukun's visual and written modes is too sharp. ${ }^{49}$

Although this may seem like a small criticism it is significant to the understanding of Ruben as culture broker. Without Ruben's guiding explanation of the sculptures, audiences may have constructed a variety of their own narratives and thus diminished the authority of the artist's voice. Standing alone, the majority of the artworks are not adequately explicit in their meaning but require the accompaniment of Ruben's text to enlarge upon their layered significance for the audiences.

This exhibit purported to position Ruben between two worlds, but it may be more accurate to say that it situated him among many worlds. A dyadic rendering of the

\footnotetext{
${ }^{148}$ Ruben in Darlene Wight Between Two Worlds (Winnipeg: Winnipeg Art Gallery, 1996) 25.

${ }^{149}$ Alison Gilmor, "Between Two Worlds: Sculpture by David Ruben Piqtoukun," Inuit Art Quarterly, vol 11, no. 4 (Winter 1996): 31 .
} 
cultures is too coarse to grasp his varied life experiences, or the many cultural facets of both the North and the South. The fact that the overall narrative of the show was divided up into eight sub-sections is indicative of Ruben's exposure to various "worlds," and the multiplicity of identities he takes on as he negotiates among these spaces.

Following the pre-planned path for the show, the first section, the visitor saw was "Two Worlds." The narrative connecting these works attempted to juxtapose the North and South as though they were extreme opposites. It was this juxtaposition that established the necessary conceptual distance between Ruben and his audience - $\mathbf{a}$ common strategy of the culture broker, according to Glass. ${ }^{150}$ In the work Airplane (Fig. i.5), a human figure is presented to the viewer with a blank and almost mask-like appearance that is contrasted by the sense of movement created by the slightly raised arms and legs as the person appears to be in flight. The body's movement is contrasted with a seemingly sedentary airplane, which is then juxtaposed with the firmly grounded igloo. In the text for this work Ruben writes "The airplane carries us to a world of wonders when we travel south. We have the same problem that the angakoqs had when they reached the spirit world. Can we find our way back to the human world?"151 The inclusion of an igloo at the base of this work is not representative of the current reality for many Inuit. While the depiction of this dwelling may be solely symbolic it does conjure ideas of an Inuit world that he can no longer find. Ruben uses the igloo to maintain a conceptual distance between himself and the audience. This work implies that a return to the human world is dependent on learning about the culture, and most importantly the spiritual beliefs that were lost to him at a young age.

\footnotetext{
${ }^{150}$ Glass, 27.

${ }^{151}$ Wight, Between Two Worlds, 4.
} 
The work The Choice (Fig. 1.6) further demonstrates the dichotomy of the worlds of the North and South as depicted in this show. An Inuk stands with his arms outstretched looking at the viewer with a quizzical expression on his face. In his left hand he holds a komatik (a sledge) and in his right a snowmobile. In the accompanying text for this work Ruben writes "Must we choose between the komatik and the snowmobile, between the old and the new? We need both and we need a culture in which both find a place." 52 It may be argued that the worlds represented by the sled and snowmobile are not as separate as Ruben implies in this work. Rather, they are connected and overlapping and there is already a place for each in his cultural experience.

Ruben explores a perceived spiritual difference between the North and the South in the work Spirits of My Ancestors (Fig. 1.7). The sculpture is made up of two easily distinguishable parts. The lower and larger portion, which is carved from a material light in colour, shows the faces of spirits that seem to emerge organically from the stone. The stylized and elongated faces, which are at different points in the surfacing process, are making an ' $o$ ' shape with their lips. The viewer is given the impression that they are blowing or emitting mournful moans. The repetitive and rounded shapes of the spirit figures create a feeling of movement throughout this stone. Above this dynamic portion of the work rests a figure carved from a darker material. This stylized depiction of a clothed person is stiff and seems to be completely disconnected from the rhythmic repetition of the emerging spirits. Unlike the expressive faces of the spirits this figure is presented to the viewer with a blank and almost mask-like appearance. Ruben writes about his inspiration for this piece:

\footnotetext{
${ }^{152}$ Wight, Between Two Worlds, 4.
} 
In the modern world, we are encouraged to be independent and totally selfreliant. We end up alone and unable to relate to others. The spirits of the ancestors see our difficulties and would help us if we called out to them. But their voices are lost in the noise and distractions of the new ways. ${ }^{153}$

Through this work Ruben expresses his belief that there was a strong presence of spirituality in the past that is lacking in contemporary culture. The "two worlds" contrasted in both this work and The Choice seem to be the old and the new, that is, two worlds conceptualized along temporal lines. In Airplane the "two worlds" compared are the North and the South, two worlds conceptualized along geographical lines. These different comparisons within a sub-section of the show further demonstrate Ruben's position among many worlds.

The work created for this show enabled Ruben to explore his perception of the religious sphere that had altered his childhood so drastically. Priest and Nun (Fig. 1.8) depicts two heads looking up and away from each other. There seems to be no concern for each other or their surroundings. They gaze heavenwards but do not appear to be engaged either spiritually or emotionally. The hole on the side of their heads is a seal ear meant to reflect their inability to listen and relate to the Inuit as humans. ${ }^{154}$ In the text for this section of the exhibit Ruben compares the listening abilities of his elders in both the residential school and his former home: "Our community leaders, the isumatoks, listened to everyone before they made a decision. The missionaries seemed to have no ears at all. They told the Inuit what to do and they never listened to anyone."155 In this section of the exhibit Ruben wrote about the lack of emotion shown by the priests and nuns and their efforts to replace Inuit worldviews with Christian ideology. For a child this would

\footnotetext{
${ }^{153}$ Ruben in Darlene Coward Wight, 7

${ }^{154}$ Wight, Between Two Worlds, 24.

${ }^{155}$ Wight, Between Two Worlds, 26.
} 
certainly be a daunting and confusing experience. At a young age Ruben was forced to negotiate an identity developing in seemingly oppositional belief systems that overlapped in his life.

As an adult Ruben has said that he tried to maintain his knowledge of Inuit language and culture while at school but that it was impossible with the seemingly all seeing nuns and priests. In a 1994 interview he told John Ayre "I lost it all, I think it's all dormant. I spoke fluently until I was four, when I stopped speaking. It's still there somewhere. I understand things when I travel home, but it's hard to have conversations." ${ }^{\prime 156}$ Ruben explains that although he transitions back and forth across languages he maintains a familiarity with each. But according to post-colonial theorist Ngugi Wa Thiong'o, the ability to converse in a language has greater implications than the possibility of communication.

Language carries culture, and culture carries... the entire body of values by which we come to perceive ourselves and our place in the world. How people perceive themselves affects how they look at their culture, at their politics and at the social production of wealth, at their entire relationship to nature and to other beings. Language is thus inseparable from ourselves as a community of human beings with a specific form and character, a specific history, a specific relationship to the world... ${ }^{157}$

Ruben's understanding of the world is coloured and formed by both languages, which he uses strategically to transfer information between both worlds. Although he does not speak or fully understand Inuktitut, he has a unique access to both languages and utilizes them both within the contact zone of the museum. For Between Two Worlds Ruben was able to use only a few Inuktitut words to stand in for the language. More recently Ruben

\footnotetext{
${ }^{156}$ James Sinclair, "David Ruben Piqtoukun: Between Two Worlds," Inuit Art Quarterly, vol. 19, no. 3 (Fall/Winter 2004): 25.

${ }^{157}$ Ngugi Wa Thiong'o, “The Language of African Literature," In The Post-Colonial Studies Reader, B. Ashcroft et al. (Routledge: 1995) 290.
} 
said "I do not speak Inuktitut any more (I forgot how to speak by the time I was 6 years old) so that makes me an "outsider" in my society: a northern boy turned southpaw!"'158 For the 1996 exhibit Ruben used his knowledge of Inuktitut to create a conceptual distance between himself and his audience. At the same time he feels a distance between himself and his Northern community due to his lacking knowledge of the language.

Ruben used Between Two Worlds to further explore his understanding and familiarity with Inuit oral tradition as expressed in legends. In the sculpture entitled Sedna Lives (Fig. 1.9), Ruben depicts a character from Inuit spiritual stories. The legend developed in an oral tradition and there are many variations on the details, but it is essentially the tale of a girl who refuses to marry any of the men in her village. Finally her father forces her to marry a man who takes her away to an island. The father begins to feel remorse for having done this to his daughter and goes after her to bring her back to her village. When the husband, who had shamanistic or magical powers, discovers that his wife had left him he changes himself into a bird and flies after the boat carrying her. The husband's rage and agitation create a storm that endangers the lives of the father and daughter in the boat. The father realizes that the only way he can survive would be to throw his daughter overboard. He attempts to do this but she holds on to the edge of the boat. He then proceeds to chop her fingers off. As her fingers fall into the sea they become the fish, seals, walruses and whales. Finally, as the daughter sinks to the bottom of the sea she becomes the sea-goddess Sedna who controls the sea creatures, and accordingly dictates whether the Inuit people will be able to hunt for their livelihood.

\footnotetext{
${ }^{158}$ Courtright, 67.
} 
For this work, Ruben has focused on Sedna's qualities of strength and her attributes as a sea creature. Unlike many of the other works produced for this show this one is not highly polished and carved details are minimal. Ruben is not presenting her as a beneficent provider but rather as the unemotional and powerful ruler of the sea creatures. Although the artist chose to exclude a detailed account about Sedna from the text panels for the show his text does state, "In the old stories, Sedna ruled our lives. Even though her importance has diminished, her image will always be in our memory and art." ${ }^{959}$ Ruben believes that even in memories she holds significant power for Inuit. He repeatedly looks to Sedna for the subject matter of his sculptures featured in Between Two Worlds.

Journey to The Great Woman (Fig. 1.10) depicts a shaman and his spirit helpers attempting to appease Sedna by combing her hair as they sing to her. In this work, Ruben presents the sea goddess as a more dynamic, elegant figure. Her feminine beauty is emphasized by the dots on her face that represent the gender specific custom of facial tattooing. ${ }^{160}$ She continues to be the focal point since she forms the largest component of the work. A vibrant sense of movement is created as the shaman and spirits interact with Sedna in the cyclical form of the sculpture. Her size and grace give the impression that she is powerful yet beneficent. In Ruben's text for this piece he writes,

Summoning all his spirit helpers, the angakoq travels to the bottom of the sea to visit the mother of the sea animals. Combing her dishevelled hair and singing his magic songs, the shaman appeases her anger. She agrees to release her children to be caught by the hunters waiting above. In this time of spiritual deprivation we can use her help again. ${ }^{161}$

\footnotetext{
${ }^{159}$ Wight, Between Two Worlds, 21.

${ }^{160}$ Hessel, 137.

${ }^{161}$ Wight, Between Two Worlds, 22.
} 
He has often used the word 'loss' when describing the cultural changes he has faced in his life. The nature of the loss suffered by Ruben, as a residential school survivor, has defined the kind of cultural brokering he has been able to perform as this schooling deprived him of direct access to traditional knowledge. Indeed, it appears that making art has provided him with a tool for restoring his own losses of traditional understanding. In 2003, Ruben said "Loss of language, culture, and traditions have given us a new incentive and need to preserve what there is left of the "losses" we have encountered."162 The exploration of the image of Sedna can be understood as part of his effort to recover the spiritual and cultural grounding that he feels he has lost.

Although the two strikingly different depictions of Sedna were made in 1995 they create a sense of ambivalence as to Ruben's sentiments regarding the sea goddess. Having grown up without knowledge of the powerful figure, he now uses stone to work through an understanding of her story from the perspectives of his various cultural and societal positions. In 2003 , he spoke of the efforts he had made throughout his artistic career to understand mythology through his sculpture: "Of the themes I have explored in my art work, I really enjoyed portraying and trying to understand the nature of Inuit mythology in the broader and more personal perspective."163

Wight developed the theme for Between Two Worlds based on what she perceived in Ruben's work. While certain individual works point to a dichotomy, the overall effect of the show demonstrated a multiplicity of worlds. According to reviewer Nancy Baele, the arrangement of sculptures gives "the impression of a dialogue going on, not only

\footnotetext{
${ }^{162}$ Courtright, 59 .

${ }^{163}$ Courtright, 65 .
} 
between the viewer and object, but also between objects." $" 164$ The works created a discourse in each section of the exhibit, as well as amongst the sub-narratives. This dialogic relationship was further developed in the texts as Ruben's words created an account of his experience that has been of multiple worlds, not two.

Ruben attempted to construct polarities between Inuit and southern worlds, which in part enhanced his own agency as a broker. He employed his authoritative position to promote his own work but at the same time validated Inuit art more broadly as a form of contemporary art. In a discussion of the response of museum staff Wight said:

It kind of converted them [museum staff] to be more sympathetic to Inuit art. There's always been, and still is, the difficulty of justifying it and having people believe it's a credible art form... with Out of Tradition, and then with Between Two Worlds it really helped the director of the gallery, and the other curators, to see Inuit art as a really credible contemporary expression in that it wasn't just seals and polar bears and the kind of stereotypical art that one thinks of. It really helped establish a credibility that hadn't existed here before, and possibly elsewhere as well. ${ }^{165}$

The works by Ruben break down these barriers and show that Inuit art can be created out of a wide range of materials and diverse subject matter. Although Ruben may not have intended to impact the broader Inuit art world, in doing so he brought himself more attention and re-affirmed his position as a culture broker.

Unlike most Inuit artists, Ruben has been able to engage in forms of cultural production other than the creation of sculpture. By participating in activities at the WAG, such as writing for catalogues, travelling North with Out of Tradition and creating works specifically for Between Two Worlds, he has been able to wear many hats while foregrounding his own interpretation for many of his works. These actions are a factor in

\footnotetext{
${ }^{164}$ Nancy Baele, "Memories and Reflection: A Sculptor uses his art to address his anger," The Ottawa Citizen, 21 April 1997, D7.

${ }^{165}$ Wight, Interview by author.
} 
his position, which enables him to mediate perceptions of life and culture in the North by controlling the information he conveys.

Prior to Between Two Worlds Ruben had an authoritative voice when negotiating the conveyance of cultural information. This position was acknowledged in the work and support of Wight and Seidelman. A unique set of financial and political circumstances led to the opportunity for Ruben to create a body of contemporary work for an exhibit at a major art institution. Furthermore, he was able to draw from his own biography for the subject matter, which in the mid 1990s was a new and rare approach for the exhibition of Inuit art. The enthusiastic response from both the Canadian museum world and the general public endorsed Ruben's mediating role, but ironically, may have led to work he completed after the exhibit being caught between two worlds. Since then Ruben has often been situated in an interstitial space between the cultures of the North and South. The more nuanced culture brokerage that characterizes his career in the 2000 s is not emphasized in the broader art world. It is only in an elite group that Ruben's evolving position is being recognized. 


\section{Virtually Ruben: Representations of David Ruben Piqtoukun on the Online Art Market}

This chapter demonstrates how Ruben uses the internet as a tool to establish transnational relationships beyond those available to him prior to the prevalence of globalizing factors such as electronic media and increased migration. I examine, compare and contrast Ruben's self-representation on the web with a variety of representations created by private, commercial sales galleries. On his own site, Ruben has moved away from the use of biographical details and narratives from Inuit culture to contextualize his sculpture. However, some art dealers representing Ruben continue to use this method of validating and promoting his work.

This then raises questions about the nature of interactions between patrons and clients. In 1971, Robert Paine argued

what distinguishes the patron from his client is that only values of the patron's choosing are circulated in their relationship. There may be goods and services that are passed in the relationship in one direction only, but these do not provide a basis for distinguishing the patron and client roles. Further, the client demonstrates, to his patron and others, his acceptance of the value which the patron has chosen for circulation between them. ${ }^{166}$

Ruben is no longer economically dependent on the position of culture broker or maintaining his role as client, but dealers continue to use the characteristics of that role to contextualize his work. In "Art, Authenticity and the Baggage of Cultural Encounter,"

Ruth B. Phillips and Christopher B. Steiner conclude:

the solution to defining the authenticity of an object circulating in the networks of world art exchange lies not in the properties of the object itself but in the very process of collection, which inscribes, at the moment of acquisition, the character

\footnotetext{
${ }^{166}$ Robert Paine, ed., Patrons and Brokers in the East Arctic. Memorial University of Newfoundland Social and Economic Papers 2 (Toronto: University of Toronto Press, 1971):15.
} 
and qualities that are associated with the object in both individual and collective memories. ${ }^{167}$

This understanding of authenticity is destabilized when one considers the purchase of objects from the online market. ${ }^{168}$ Consumption in virtual space is not necessarily coloured by direct links or interactions between individuals. ${ }^{169}$ However, websites can be designed to fabricate a process of collection that makes the object authentic. Margaret Dubin suggests that the developing online art market may not lead to significant changes for the consumption of Native art, since the pre-existing methods of collecting can be perpetuated on the online art market. She posits that collectors prefer to make purchases in person for a fulfilling cultural experience. ${ }^{170}$

The bricks and mortar gallery also continues to be important as its presence legitimizes the virtual gallery. In 2004 art dealer Choire Sicha acknowledged:

I was talking with some other dealers during the New Art Dealers Alliance fair [in Miami last December] and everyone finally admitted that they spend whole days sitting at their desk sending out JPG images... At some level, we're all running virtual galleries these days. But it still helps your business to have an actual gallery. It gives collectors confidence in you, even if many of them are too lazy actually to bother seeing your shows. ${ }^{171}$

Although real world galleries continue to be important for both the consumer experience and as validation of the virtual gallery, websites are becoming an increasingly important supplement for commercial galleries. Websites selling Native art are flourishing, and as

\footnotetext{
${ }^{167}$ Ruth B. Phillips and Christopher B. Steiner. "Art Authenticity and the Baggage of Cultural Encounter." In Unpacking Culture: Art and Commodity in Colonial and Postcolonial Worlds, ed. Ruth B. Phillips and Christopher B. Steiner (Berkeley: University of California Press, 1999), 19.

${ }^{168}$ To date little scholarship has been produced about the online art market.

${ }^{169}$ Real-life places and events are now often connected to websites, and thus may inform the experiences of some site visitors.

${ }^{170}$ Margaret Dubin, Native America Collected: The Culture of An Art World (Albuquerque: University of New Mexico Press, 2001), 59.

${ }^{171}$ Choire Sicha, co-owner of New York's Debs \& Co Gallery in Marc Spiegler, "Do Contemporary Dealers still Need Galleries?," The Art Newspaper no. 148 (June 2004): 26.
} 
they develop so do possibilities for new, but still satisfying, cultural experiences. The quickly growing online art market demands a re-evaluation of how and when an object is constituted as "authentic."

For an analysis of portrayals of artists, I propose a tripartite division of online commercial art sites: the "white cube site," the "Native art site,' and the "artist's site." The white cube site presents art objects as "fine" or "high" art, whereas the Native art site relies on Native narratives and meanings to interest potential buyers. The artist's site is under the control of the artist and may use a combination of methods employed by the other types of site. These categories contribute to an understanding of Ruben's positioning in a new forum that does not privilege the perspective of dominant institutions, but rather creates a space for the views of minorities. The division of the sites should also be considered in relation to their users as they cater to the varying interests of collectors, decorators, tourists and other artists. ${ }^{172}$ For Dubin,

To be a "decorator" implies having only a superficial interest, although the interest may be long-term and the items expensive. Decorators are less engaged in the Native American art world than collectors because their objects are selected for the contribution they make to an aesthetic environment, an environment that may or may not include objects from other cultures. ${ }^{173}$

A tourist "is assumed to have a superficial level of engagement in the process of collecting. Tourists may be genuinely interested in Indian people, art, or culture... but their interest is temporary." 174 Dubin writes "Even though collectors take care to distinguish themselves from tourists, there is a touristic component to all collecting that

\footnotetext{
${ }^{172}$ Dubin, 56.

${ }^{173}$ Dubin, 56.

${ }^{174}$ Dubin, 59.
} 
works to regionalize consumption." ${ }^{175}$ Furthermore, according to her classification, "collectors often prefer to make their purchases "on-site" as it were, in order to achieve a more satisfying cultural experience." ${ }^{176}$ Dubin has used these groupings of consumers to facilitate an understanding of people's engagements with other aspects of the art market. In her analysis the typology can be used to indicate the consumer's level of dedication to the product. ${ }^{177}$ Both Dubin's categories and the three types of commercial art sites will be applied to an examination of representations of Ruben on the online art market.

The collector and decorator can easily be translated to the online art market since their roles are characterized by their consumption, however, the tourist must be reconsidered. Kristin Potter developed the idea of indirect tourism in relation to James Houston's efforts to help establish the Inuit art market. ${ }^{178}$ For this form of tourism neither travel nor direct contact with the producers is necessary. ${ }^{179}$ Through Houston's writings about the Inuit and their artistic production he was able to create an experience based in text that was appealing to those wishing to interact with an exotic cultural other. ${ }^{180}$ For example, in his article "In Search of Contemporary Eskimo Art" Houston draws his readers into a narrative account:

...we see art through the eyes of a hunter. He keenly portrays the other hunters, the animals and objects around him... We also see in his work a reflection of his playfulness and good humour - a quality rarely found in our Inuit arts... [the

\footnotetext{
${ }^{175}$ Dubin, 59.

${ }^{176}$ Dubin, 59.

${ }^{177}$ Dubin, 56.

${ }^{178}$ James Houston, an artist who first travelled to the north in 1948, began promoting Inuit art with the support of the Canadian government and the Canadian Handicrafts guild, in the south in 1949. In 1957 he was instrumental in establishing printmaking in the north.

${ }^{179}$ Kristin K. Potter, "James Houston, Armchair Tourism, and the Marketing of Inuit Art." In Native American Art in the Twentieth Century, ed. Rusthing III, W. Jackson, 39-56. (New York, NY: Routledge, 1999), 42.

${ }^{180}$ Potter, 43.
} 
Inuit's] geographic remoteness protected the Eskimos, who were by-passed, and the link between past and present in their art is as yet unbroken. ${ }^{181}$

Houston creates a connection between the reader and the Inuit by using the first person.

At the same time he draws attention to the enigmatic differences due to the "untouched" condition of the Inuit who live in a geographically remote location. Houston further romanticizes the Inuit later in the text: "The Eskimo never has wasted his energies on warfare, and the climate demands that he spend a considerable amount of his time inside his home. Thus, he has had the opportunity to perfect his art." ${ }^{182}$ Houston fosters an idea that the Inuit are innocent and pure as they supposedly do not participate in warfare. Through a colourful and attractive portrayal of the Northern artists Houston was able to successfully create a touristic market for readers in the South. A similar method is used to attract consumers to the "Native art site," but in the context of the online world boundaries are easily blurred, and the tourist who might be on an exploratory googling expedition could just as easily access a "white cube site" as a "Native art site."

The "white cube site" presents the work in organized and aesthetically appealing virtual galleries that offer little contextual information about the artists. In this case the majority of viewers would be collectors rather than interior decorators or tourists. Potential consumers would already be familiar with the art world and perhaps even particular artists. The "Native art site" may be used by collectors, but also meets the needs of decorators. These sites offer more contextual information than the "white cube site" and take an aesthetic approach that contributes to a nostalgic and romanticized perception of the work and its creators. These methods of portraying the work are most

\footnotetext{
${ }^{181}$ James Houston, "In Search of Contemporary Eskimo Art," Canadian Art. vol. 9, no. 3 (Spring 1952): 99.

${ }^{182}$ Houston, 101.
} 
suited to a culture broker as they strategically position the artist in terms of cultural identities. The "Native art site" differs from "the white cube sites" in practical terms because it provides more extensive textual accounts and includes images not directly related to the art works. The intended audience may be less clear for the "artist's site." Depending on the artist's status in the art world he or she may choose to create a site with contextual information to draw in unfamiliar viewers, or the individual may believe that his or her work will sell without this information. As in Ruben's site, the artist may choose a complex and nuanced combination of both the methods used by white cube and Native art sites.

Even more than the white cube site, the artist's site caters to those rich in cultural and economic capital as they have both the financial means and cultural knowledge to participate in the commercial art world. ${ }^{183}$ The artist's site provides the means by which one can create symbolic capital, in other words, how one may attain greater prestige. As Pierre Bourdieu writes:

Of all the conversion techniques designed to create and accumulate symbolic capital, the purchase of works of art, objectified evidence of 'personal taste', is the one which is closest to the most irreproachable and inimitable form of accumulation, that is, the internalization of distinctive signs and symbols of power in the form of natural 'distinction', personal 'authority' or 'culture'. ${ }^{184}$

There is a symbiotic relationship between producer and consumer in which the purchase of an artwork creates symbolic capital for both participants.

Galerie d'art Vincent, which has a bricks and mortar site located in the Château Laurier in Ottawa, is one of three private galleries associated with former Canadian

\footnotetext{
${ }^{183}$ Pierre Bourdieu, "The Sense of Distinction." In Distinction: A Social Critique of the Judgment of Taste, trans. Richard Nice (Cambridge, MA: Harvard University Press, 1994).

${ }^{184}$ Bourdieu, 282.
} 
Pacific Railway hotels, which are now owned by Fairmont Hotels and Resorts.

Although it does not deal solely in Inuit art, it does focus on Inuit art, particularly in their print and sculpture collections. Galerie d'Art Vincent has a "white cube site" that dedicates several pages to Ruben. The main page of his work includes thumbnails of four sculptures that are currently for sale (Fig. 2.1).$^{185}$ These sculpture are part of the exhibit, David Ruben Piqtoukun: Keeper of Myths, ${ }^{186}$ which is advertised at the top of Ruben's page. Near the top of the page are the words "All prices are in Canadian dollars," which implies an international clientele. The prominence of this statement is a clear indication that the primary concern for the site is the sale of art. The gallery has little interest in educating viewers or providing decorative trinkets. Ruben's abilities as a culture broker are inconsequential to the sale of his work on this site. This page provides no information beyond the titles of the works. Site visitors can click on images to view a page with minimal additional information and alternative views and details of the sculpture. ${ }^{187}$ This page includes the dimensions and price of the work as well as the words "Paulatuk/Toronto" referring to Ruben's place of birth and current city of residence. Similar to many "white cube" or contemporary commercial galleries, this site provides little information beyond that which is directly related to the sale of the work.

While the Galerie Elca London site, which has a concrete location in Montreal, should also be classified as "white cube," it does provide more information to the visitor. As this gallery specializes in Inuit art it has a smaller niche market and may have

\footnotetext{
${ }^{185}$ Gallery d'Art Vincent, virtual gallery of David Ruben Ruben's work, http://www.inuitfinearts.com/vincent/index.html, Accessed 22 March 2007.

${ }^{186}$ David Ruben Piqtoukun: Keeper of Myths ran 16-30 April 2006.

${ }^{187}$ Gallery d'Art Vincent, virtual gallery of David Ruben Ruben's work, details of Mischevious Owl-Man, http://www.inuitfinearts.com/vincent/exhibitions/Ruben/MOM.html, Accessed 22 March 2007.
} 
relatively few visitors that seek out this site specifically. The website emphasizes the gallery's specialty by including the words "Inuit Art" with the logo at the top of every page on its site. For this reason this virtual gallery may be more accessible than other commercial galleries to the googling tourist who is seeking out information about Inuit art. Fortunately, unlike a bricks and mortar gallery, an "accidental" tourist, who is uninitiated into art world etiquette does not "stumble in" posing a possible threat to delicate and valuable artworks. The gallery may even benefit from wealthy tourists who chance upon the site. This website is more user-friendly and provides the visitor with a virtual space that is more easily navigated than Galerie d'art Vincent. The virtual galleries have text solely along the top of the page and there is no visual distraction from images (Fig. 2.2). ${ }^{188}$ One can click on thumbnails to see larger photographs of artworks as well as basic information such as title, dimensions and price. ${ }^{189}$ It is apparent that this site is catering to an international clientele as this page provides conversions from Canadian dollars to American dollars or Euros.

The other notable difference between Galerie Elca London's site and that of Galerie d'art Vincent is the amount of information provided. This virtual gallery, which shows thirteen of Ruben's work, has a link to an "artist bio" (Fig. 2.3). ${ }^{190}$ This biography is similar to a curriculum vitae and focuses on the collections and references related to the artist's work. The only information that is not directly related to his career is his date

\footnotetext{
${ }^{188}$ Galerie Elca London, virtual gallery of David Ruben Ruben's work, http://www.elcalondon.com/dynamic/category artist.asp?ArtistID=21, Accessed 22 March 2007.

${ }^{189}$ Galerie Elca London, virtual gallery of David Ruben Ruben's work, detail of Shaman Muskox

Transformation, http:/www.elcalondon.com/dynamic/category artist.asp?ArtistID=21, Accessed $22 \mathrm{March}$ 2007.

${ }^{190}$ Galerie Elca London, David Ruben Ruben's biography, http://www.elcalondon.com/dynamic/artisst bio.asp?ArtistID=21, Accessed 22 March 2007.
} 
of birth and the communities in which he has lived. By supplying information about exhibits and collections in which Ruben is represented, the gallery "authenticates" him as an established artist. Both of the "white cube sites" discussed demonstrate their focus on the artworks through multiple images and minimal text.

The approach of the "Native art site" is to capture its audience by giving its viewers additional and carefully chosen information. The website for the Home and Away Gallery, which has a bricks and mortar location in Kennebunkport, Maine, provides a visually disorganized space in which thumbnails are displayed on the virtual page in a seemingly haphazard way. Near the top of the page showing Ruben's work is the artist's name followed by the classification "Inuit, (Paulatuk)" (Fig. 2.4). ${ }^{191}$ Visitors are re-assured that they are viewing work created by an "authentic" Native artist. Unlike the site for Galerie d'art Vincent this site does not indicate that the artist no longer lives in the North. Below the artist's name is a link to a page with biographical information and a photograph of the artist working (Fig. 2.5). ${ }^{192}$ The text on this page is written in a narrative format and includes a romanticized and highly subjective interpretation of his oeuvre:

Sometimes we speak too much; sometimes we speak not enough. David Ruben Piqtoukun's sculptures speak volumes without saying a word. They tease, they threaten, they purr with pleasure. They coax us to think; all we have to do is listen. How do we explain the attraction to Ruben's work? How do we explain the genius? We can not [sic]. Ruben's sculptures are mirrors into worlds we can not [sic] fully comprehend. They offer quiet glimpses into these worlds, but they do not reveal their secrets to us. ${ }^{.93}$

\footnotetext{
${ }^{191}$ Home and Away Gallery, virtual gallery of David Ruben Piqtoukun's work, http://www.homeandaway.biz/Featured-gallery.cfm?Manufacturer ID=101, Accessed 22 March 2007. ${ }^{192}$ Home and Away Gallery, David Ruben Piqtoukun's biography, http://www.homeandaway.biz/Artistbio.cfm?Manufacturer ID=101, Accessed 22 March 2007.

${ }^{193}$ Home and Away Gallery, David Ruben Piqtoukun's biography, http://www.homeandaway.biz/Artistbio.cfm?Manufacturer ID=101, Accessed 22 March 2007.
} 
This section of the biography conflates Ruben's character and his work as an enigma that could only ever be partially understood by a Western audience. In this site, the audience can access the contact zone but not cross into the other culture represented. Home and Away has used a tactic similar to that of James Houston when he made contributions to the development of indirect tourism. These methods are similar to the choices Ruben has made as a self-stylized culture broker. The desires of the audience enable the site to perpetuate stereotypes that hide contemporary realities. ${ }^{194}$

The Home and Away website currently shows a selection of ten sculptures in the gallery of Ruben's work. When visitors click on images they can view larger images and the basic information about the works. The interesting feature that was not seen in the "white cube sites" is a brief notation related to the work. Some of these comments offer explanatory text that summarizes the narratives that Ruben uses for subject matter: ${ }^{195}$ "The shaman transforms into a raven to fly to the moon. He brings back a golden nugget to prove his journeys to his people."196 Other remarks attempt to contextualize and "authenticate" the Inuk artist: "A seal-man emerging from the ice by master carver David Ruben Piqtoukun. This carving has the sweetest face we have seen on Rubens [sic] sculpture in a long time." 197 The seemingly arbitrary use of the term "master carver" seems to provide the viewer with an authoritative opinion of the artist's technical

\footnotetext{
${ }^{194}$ Dubin, 131.

${ }^{195}$ Home and Away Gallery, virtual gallery of David Ruben Ruben's work, Detail of Raven Steals the Moon, http://www.homeandaway.biz/Featured-gallery.cfm?Manufacturer ID=101, Accessed 22 March 2007.

${ }^{196}$ Home and Away Gallery, virtual gallery of David Ruben Ruben's work, Detail of Raven Steals the Moon, http:/www.homeandaway.biz/Featured-gallery.cfm?Manufacturer ID=101, Accessed $22 \mathrm{March}$ 2007.

${ }^{197}$ Home and Away Gallery, virtual gallery of David Ruben Ruben's work, Detail of Raven Steals the Moon, http://www.homeandaway.biz/Featured-gallery.cfm?Manufacturer ID=101, Accessed 22 March 2007.
} 
abilities. The knowledgeable voice behind the website is further undermined in the next sentence by the use of the superlative "sweetest." While this term may be appealing to a tourist or decorator it is not part of the formal aesthetic vocabulary of a collector. For the collector the use of this word could even be detrimental to his/her view of the work as Home and Away has, in effect, distanced the work from "fine" or "high" art. ${ }^{198}$ The brief commentary provided with the images initially seems innocuous but could have a greater impact on a visitor's perspective of the work and its creator as it perpetuates romanticized notions and stereotypes of "authentic" Natives.

Thus far this chapter has focused on sites in which an obvious middleman intervenes between the art producer and consumer. In contrast, the "artist's site" provides a unique forum in which an artist may be able to exert more direct agency over the marketing of their work. For Inuit artists working in the North, the internet may provide a means by which they can circumvent the cooperatives if they have access to the digital technologies and expertise required to set up a website. Currently this is not a viable option for most artists if they are not working in major city centres since the cooperatives provide forms of support beyond basic marketing needs. For Ruben, the internet is a new tool that may be used to develop his self-representation as well as to foster new transnational relationships. He has spent his entire artistic career working in the South, and, as a well-established artist, an "artist's site" enables him to exclude the middleman from some of his art sales. The continued importance of the middleman is demonstrated by the fact that he is still represented by other galleries.

${ }^{198}$ Dubin, 36. 
Ruben has his own commercial site, www.davidruben.com. While one can

visit a gallery in the artist's home by appointment, the primary point of contact with potential consumers is the website. ${ }^{199}$ The homepage is titled "David Ruben Piqtoukun:

Artist Romancing the Stone" and features a small image of the artist in the upper right corner (Fig. 2.6) ${ }^{200}$ Below this is a message from Ruben to site visitors:

I would like to introduce you to my site and hopefully give you all an indication of my creative endeavors over the years. Using a combination of many varieties of stone, which I enjoy very much for the work that has consumed my time since 1972. Welcome to my website. I would really enjoy any commentary on improving the design for the purpose of better serving the viewer or for business related improvements and general design. For that I thank you. Please enjoy the virtual gallery of some important works I have assembled. ${ }^{201}$

The message demonstrates Ruben's focus on the website and business practices. There is little reference to his actual artistic practice or his biography, which he has previously acknowledged as a strong influence on his work. Ruben makes no attempt to "authenticate" the work as the product of an Inuk or to perpetuate his position amongst cultures.

At the left of the page is an image resembling the sculpture Journey to the Great Woman, 1995, which is featured on the cover of the exhibition catalogue for Between Two Worlds. The representation of the sculpture has been altered and is less detailed and appears more highly polished. The effect creates the impression that the artwork is flattened like a relief carving rather than a sculpture in the round.

\footnotetext{
${ }^{199}$ David Ruben Piqtoukun Current Works. http://davidruben.com/contact.html, last modified on $8 \mathrm{March}$ 2007, Accessed 15 March 2007.

${ }^{200}$ David Ruben Piqtoukun: Artist Romancing the Stone. http://davidruben.com/, last modified on $8 \mathrm{March}$ 2007, Accessed 15 March 2007.

${ }^{201}$ David Ruben Piqtoukun: Artist Romancing the Stone. http://davidruben.com/, last modified on $8 \mathrm{March}$ 2007, Accessed 15 March 2007.
} 
The use of an image of Journey to the Great Woman on Ruben's homepage is a visual cue for people with the requisite cultural capital to understand the work's link with Between Two Worlds. Modifications were made to davidruben.com on 8 March 2007 but prior to this the site provided visitors with more information about Ruben and his work. ${ }^{202}$ The homepage formerly had the links 'resume,' 'current works,' 'virtual gallery,' 'links to art sites,' and 'contact." ${ }^{203}$ Each of the pages on the site had the menu at the top of the page over an understated image of an elegant sculpture of the neck and head of a polar bear. For unknown reasons, the aforementioned links were removed from davidruben.com in March 2007.

The 'resume' page included listings of exhibitions that have shown his work, and collections in which his sculptures are represented. ${ }^{204}$ This information situates him within the context of the art world. His participation in the art world, both nationally and internationally, acted to reinforce an uninformed visitor's confidence in his abilities and stature. Any potential customers could further familiarize themselves with Ruben's career and oeuvre in the virtual gallery and on the page with his current works (Fig. 2.72.8). ${ }^{205}$ This gallery was divided into the decades of his career so that one could see the developments in his work from some of his earliest pieces in the 1970s to contemporary works. In total, 91 sculptures could be viewed but were not available for purchase. On the homepage Ruben writes that he hopes to give visitors "an indication of [his] creative

\footnotetext{
${ }^{202}$ davidruben.com archived pages in the author's files, last modified 7 May 2006.

${ }^{203}$ The site included information for the years from 1973-2001.

Since this page is currently unavailable and was not archived prior to 8 March 2007 the specific links cannot be discussed.

${ }^{204}$ davidruben.com archived pages in the author's files, last modified 7 May 2006.

${ }^{205}$ davidruben.com archived pages in the author's files, last modified 7 May 2006.
} 
endeavors over the years." ${ }^{206}$ It was only through the gallery that uninformed visitors had the opportunity to learn about his artistic production. After the modification of the site, this is no longer possible, but as of yet, the homepage message has not been changed.

Although there has never been explicit discussion of Ruben's personal biographical details or his Inuit background some of this information could be extrapolated from the resumé as the majority of the shows reference Inuit art. The only other cue is the subtle use of the polar bear, a stereotypical subject matter in Inuit art, for the background of the menu. The recent changes to his site then, appear to demonstrate a transition from a "Native art-artist's site" to a "white cube-artist's site." This may be indicative of Ruben's interest in developing connections with "collectors" rather than educating or "authenticating" for those unfamiliar with his work. In 2001 he clearly stated that he has worked hard to establish himself so that he is able to work more independently and have more control over the sale of his work. ${ }^{207}$ In 2003 Ruben expressed his observations about the Inuit art market:

Since the early 1970 s I have notice the many changes in the marketplace. My early works were not very good, but the interest in the carvings was still always there. After some recognition in the late 1970 s into the $1980 \mathrm{~s}$, the market stature began to improve dramatically for high quality stone works, not just for me but all around in general. The U.S. markets were becoming more and more interested in the Inuit art form. The present interest in the Inuit art form today has improved to the point where prices at auction for older art works has basically gone through the roof! Old works and high quality art works are in high demand. The marketplace and interest over the course of my tenure has vastly improved. The international marketplace is ready to accept our art form with open arms. The overall interest will only depend on the quality and scale of the carvings and

\footnotetext{
${ }^{206}$ David Ruben Piqtoukun: Artist Romancing the Stone. http://davidruben.com/, last modified on 8 March 2007, Accessed 15 March 2007.

${ }^{207}$ David Ruben Piqtoukun in Heather Campbell "Urban Inuit Artists," Inuit Art Quarterly vol. 6, no 2 (Summer 2001): 6 .
} 
sculptures being created today. Through continued education, exhibitions and exposure for this form of art, the sky is the limit for the future. ${ }^{208}$

Ruben is cognizant of the fact that he no longer needs to foster his role as culture broker to the same extent in order to maintain his success on the market, and instead can now focus on developing transnational relationships.

Before the changes were made to the site, the contact information was accompanied by the explicit message "Contact Information - For Serious Enquiries Only." ${ }^{209}$ This section of the page included the statement "We Accept Visa, Mastercard, and American Express" accompanied by the well-known credit card logos. There was no attempt to veil the financial aspect of Ruben's work unlike the beliefs espoused in the concept of "art for art's sake." The site did not romanticize the artist but, by educating visitors about the artist, invited an unfamiliar audience to engage with the site and artist. The anonymity of the internet enables a statement such as "For Serious Enquiries Only" to not necessarily be given the same consideration as a face-to-face enquiry. For a businessman, seemingly frivolous questions from site visitors uninterested in purchasing works may have precipitated the transition to a "white cube site" approach. By providing minimal information the site creates fewer opportunities for those without the correct cultural or economic capital to enter into interactions with the site or artist. The changes in Ruben's site are indicative of his primary concern for his career, that is, being a financially successful artist. In March 2007, the contact information and invitation to learn of "coming events" was accompanied by the message "Please make direct contact

\footnotetext{
${ }^{208}$ Courtright, 65.

${ }^{209}$ davidruben.com archived pages in the author's files, last modified 7 May 2006.
} 
with the Artist to commission works of any scale." 210 The visitor is not invited to learn

more but rather to engage in a business transaction with Ruben.

Further changes were made to the site on 8 October $2007 .^{211}$ The homepage and contact information remain unaltered, but images and text were updated on the "current works' and 'coming events' pages. Both pages reference the exhibition Talking Stones, which ran from 22 September to 22 October 2007 and featured the work of Ruben and Washington Msonza. Ruben initially met the Zimbabwe Shona artist at a symposium in China in $2000 .^{212}$ They met again in November 2006 when they both participated in an exhibition that took place at the National Gallery in Zimbabwe. ${ }^{213}$

Ruben wrote about his experience when he met other artists at the symposium in China:

For the artists from the twenty-four countries who met in Changchun, this was an opportunity to share the stories. As individual artists, they nonetheless represented the sum total of their cultural experience... Our time together allowed us to integrate our personal experiences and the many friendships that resulted from this exchange will enhance everyone's life and work. We had one common bond - our love of bronze and stone.

We have left behind, for the people of China, a testament to that love. Despite the language barriers, we were able to speak in our common language of sculpture, which we hope will be an inspiration to all. ${ }^{214}$

${ }^{210}$ David Ruben Piqtoukun Contact. http://davidruben.com/contact.html, last modified on 8 March 2007, Accessed 15 March 2007 and David Ruben Piqtoukun Coming Events. http://davidruben.com/events.html, last modified on 8 March 2007, Accessed 15 March 2007.

${ }^{211}$ David Ruben Piqtoukun, Current works, http://davidruben.com/current.html, last modified on 8 October 2007, Accessed 13 October 2007.

${ }_{212}$ Ruben was chosen to represent Canada at a Changchun China International Sculpture Symposium during the summer of 2000. Artists from twenty-four countries participated in the conference. David Ruben Piqtoukun, "Inuit Sculpture Arts and China Changchun International Sculpture Symposium," in Sculpturing Brilliance, Changchun Publishing House, 136-138.

${ }^{213}$ The exhibition of Inuit and Zimbabwean Shona sculpture raised money for orphans with HIV/AIDS. Ruben also participated in a stone carving demonstration at the National Gallery of Zimbabwe. Sonia Gunderson, "David Ruben Piqtoukun: In Search of a Softer Wind," Inuit Art Quarterly vol. 22, no.1 (Spring 2007): 34.

${ }^{214}$ Ruben, Sculpturing Brilliance, 138. 
This text exemplifies Ruben's interest in cross-cultural connections. Talking Stones demonstrates that he has been able to utilize the tools of transnationalism to foster a minor-to-minor relationship that was initially made possible by nation-states.

Below the basic information about Talking Stones is an informal photograph of the two artists standing outdoors behind Msonza's sculpture entitled Strong Hands (Fig. 2.9). Below this is the caption "Brothers in Stone" followed by an explanation of how the artists met as well as their plan to offer continuous exhibitions in Georgina, Ontario. Ruben has distanced himself from his earlier actions that characterized him as a culture broker, but by engaging in this partnership, he is exploring a slightly different method to attain a strategic position as an artist amongst world cultures. He makes a direct connection between himself and Msonza by using the term "brothers" and uses the relationship to draw attention to his unique ability to gain access to other minority cultures. The familial term implies a strong, personal connection that cannot be experienced by site visitors. By including this relationship Ruben draws davidruben.com away from the white cube site style, and demonstrates a unique possibility in the artist's positioning of himself on the site.

The current works page features thumbnails of five works by Ruben and four by Msonza. ${ }^{215}$ Unlike the images for the virtual galleries, which were displayed closely together in rows, these thumbnails, which are slightly larger, are surrounded by white space. Viewers are able to devote their attention to each image without visual distraction. Ruben's five works, each of which resembles a mask, are at the top of the page. His

${ }^{215}$ The five works by Ruben on the page are One-eyed Shaman, Old Three Eyed Shaman, Self-Portrait, Owl-Man Transformation and My Great Grandfather: The Whale Hunter. The four works by Msonza are Strong Hands, Congratulations, Waiting For Father and Our First Born. 
works were photographed indoors, whereas Msonza's four works were photographed outside, thus creating a strong visual distinction between each artist's works.

The first two works by Ruben have the distinctive lines marking the cheeks that can be seen in his work since his visit to the Ivory Coast in 1982. The third work, entitled Self-Portrait, is unusual in that he has rarely explicitly referenced himself in his work. Ruben has often based his subject matter on his knowledge of Inuit culture or his experiences amongst cultures. While he has related these to his personal life experiences, his works have depicted broader culture subject matter as opposed to explicitly personal imagery. This face, which has distorted features and appears to be moving in an impossible cyclical direction, has both Ruben's name and his disc number carved into the forehead. ${ }^{216}$ The final two works are made primarily of wood, a material that has rarely been used by Ruben. He has used nails in the wooden masks to create patterns that are reminiscent of the stylized lines he began incorporating into his work in the early $1980 \mathrm{~s}$.

Delicate materials that have rarely, if ever, been used by Ruben have been employed for all of these works. Four of the five works include feathers, but unique is the use of bowhead whale baleen in My Great-Grandfather: The Whale Hunter. By using this material that is difficult to obtain, Ruben connects himself to the narrative implied in the title. This re-iterates the family motif because the artist, like his great

\footnotetext{
${ }^{216}$ Ruben has carved his childhood name, Piqtou, into this work. As an adult he extended the name to Piqtoukun, meaning "soft wind." Gunderson, Inuit Art Quarterly, vol. 22, no.1, 31.

Disk numbers were four-digit numbers assigned to Inuit by police starting in 1941. The numbers were inscribed on thin disks, which were intended to be worn around the neck. In 1945 the system was upgraded to include district designation to facilitate administrative issues. Disc numbers were later used to identify carvings made for sale in the South. This system was discontinued in 1971 when Inuit adopted surnames. Marybelle Mitchell, From Talking Chiefs to A Native Corporate Elite. Montreal and Kingston: McGillQueen's University Press, 112.
} 
grandfather, is able to obtain a by-product from whale hunting that is not easily accessible. Ruben is including more overtly personal information in his recent works.

Msonza's works on the site are an aesthetic contrast to Ruben's oeuvre. Three of this artist's four works depict the elongated and flowing figures of adults and children. The titles, such as Waiting For Father and The First Born, indicate that the people embracing are family members. The fourth work is an abstract and angular depiction of three hands, and is a strong contrast to the soft figural works. Below the images of current works the information on the current events page is repeated. Underneath this are the specifics for the purchasing and shipping of artworks, as well as the option for a "Private viewing at 'Ruben's on Moonlight Bay Gallery' upon request."217 This indicates the primary goal of this artist's site, which is to engage in commercial transactions. This is similar to the explicit interests of a white cube site, but the incorporation of information about his relationship with Msonza is consistent with Native art sites. Ruben has combined the two methods to pursue his economic interests, which no longer depend on dealers, and are instead under his control on the web.

Ruben's choices should be considered as part of a complex network of players on the online art market, which creates a new nexus in which the "authenticity" of Native art objects must be evaluated according to different criteria. Dubin developed a "theoretical understanding of collecting in which political positions and cultural identities are negotiated, not pre-ordained by post-colonial formulations." 218 The internet is a new forum for these political negotiations as it allows power to be decentred and different

${ }^{217}$ David Ruben Piqtoukun, Current works, http://davidruben.com/current.html, last modified on 8 October 2007, Accessed 13 October 2007.

${ }^{218}$ Dubin, 3. 
players to have a stronger voice. Ruben's contemporary engagement is no longer dependent on institutions that are part of the nation-state framework. The dynamism and fluidity of transnationalism has given him the power to advance his career by taking advantage of the increased speed and volume of electronic media and migration that characterize globalization.

All parties discussed in this chapter are able to use virtual space to advance their agendas, which are primarily economic, across previously impenetrable boundaries. The sites enable them to express views about Ruben and Native art through the portrayal of the artist. For the "white cube sites" this means focusing on the artworks as "fine" art and giving minimal attention to his Native background. The "Native art site" perpetuates a view of Ruben as an "authentic" Native whose works contribute to a touristic experience. While each of the sites examined does have a bricks and mortar location, their use of websites demonstrates their recognition of the significance of the online art market. They are negotiating a relatively new marketing forum and as they do so are reaching a wider audience of collectors, decorators and tourists than would otherwise be possible. Websites are becoming an increasingly important supplement for real world commercial galleries.

Ruben has used this new forum and flourished in it as it has enabled him to have greater control over the portrayal of himself and his art. Authentication of his work does not come from his background or cultural narratives, but rather at the point of consumption when the consumer validates his aesthetic accomplishments. He uses an "artist's site" approach to encourage an elite group of consumers who have adequate symbolic, cultural and economic capital to engage in interactions with the artist. Ruben 
has successfully utilized the tools of transnationalism to find new ways to develop relationships across cultural borders. 


\section{Conclusion}

This thesis demonstrates Ruben's unique self-positioning as a cultural intermediary in the art world, who has been able to convey information about the experiences of his generation of residential school survivors. The evolution of his culture brokerage has been traced in the strategic relationships he has fostered with various institutions, such as museums, the art market, critics and patrons. Ruben's conveyance of information across borders between the North and South, Inuit and non-Inuit, east and west, among others, was initially limited by hierarchical nation-state structures.

Technological advances in media and migration, have provided him with the means to utilize new transnational fora, and thereby both assume further agency and have more independence in his career.

The main theorists I have used to examine Ruben's oeuvre as a form of culture brokerage are Aaron Glass, James Clifford, Robert Paine and Mary-Louise Pratt. Their work elucidates the events in his life that have influenced his interactions in scholarly, political, artistic and cultural spheres. Involvement within these realms has led to opportunities for Ruben to travel, convey information and form relationships within and across national borders.

The discussion of Between Two Worlds demonstrates how Ruben, with the assistance of various art institutions, was able to create a new body of work and write interpretive text for a solo exhibition. The Winnipeg Art Gallery's Assistant Curator Darlene Wight employed a collaborative curatorial method that enabled Ruben to strategically convey information that perpetuated specific views of his role and work. Wight's approach developed at a time of significant change in the museum world as the 
Task force was influencing the relationships between museums and aboriginal peoples.

While there were presumably some constraints on the artist, he did have an unprecedented involvement in the preparation of the exhibit. The curatorial methods used for this show may be understood as part of a trajectory of Inuit art exhibitions. Along with developments in the increasingly transnational museum world, Ruben had the financial support of his commercial dealer, Harold Seidelman. The curatorial method and stable pecuniary situation enabled Ruben to develop his culture brokerage through text and images for a broad audience.

To bring Ruben's culture brokerage into the contemporary, I compare and contrast commercial gallery portrayals of him as seen on the web. This research demonstrates the increasing significance of the online art market and how the artist now has greater agency through the use of transnational tools. Sites that $I$ have classified as white cube present Ruben's sculptures as "fine" art, whereas the category of Native art site contextualizes his work in relation to his biography and Inuit cultural narratives. Ruben's own site initially presented information that contextualized his current work, but now focuses on the commercial aspect of his contemporary artistic production. Ruben has extensive control over www.davidruben.com, however, he has little, if any control, over other representations of himself on the web.

Globalizing factors, such as the increase in the speed and volume of the movement of people and information, have created new possibilities for Ruben to develop his career. He has become less dependent on organizations that were part of a nation-state framework, and instead can foster transnational relationships that circumvent major institutions. The tools of transnationalism also enabled him to focus on the 
financial aspect of his career. Rather than relying on dealers, critics and galleries to publicize and sell his work, Ruben has taken a more active role by connecting directly. with consumers through www.davidruben.com.

Developments in communication, media and migration led to opportunities for both Ruben's artistic production and culture brokerage. His future career will likely present further opportunities to examine the use of globalizing forces. In light of the work completed for this thesis, it will now be useful to examine how other members of the Inuit art community are using the tools of transnationalism. Globalization has played an important role in the movement of northern art and artists both within and across national borders. Although for many years institutions have facilitated the travel of Inuit artists, these movements have not received extensive attention in terms of transnationalism. I hope this study of Ruben's culture brokerage contributes to the early stages of this discussion. 
Illustrations 


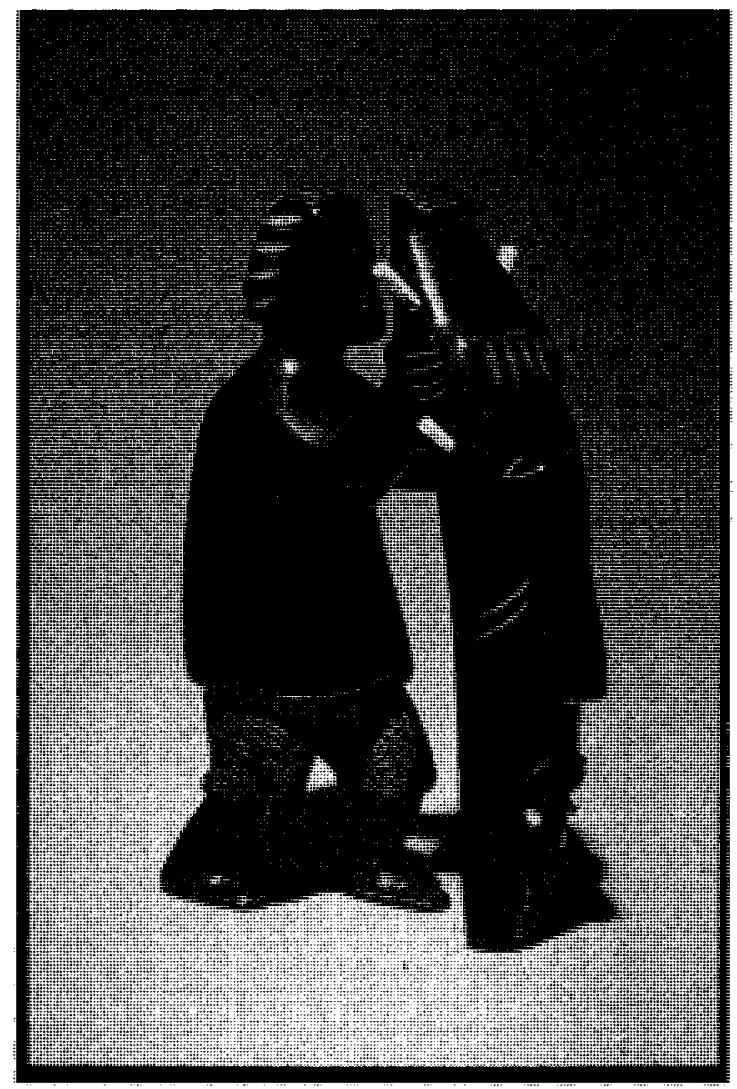

Fig. i.1. Absorbing the African Way, 1982

African wonderstone

www.davidruben.com, virtual gallery, archived pages in author's files 


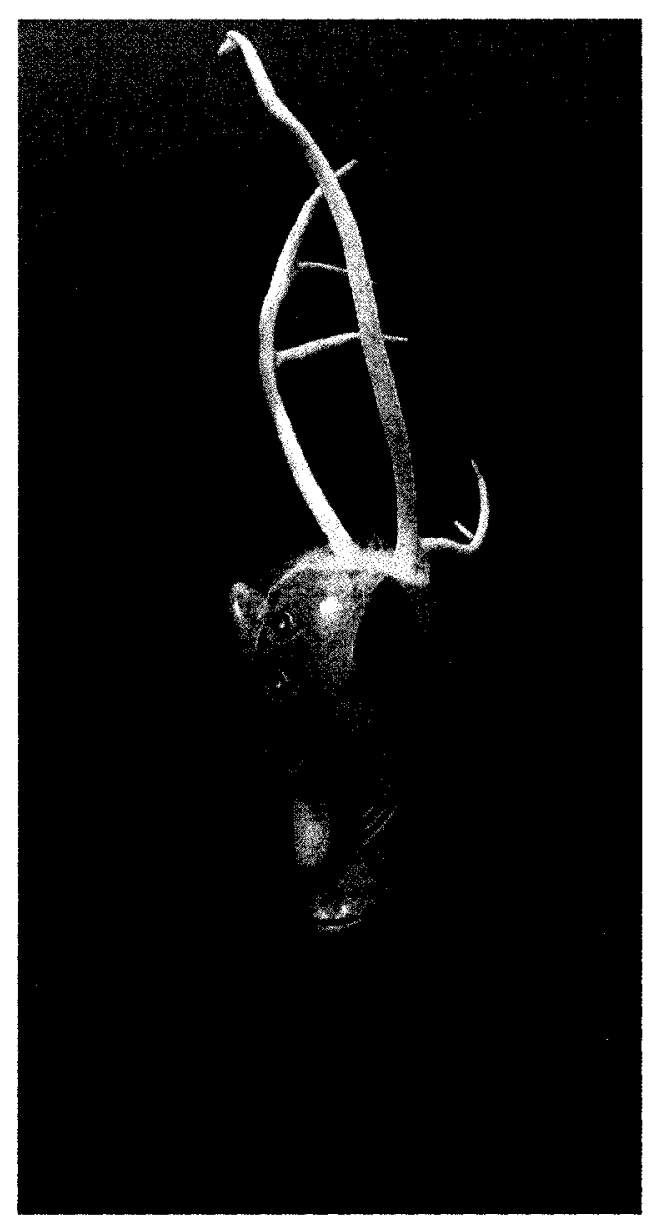

Fig. i.2. Like Father, Like Son, 2004

Brazilian soapstone, fur, caribou antler height: $67 \mathrm{~cm}$.

Allan Ryan and Zena Pearlstone, curators, About Face: Native American, First Nations and Inuit Self-Portraits (Santa Fe, New Mexico: Wheelwright Museum of the American Indian, 2006). 


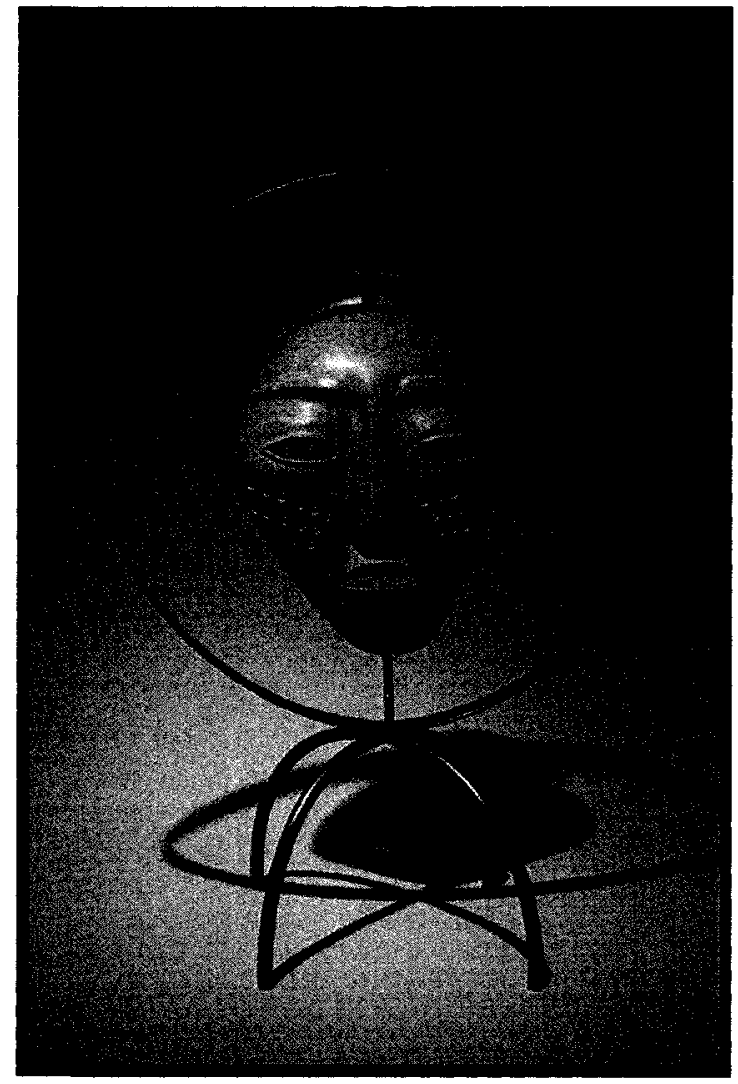

Fig. i.3. Aura, 1996

Brazilian Soapstone, welded steel

$39.7 \times 72.8 \times 37.5$

Private Collection

www.davidruben.com, virtual gallery, archived pages in author's files 


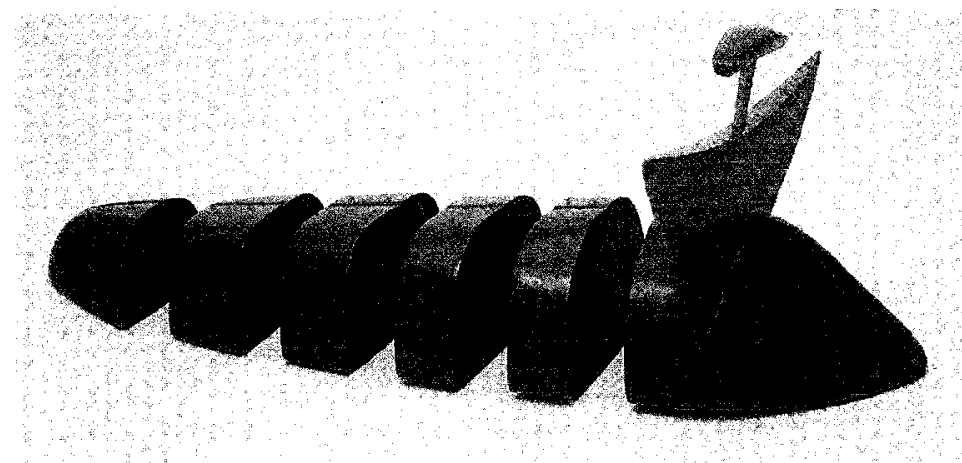

Fig. 1.4. Division of Meat, 1996

Brazilian soapstone, antler

$19.5 \times 47.0 \times 31.7$ (variable)

Private Collection

Darlene Coward Wight, Between Two Worlds: Sculpture by David Ruben Piqtoukun (Winnipeg: Winnipeg Art Gallery, 1996). 


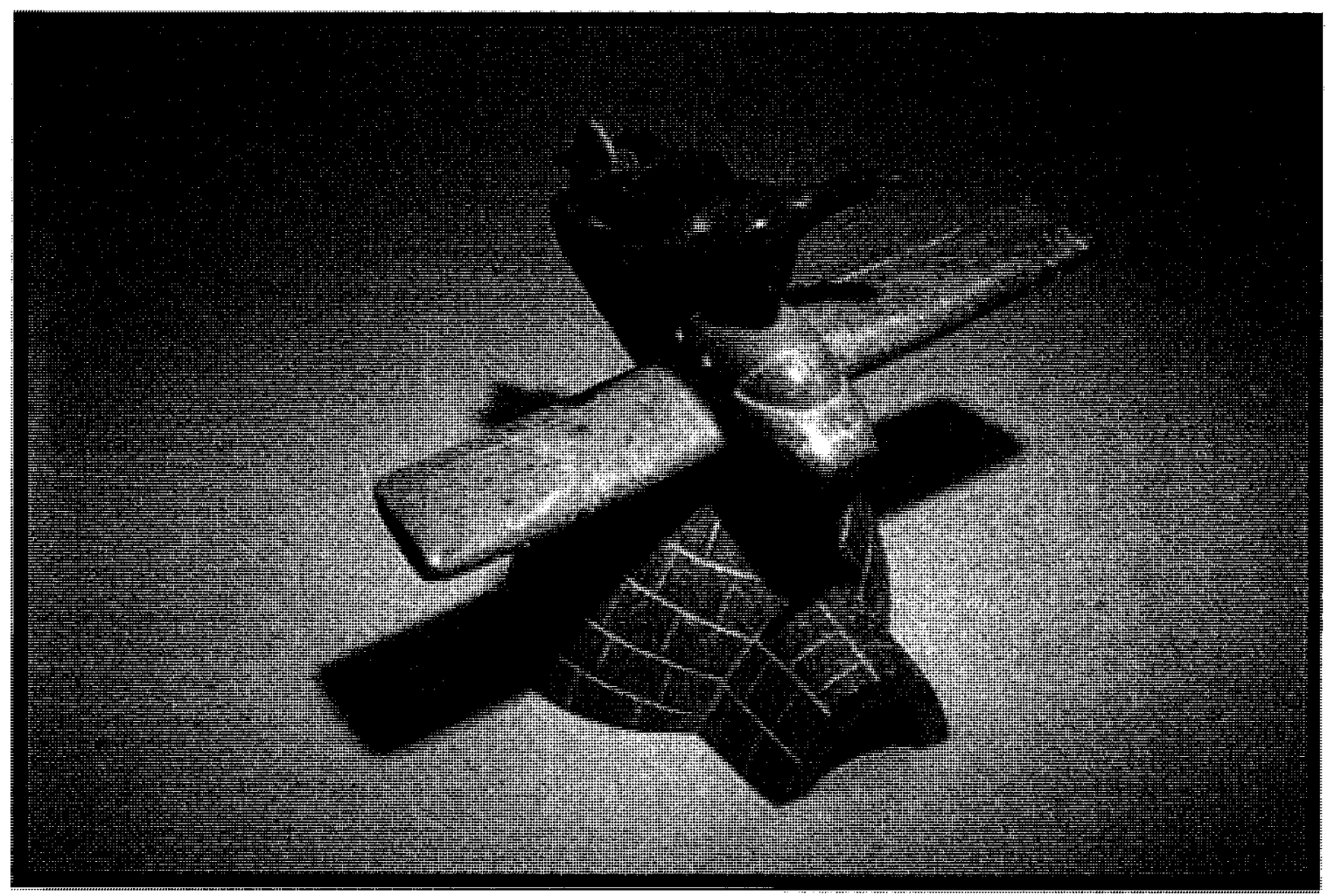

Fig. i.5. Airplane, 1995

Brazilian soapstone, African wonderstone

$26.0 \times 36.5 \times 27.5$

Private Collection

www.davidruben.com, virtual gallery, archived pages in author's files 


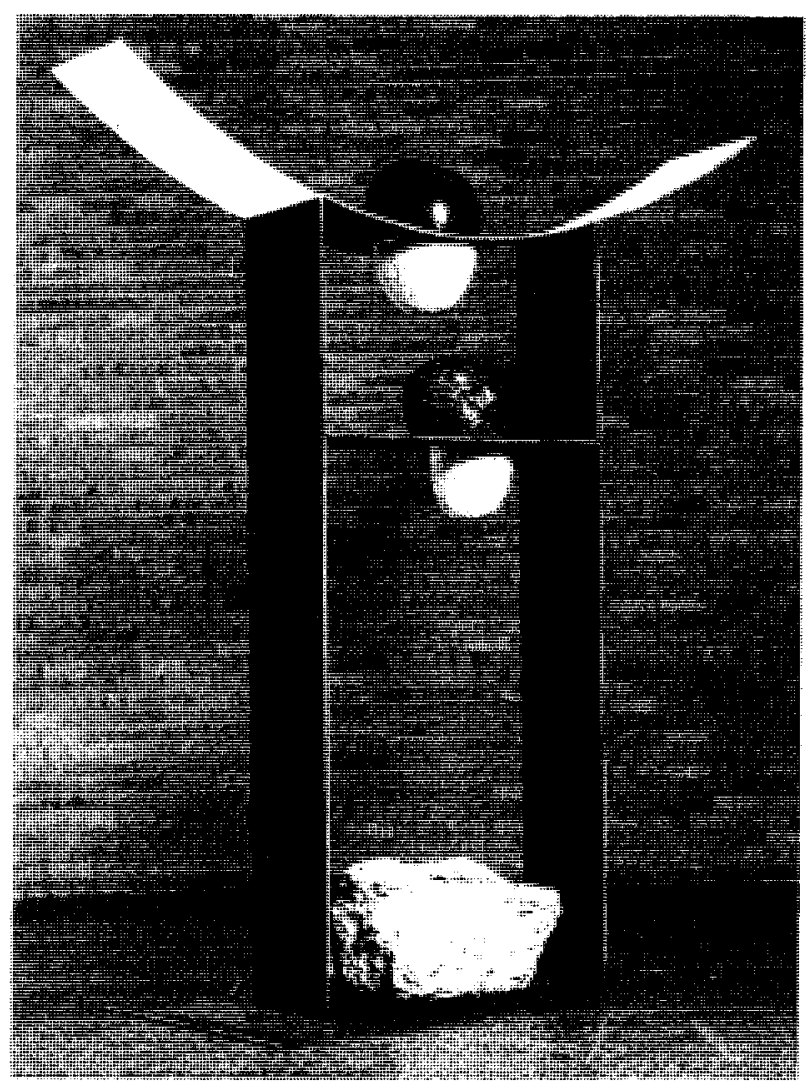

Fig. i.6. Our Spirits: They Soar High, 2007

Steel, paint, field stones, granite, dolomite

$213 \times 244$

Collection of Indian and Northern Affairs Canada

"Provocative Inuksuk Installed in Government Building," Inuit Art Quarterly vol. 22, no.3 (Fall 2007): 33. 


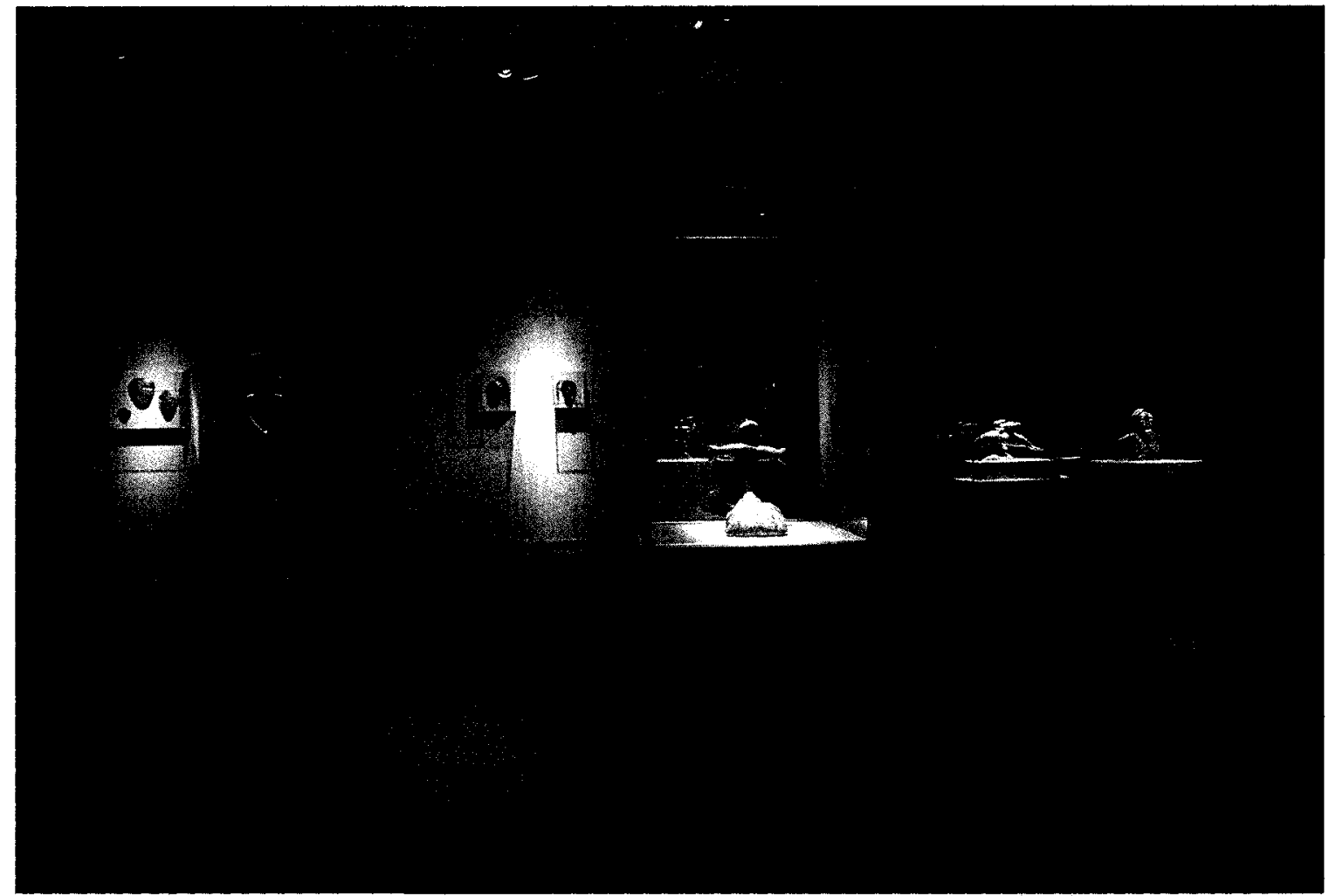

Fig. 1.1. Exhibition Between Two Worlds

(C) Canadian Museum of Civilization, photo Steven Darby, 1998, S2007-0009 


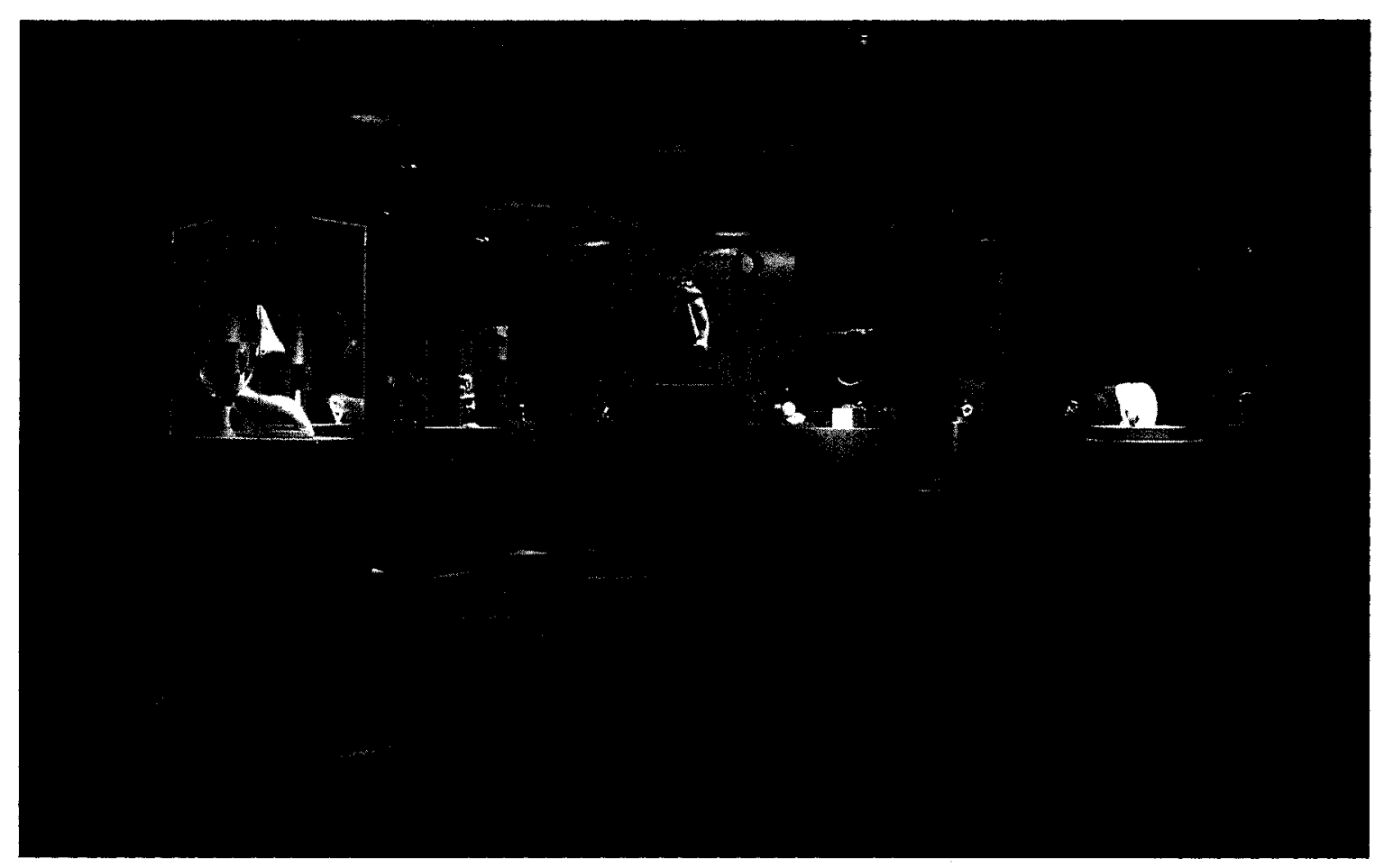

Fig. 1.2. Exhibition Between Two Worlds

(C) Canadian Museum of Civilization, photo Steven Darby, 1998, S2007-0010 


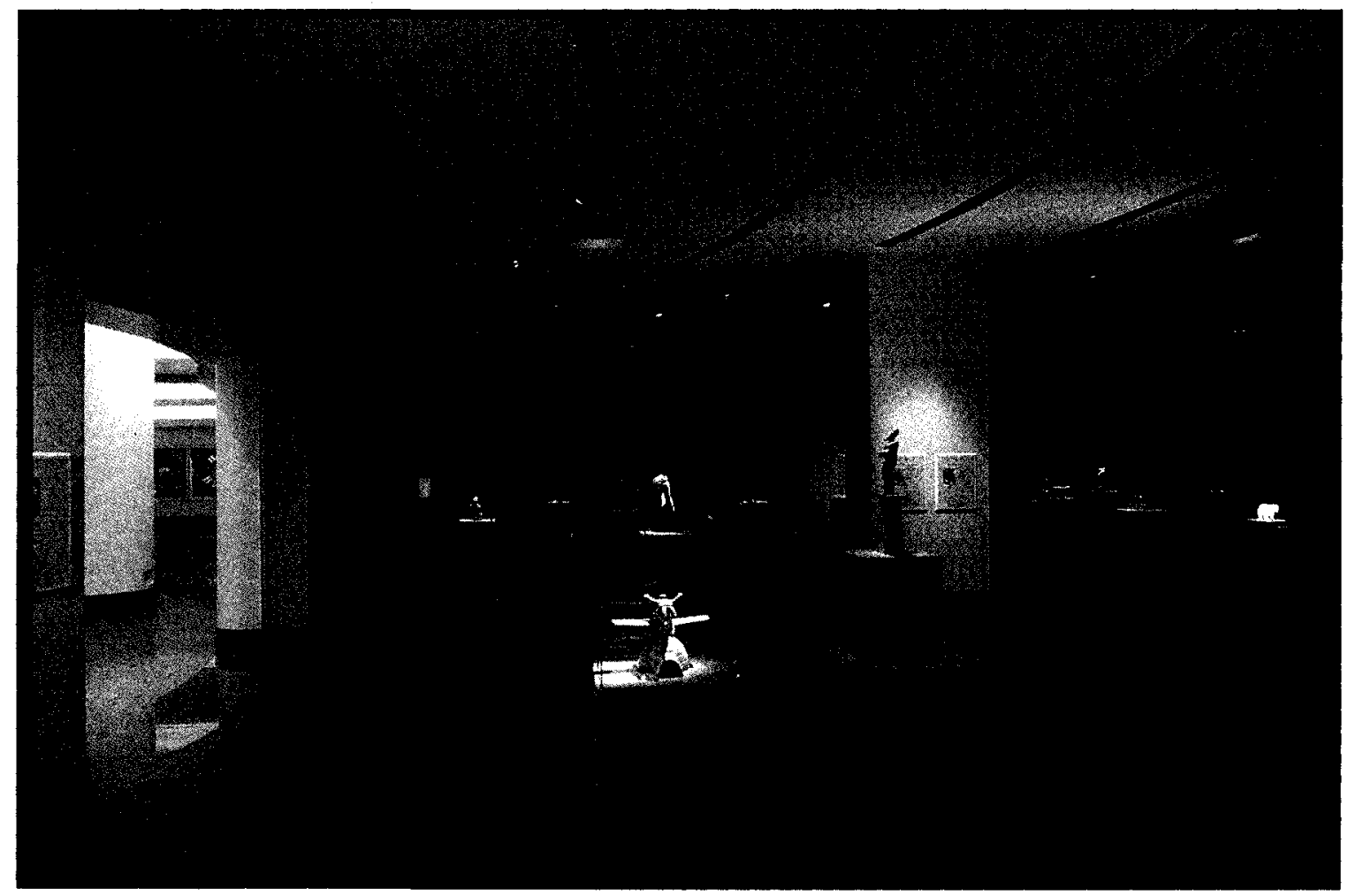

Fig. 1.3. Exhibition Between Two Worlds

(C) Canadian Museum of Civilization, photo Steven Darby, 1998, S2007-0011 


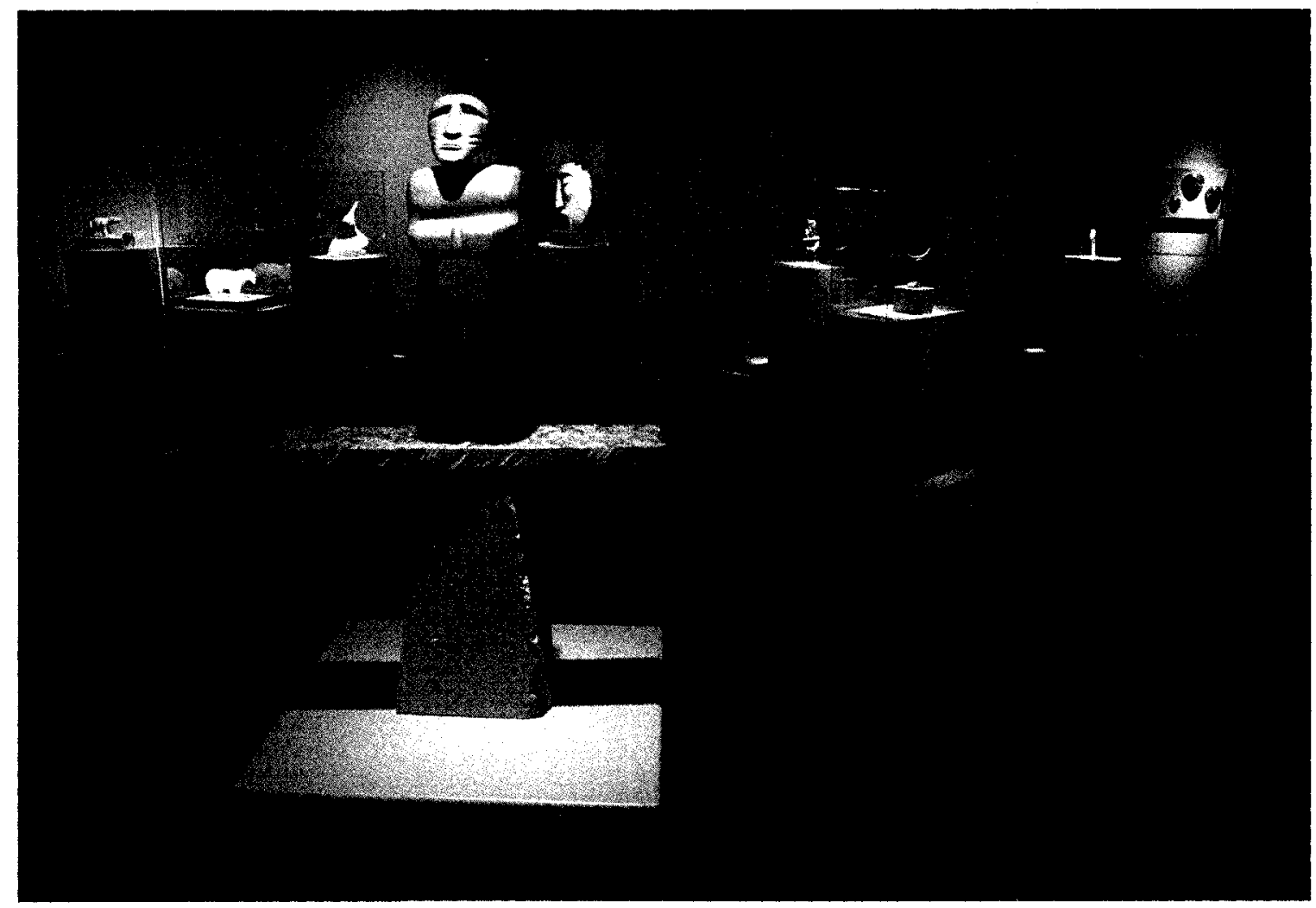

Fig. 1.4. Exhibition Between Two Worlds (C) Canadian Museum of Civilization, photo Steven Darby, 1998, S2007-0012 


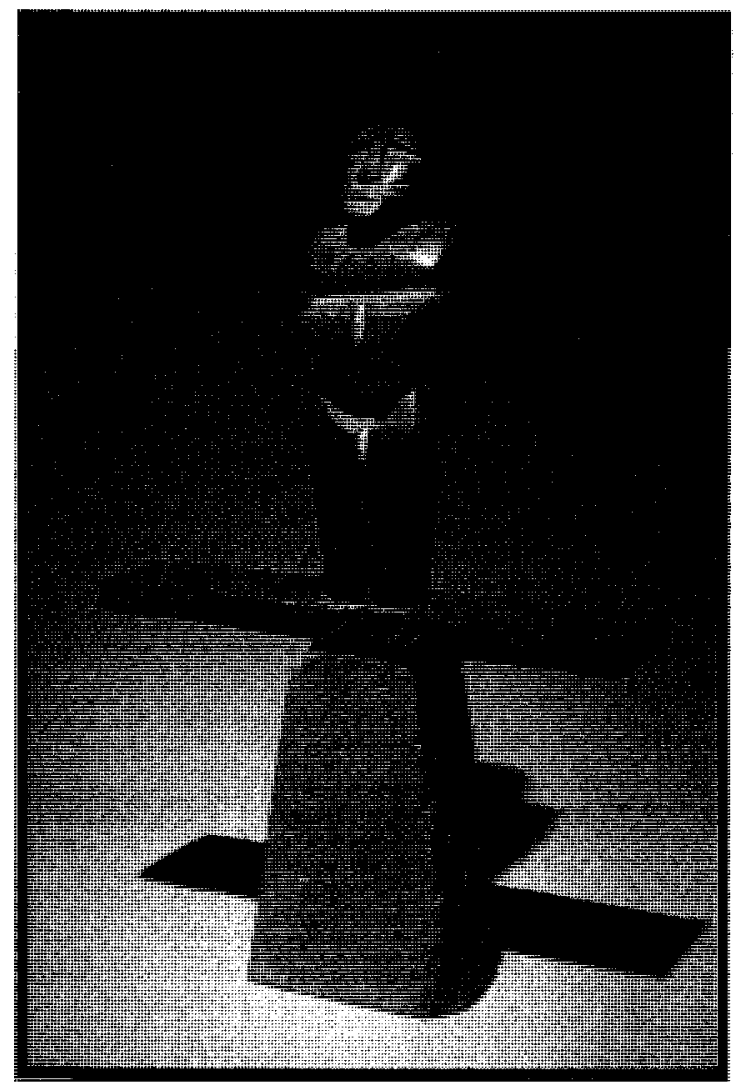

Fig. 1.5. Guidepost, 1995

Brazilian soapstone, limestone, slate

$94.5 \times 61.0 \times 14.5$

Private Collection

www.davidruben.com, virtual gallery, archived pages in author's files 


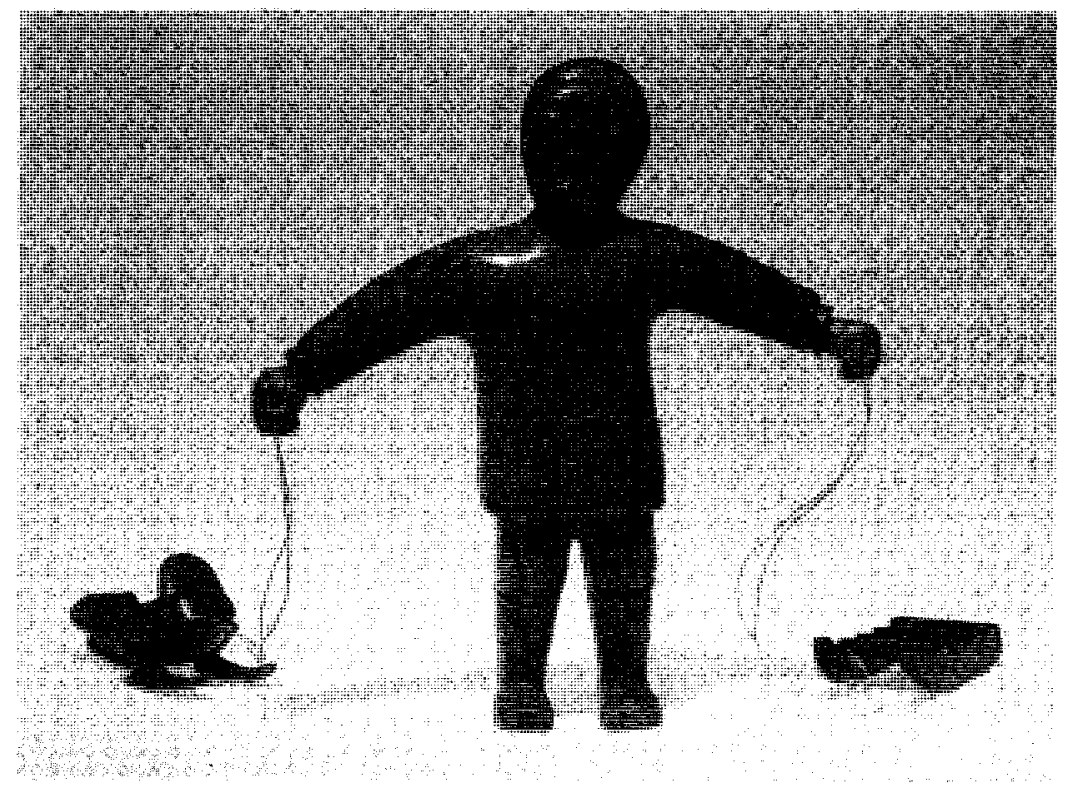

Fig. 1.6. The Choice, 1995 Brazilian soapstone, sinew

$32.3 \times 30.8 \times 13.7$

Private Collection

Darlene Coward Wight, Between Two Worlds: Sculpture by David Ruben Piqtoukun (Winnipeg: Winnipeg Art Gallery, 1996). 


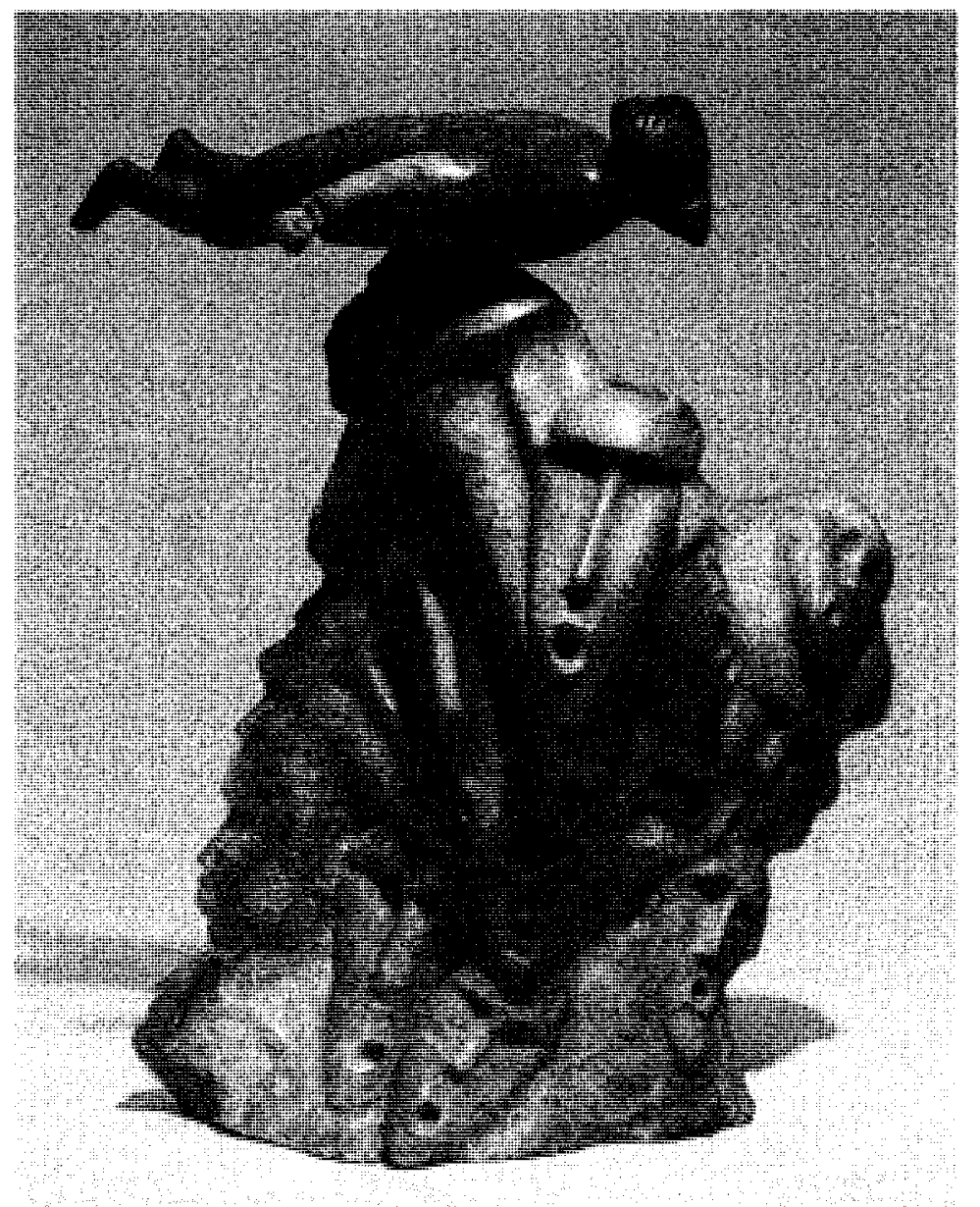

Fig. 1.7. Spirits of My Ancestors, 1995

Greek alabaster, Brazilian soapstone, African wonderstone

$37.4 \times 28.8 \times 17.0$

Private Collection

Darlene Coward Wight, Between Two Worlds: Sculpture by David Ruben Piqtoukun

(Winnipeg: Winnipeg Art Gallery, 1996). 


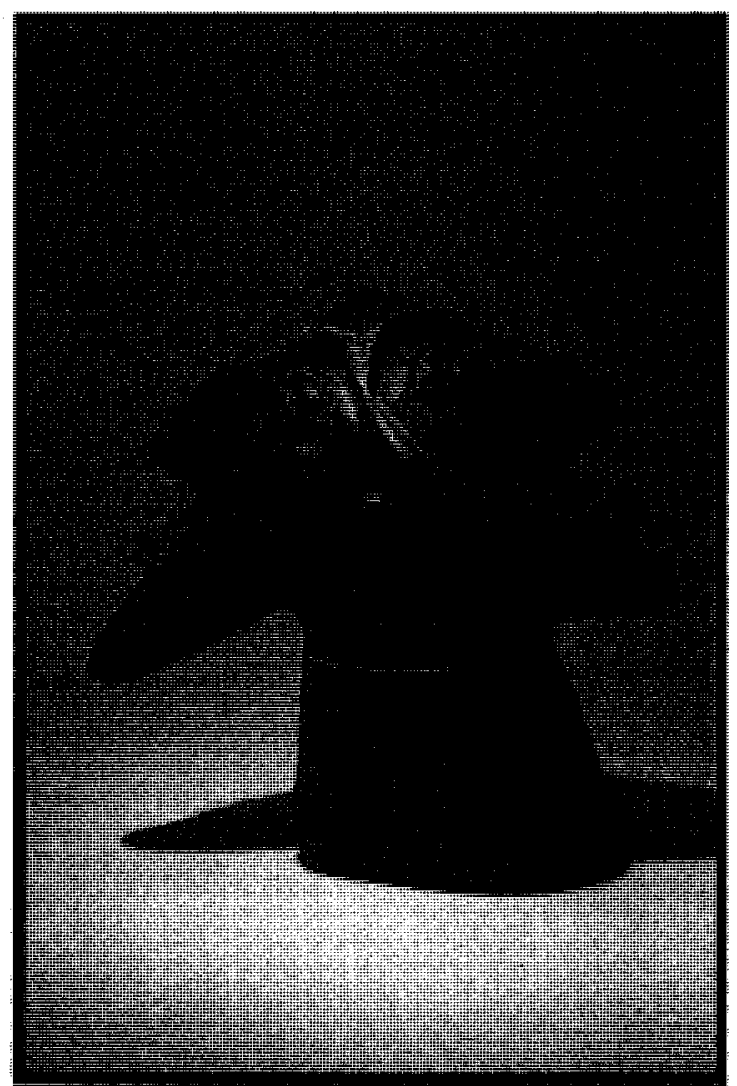

Fig. 1.8. Priest and Nun, 1995

Brazilian soapstone, African wonderstone

$31.3 \times 31.6 \times 19.5$

Private Collection

www.davidruben.com, virtual gallery, archived pages in author's files 


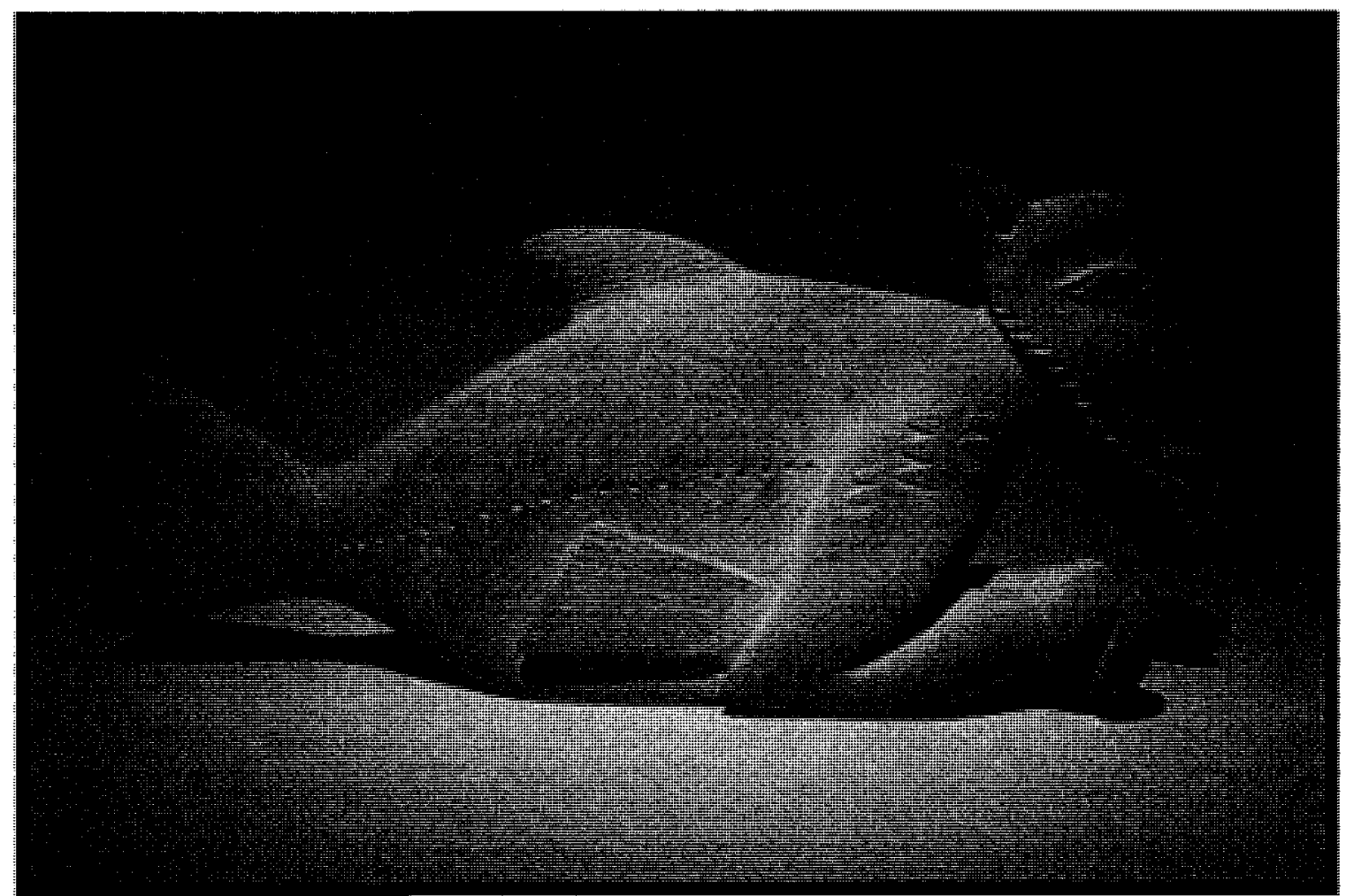

Fig. 1.9. Sedna Lives, 1995

Limestone, African wonderstone, Arizona pipestone

$33.2 \times 74.0 \times 12.3$

Private Collection

www.davidruben.com, virtual gallery, archived pages in author's files 


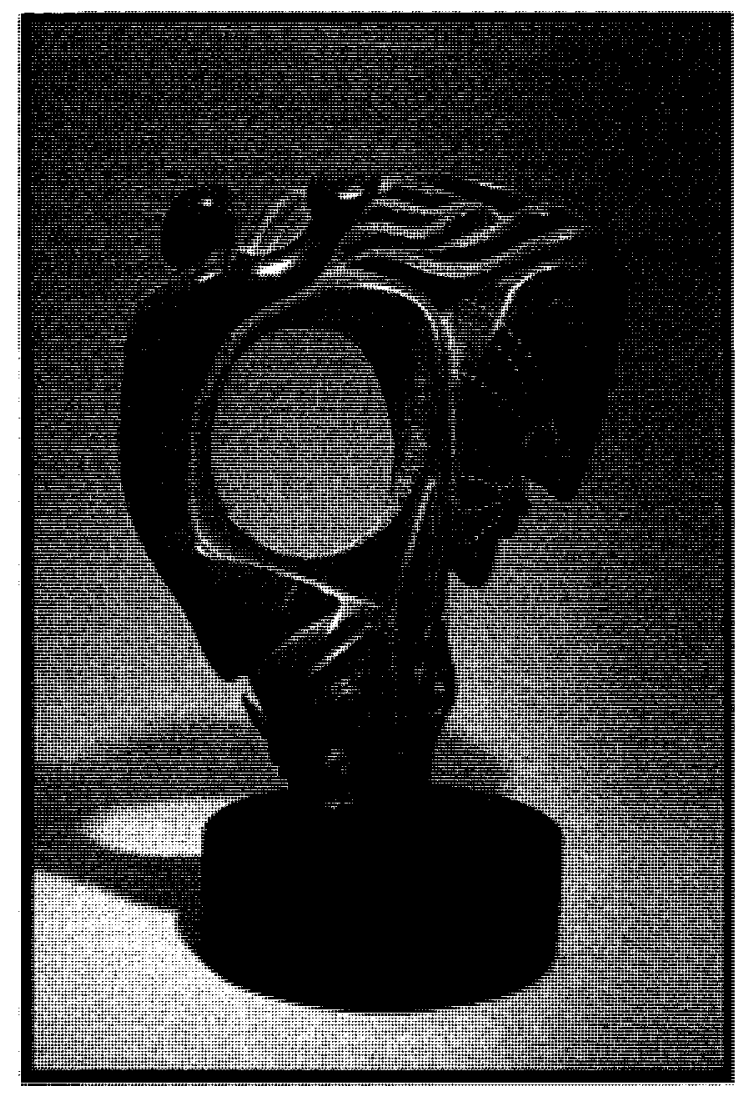

Fig. 1.10. Journey to the Great Woman, 1995

Brazilian soapstone, Ontario marble, Italian crystal alabaster, African wonderstone $58.0 \times 41.0 \times 15.5$

Private Collection

www.davidruben.com, virtual gallery, archived pages in author's files 


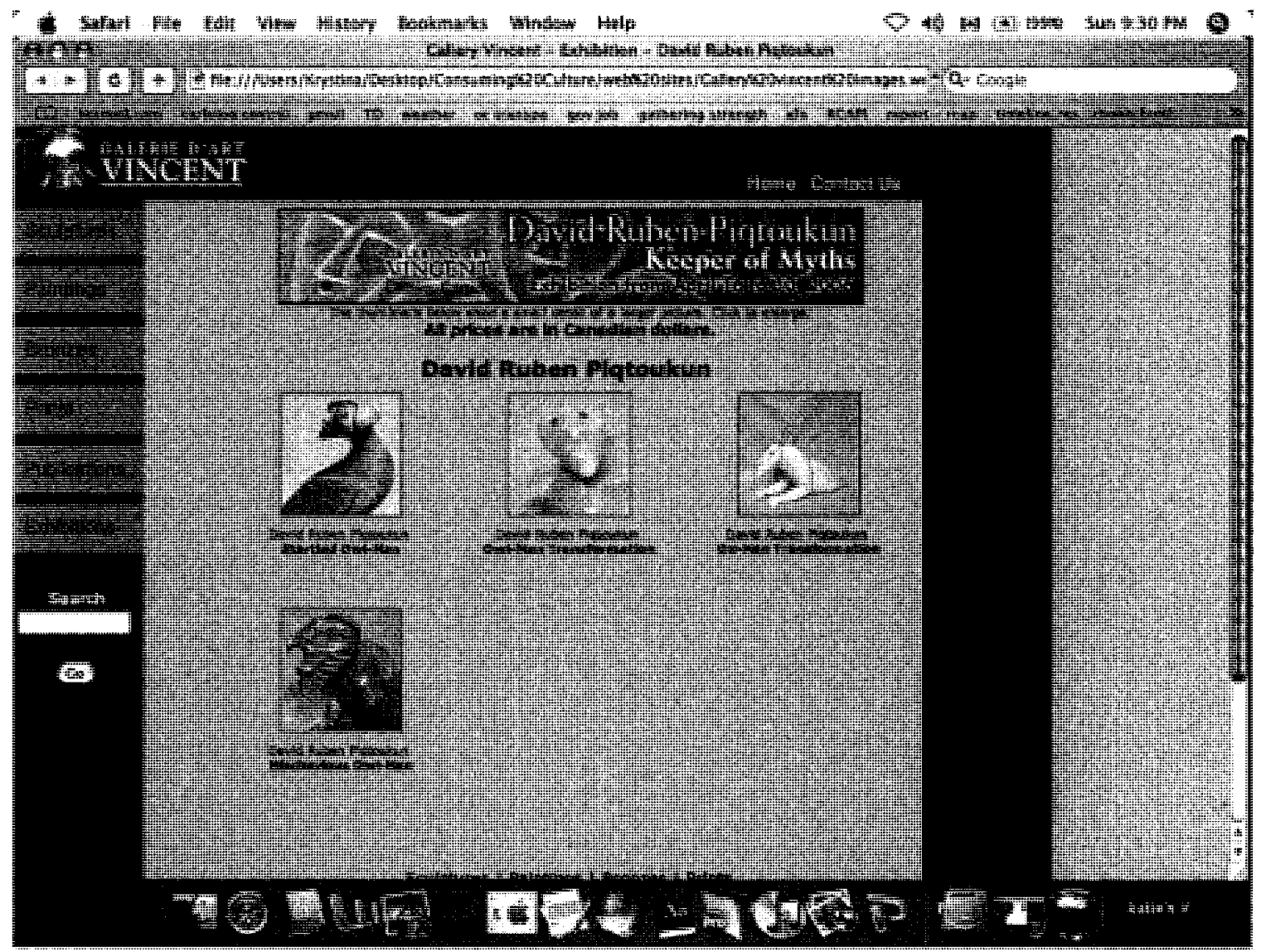

Fig. 2.1. Screenshot, Gallery d'Art Vincent website, virtual gallery of David Ruben Piqtoukun's work

http://www.inuitfinearts.com/vincent/index.html, Accessed 22 March 2007 


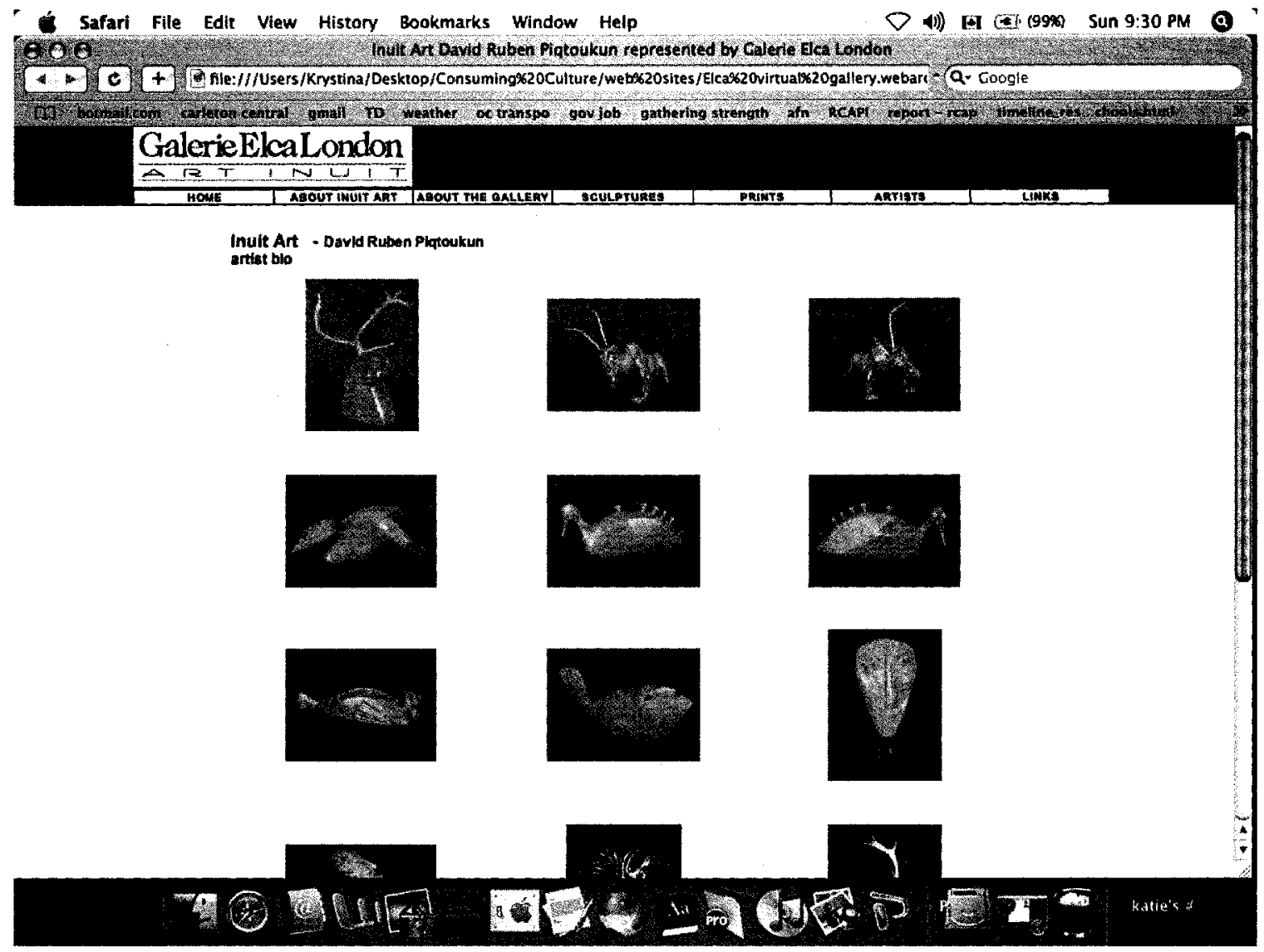

Fig. 2.1. Screenshot, Galerie Elca London website, virtual gallery of David Ruben Piqtoukun's work http://www.elcalondon.com/dynamic/category artist.asp?ArtistID=21, Accessed 22 March 2007 


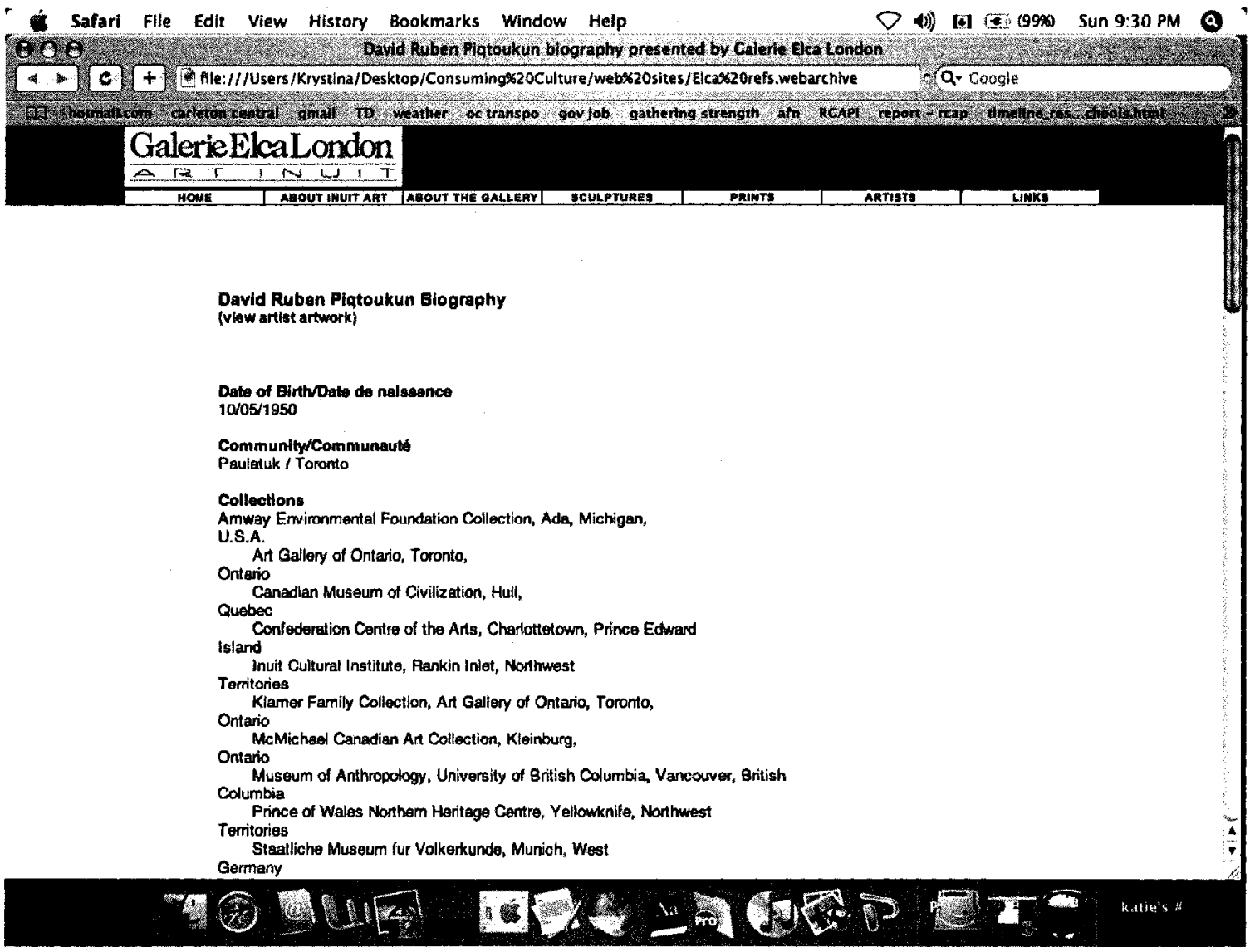

Fig. 2.3. Screenshot, Galerie Elca London website, David Ruben Piqtoukun's biography http://www.elcalondon.com/dynamic/artisst bio.asp?ArtistID=21,

Accessed 22 March 2007 


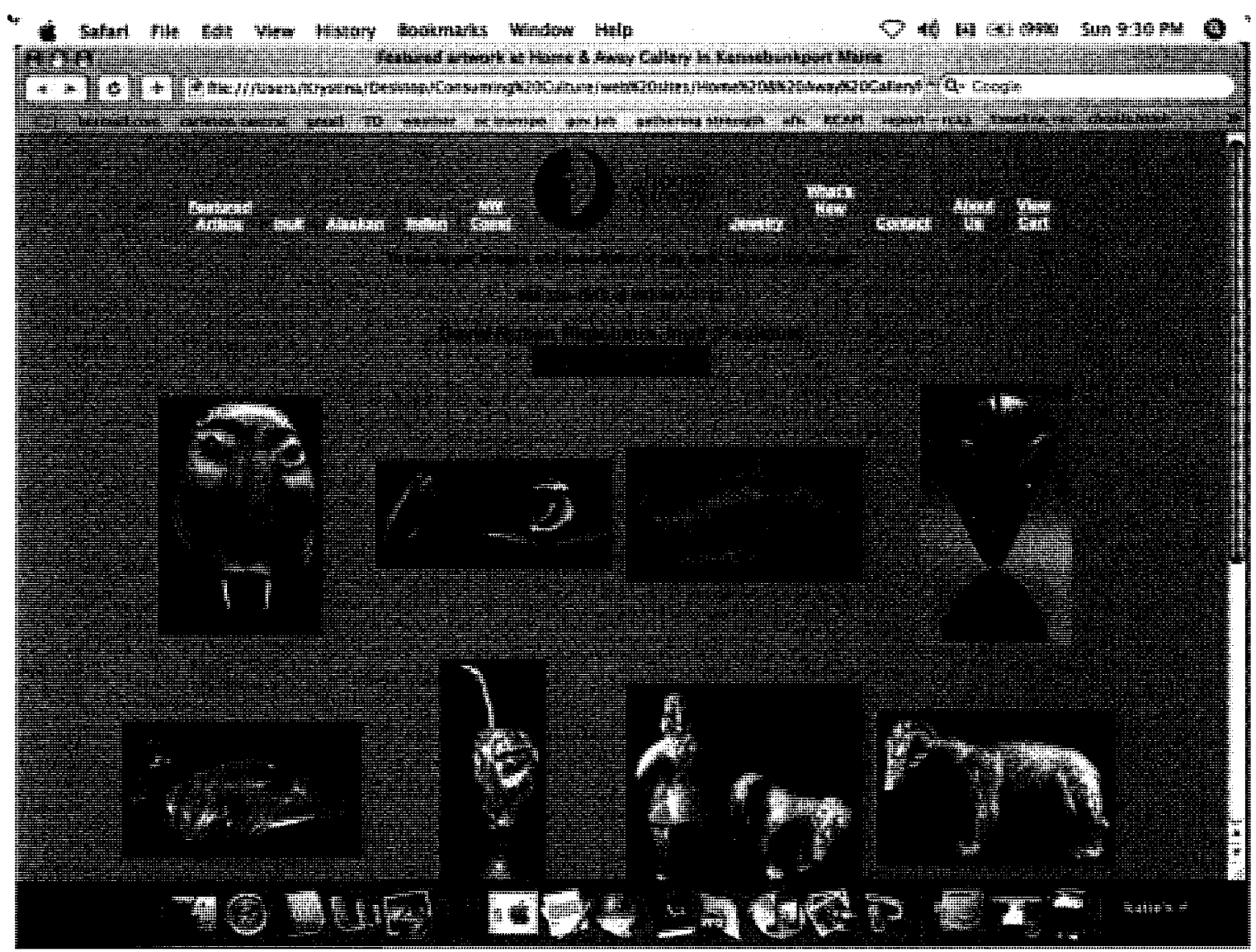

Fig. 2.4. Screenshot, Home and Away Gallery website, virtual gallery of David Ruben Piqtoukun's work

http://www.homeandaway.biz/Featured-gallery.cfm?Manufacturer ID=101, Accessed 22 March 2007 


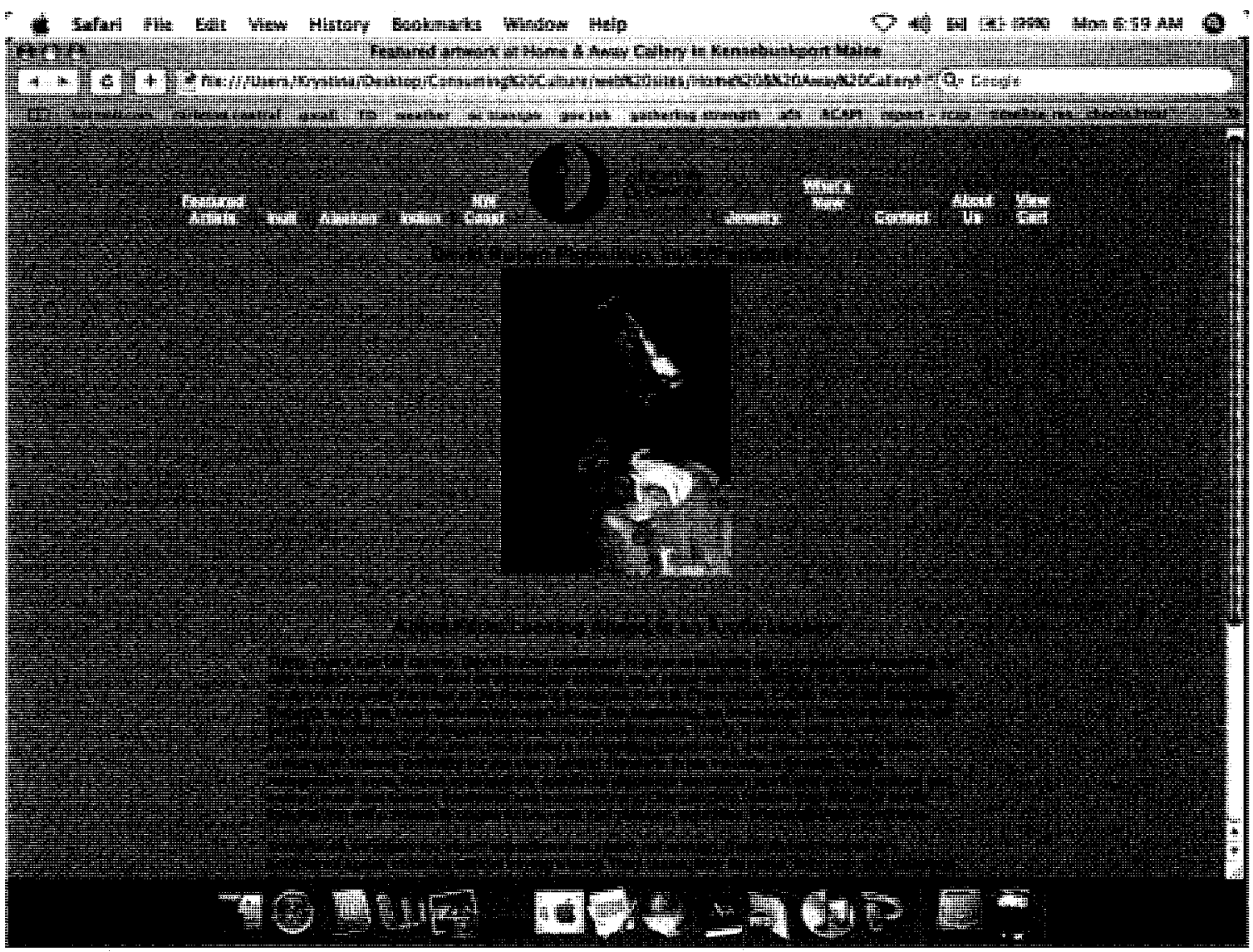

Fig. 2.5. Screenshot, Home and Away Gallery website, David Ruben Piqtoukun's biography

http://www.homeandaway.biz/Artist-bio.cfm?Manufacturer ID=101, Accessed 22 March 2007 


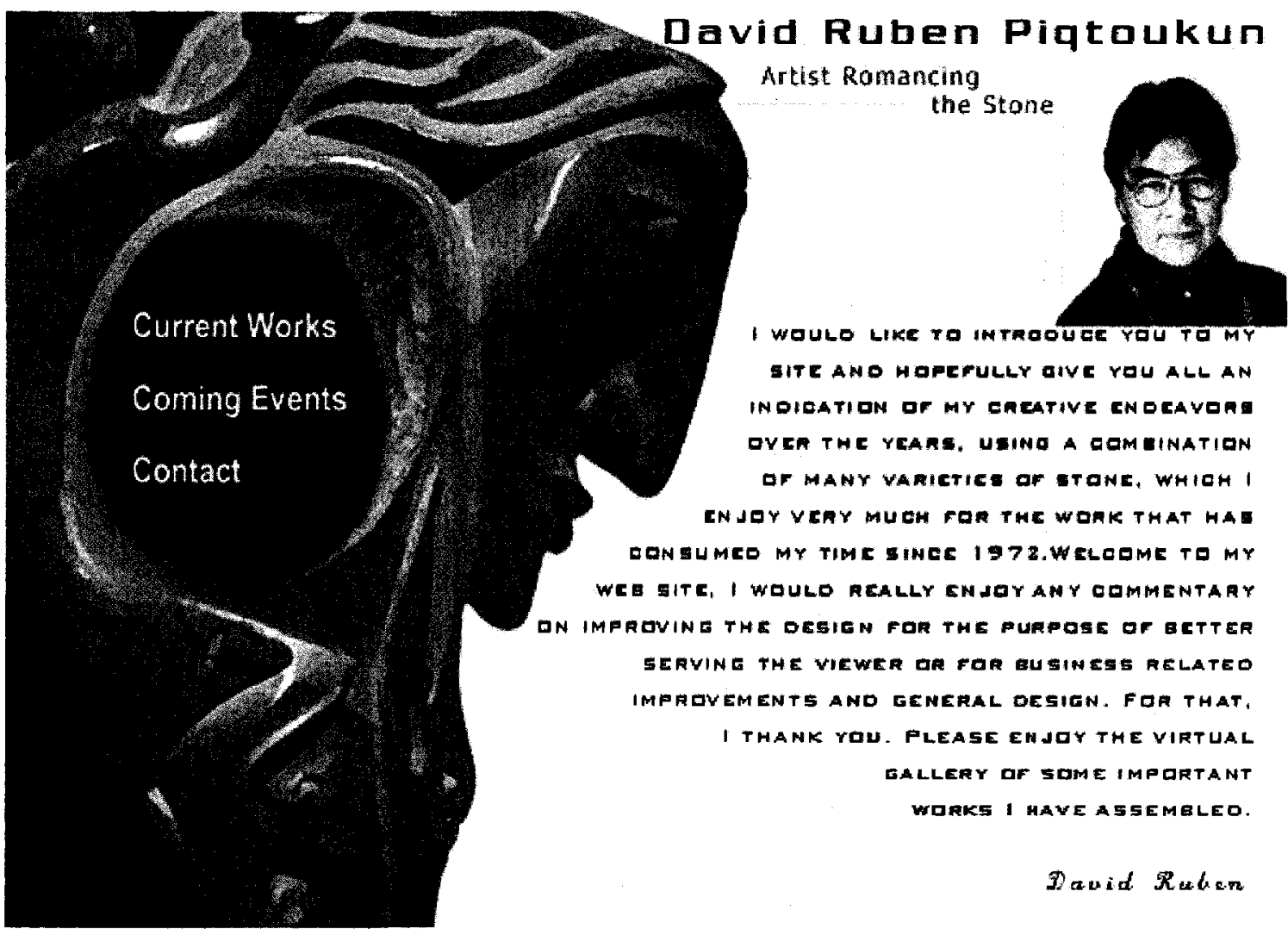

Fig. 2.6. Screenshot, David Ruben Piqtoukun: Artist Romancing the Stone, http://davidruben.com/, last modified on 8 March 2007, Accessed 15 March 2007 


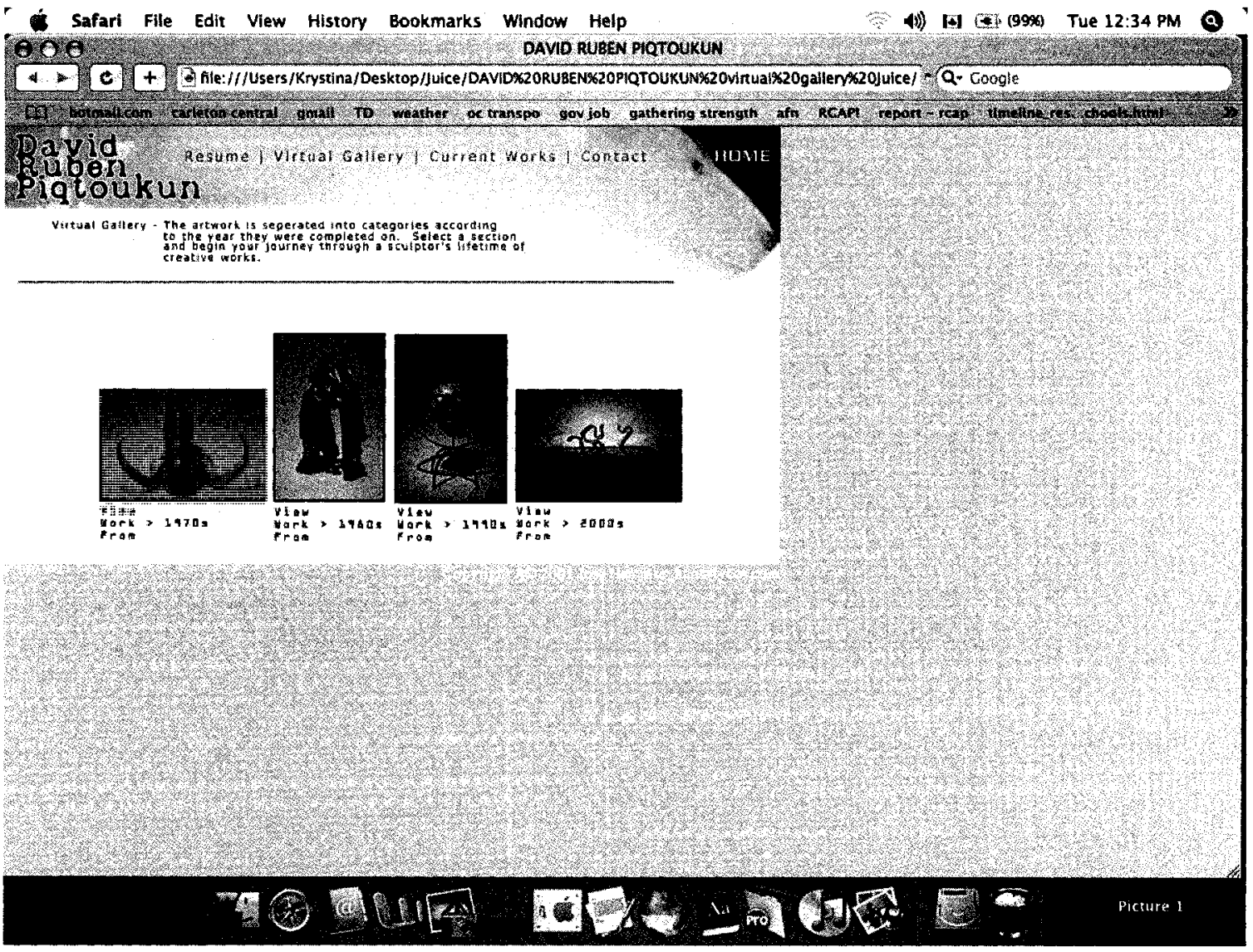

Fig. 2.7. Screenshot, www.davidruben.com virtual gallery, Archived page in the author's files 


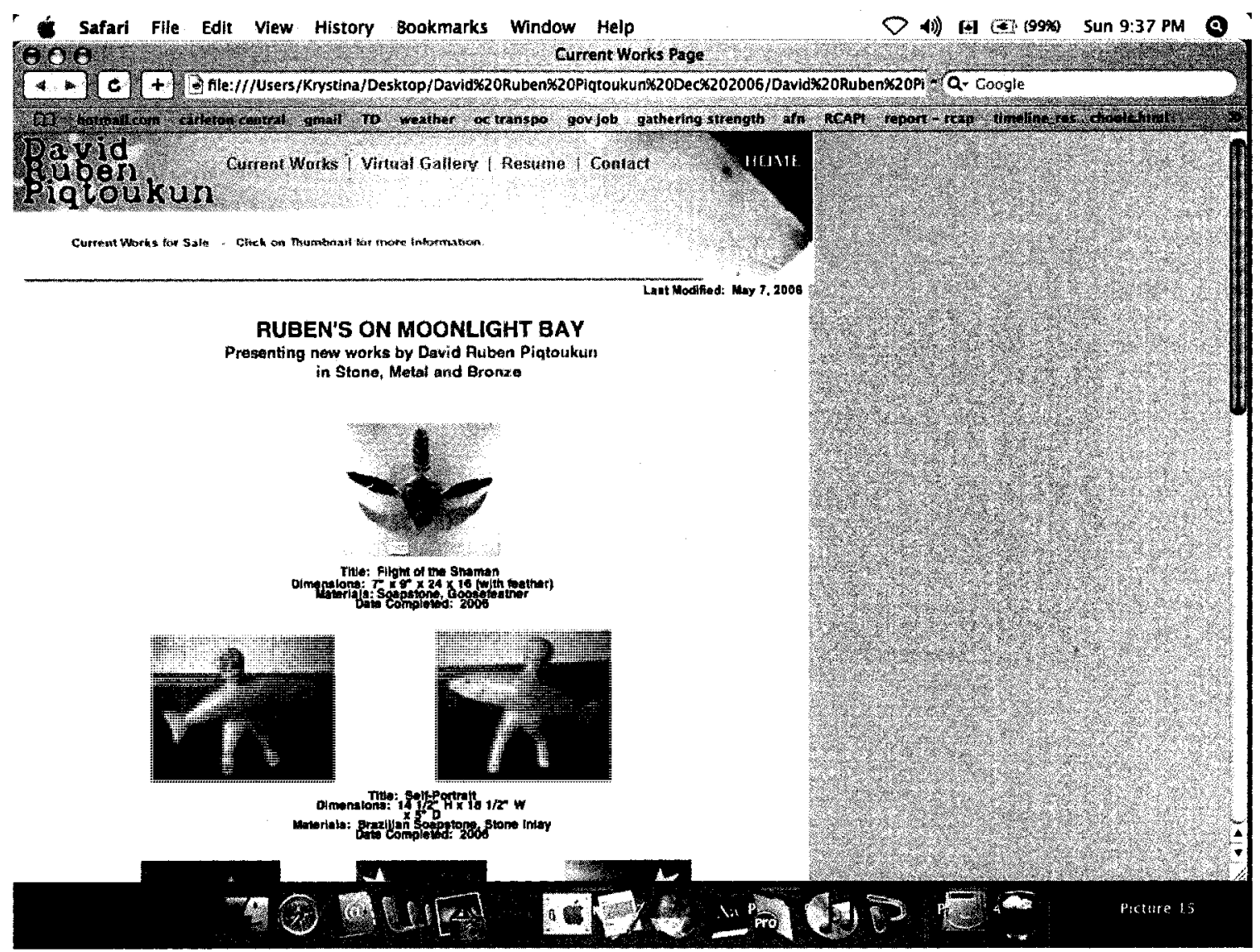

Fig. 2.8. Screenshot, www.davidruben.com virtual gallery of contemporary work, http://davidruben.com/current.html, last modified on 8 October 2007, Accessed 13 October 2007 


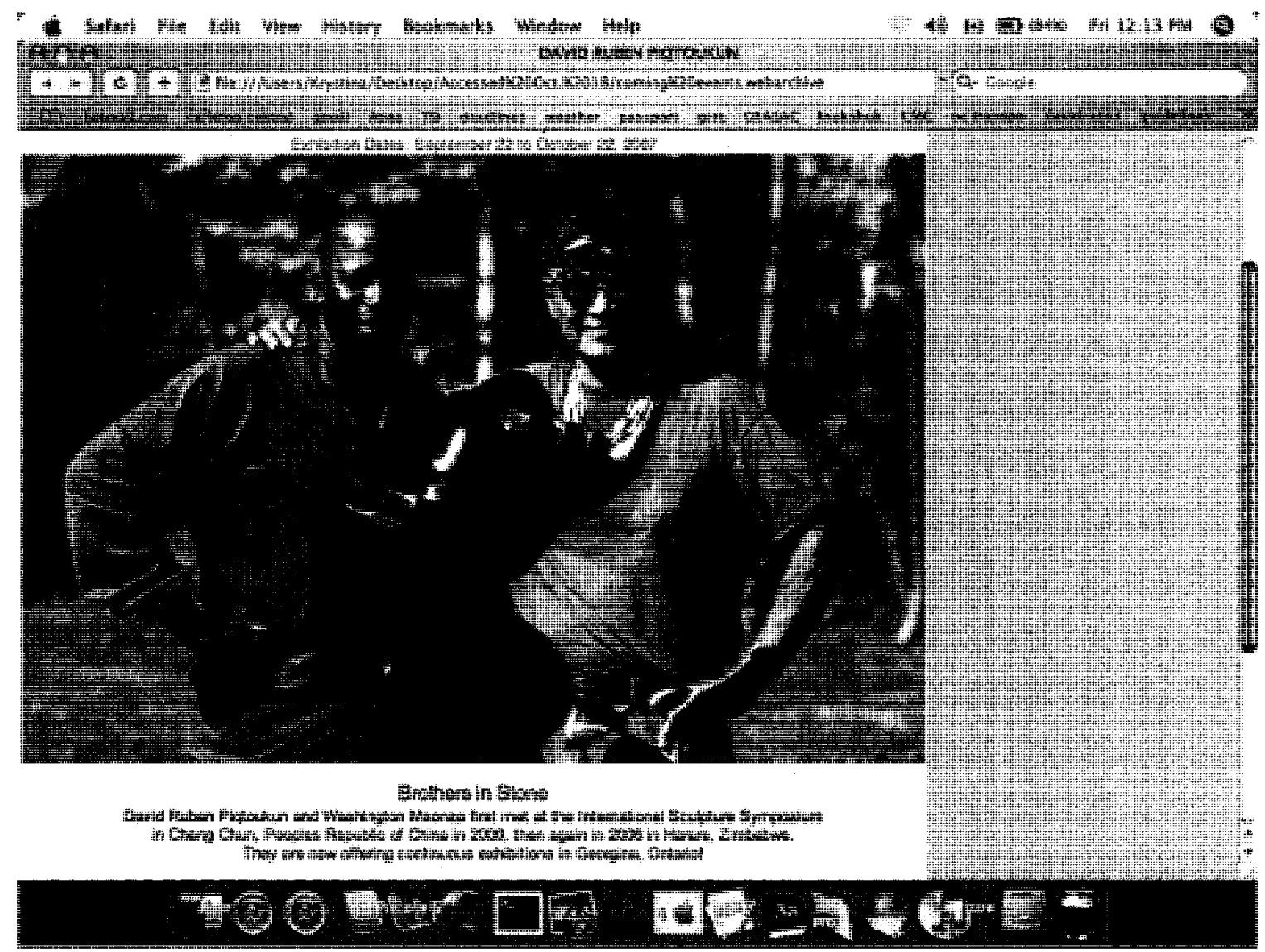

Fig. 2.9. Screenshot, www.davidruben.com coming events, http://davidruben.com/events.html, Last modified on 8 March 2007, Accessed 15 March 2007 


\section{Bibliography}

Appadurai, Arjun. Modernity at Large. Minneapolis: University of Minnesota Press, 1996.

Arnold, Matthew. "Culture and Anarchy," in Cultural Theory and Popular Culture, ed. John Storey, 7-12. Athens, Georgia: The University of Georgia Press, 1998.

Ayre, John. "Piqtoukun, David Ruben." Interview by John Ayre. Inuit Art Quarterly. vol. 9, no. 3 (Fall 1994): 17-22.

Babinski, Roxanne. Shaman Never Die, Jane Ash Poitras and David Ruben Piqtoukun. Ottawa: Gallery Vincent, 1998.

Baele, Nancy. "Memories and Reflection." The Ottawa Citizen. 21 April 1997.

Bagg, Shannon. "The Anthropology of Inuit Art: A Problem for Art Historians," in On Aboriginal Representation in the Gallery, ed Lynda Jessup and Shannon Bagg. Hull, Quebec: Canadian Museum of Civilization, 2002.

Barth, Frederick. Models of Social Organization. Royal Anthropological Institute Occasional Paper 23. London: Royal Anthropological Institute of Great Britain and Ireland, 1966.

Berlo, Janet Catherine. "An Exhibition, a Book and an Exaggerated Reaction," Inuit Art Quarterly, vol. 10, no. 1 (Spring 1995): 26-36.

Bourdieu, Pierre. Distinctions: A Social Critique of the Judgment of Taste, Richard Nice, trans. Cambridge: Harvard University Press, 1984.

Campbell, Heather. "Urban Inuit Artists." Inuit Art Quarterly. vol. 9, no. 2 (Summer 1994): 4-10.

Clifford, James. Routes: Travel and Translation in the late Twentieth Century.

Cambridge, Massachusetts: Harvard University Press, 1997.

Conference for Curators and Specialists who Work with Inuit Art, Canadian Government Conference Centre, September 15 and 16, 1982, Ottawa: Indian Affairs and Northern Development, 1983.

Conlogue, Ray. "A curatorial square-off," The Globe and Mail, 22 October 1994, C17.

Courtright, Merissa. Interview with David Ruben Piqtoukun in Lands of Ice, Hearts of Fire, Inuit Art and Culture. Newark: University of Delaware, 2003: 56-67. 
Coward Wight, Darlene. Between Two Worlds. Winnipeg: Winnipeg Art Gallery, 1996.

“David Ruben Piqtoukun." Inuit Art Quarterly. vol. 18, no. 4 (Winter 2003): 22-25.

David Ruben Piqtoukun: Artist Romancing the Stone. http://davidruben.com/, last modified on 8 March 2007. Accessed 15 March 2007.

. Coming Events. http://davidruben.com/events.html, last modified on 8 March 2007, Accessed 15 March 2007.

. Contact. http://davidruben.com/contact.html, last modified on 8 March 2007, Accessed 15 March 2007.

Current Works. http://davidruben.com/contact.html, version last modified on 8 March 2007, Accessed 15 March 2007.

. Current works, http://davidruben.com/current.html, last modified on 8 October 2007, Accessed 13 October 2007.

Davies, Anthony and Simon Ford, “Art Futures," Art Monthly vol. 9, no. 223 (February 1999): n.p.

Devine, Martha. "Paulatuk Exhibition Shows Spirit, Power." Native Press, July 24, 1987.

Dubin, Margaret. Native America Collected: The Culture of An Art World. Albuquerque: University of New Mexico Press, 2001.

Eggertson, Laura. "Arctic Images Provide Inspiration in Inuit Sculptor's Toronto Studio," The Globe and Mail, 29 December 1987, C7.

Foster, Hal. "Artist as Ethnographer," in The Return of the Real. Cambridge, Massachusetts: The MIT Press, 1996.

Foucault, Michel. "Politics and the Study of Discourse," in The Foucault Effect, ed. Graham Burchell et al. eds. Chicago: University of Chicago Press, 1991.

Galerie Elca London, David Ruben Piqtoukun's biography, http://www.elcalondon.com/dynamic/artisst bio.asp?ArtistID=21, Accessed 22 March 2007.

Virtual gallery of David Ruben Piqtoukun's work, http://www.elcalondon.com/dynamic/category artist.asp?ArtistID=21, Accessed 22 March 2007. 
. Virtual gallery of David Ruben Ruben's work, detail of Shaman Muskox Transformation, http://www.elcalondon.com/dynamic/category artist.asp?ArtistID=21, Accessed 22 March 2007.

Gallery d'Art Vincent. Virtual gallery of David Ruben Piqtoukun's work, http://www.inuitfinearts.com/vincent/index.html, Accessed 22 March 2007.

. Virtual gallery of David Ruben Piqtoukun's work, details of Mischevious OwlMan, http://www.inuitfinearts.com/vincent/exhibitions/Ruben/MOM.html, Accessed 22 March 2007.

Geertz, Clifford. After the Fact. Cambridge, Massachusetts: Harvard University Press, 1995.

. "The Javanese Kijaji: The Changing Role of a Cultural Broker," Comparative Studies in Society and History vol. 2, no. 2 (January 1960): 228-249.

Gillmor, Alison. "Between Two Worlds: Sculpture by David Ruben Piqtoukun.” Inuit Art Quarterly vol. 11, no. 4 (Winter 1996): 30-34.

Glass, Aaron. "Mungo Martin and the Emergence of Northwest Coast Art" Museum Anthropology. vol. 29, no. 1 (2006): 20-43.

Goose, Wayne. Ruben Carving/Photo Exhibit in Yellowknife. Tusaayaksat, August, 1987.

Gunderson, Sonia. "David Ruben Piqtoukun: In Search of a Softer Wind," Inuit Art Quarterly vol. 22, no.1 (Spring 2007): 28-35.

Hallowell, Irving. "American Indians, White and Black: The Phenomenon of Transculturalization." Current Anthropology. vol. 4, no. 5 (1963): 519-531.

Hessel, Ingo. Inuit Art: An Introduction. Toronto: Douglas and McIntyre, 1998.

Home and Away Gallery, David Ruben Piqtoukun's biography, http://www.homeandaway.biz/Artist-bio.cfm?Manufacturer ID=101, Accessed 22 March 2007.

- Virtual gallery of David Ruben Piqtoukun's work, http://www.homeandaway.biz/Featured-gallery.cfm?Manufacturer ID=101, Accessed 22 March 2007. 
- Virtual gallery of David Ruben Ruben's work, Detail of Raven Steals the Moon, http://www.homeandaway.biz/Featured-

gallery.cfm?Manufacturer ID=101, Accessed 22 March 2007.

Hooper- Greenhill, Eilean. "Education, communication and interpretation: Towards a Critical Pedagogy in Museums," In The Educational Role of the Museum, $2^{\text {nd }}$ ed. Eilean Hooper-Greenhill, ed. New York: Routledge, 1999.

Houston, James. "In Search of Contemporary Eskimo Art," Canadian Art. vol. 9, no 3 (Spring 1952): 99-104.

Hyer, Sally. "Pablita Velarde: The Pueblo Artist As Cultural Broker," in Between Indian and White Worlds: The Cultural Broker, Edited by Margaret Connell Szasz. Norman, Oklahoma: University of Oklahoma Press, 1994.

"Inuit Legends Kept Alive in Artist's Work of Stone." Winnipeg Free Press, January 2, 1988.

Jonaitis, Aldona. "First Nations and Art Museums," in On Aboriginal Representation in the Gallery, ed Lynda Jessup and Shannon Bagg. Hull, Quebec: Canadian Museum of Civilization, 2002.

Jones, Brian. “Artist Sees Tundra as a Cleansing Process." News/North. JulySeptember, 1987 (also printed in Weekender, "Piqtoukun's Magic Mitt").

Jones, Gloria. "Sculpture Symposium Unique to West Coast." Monday Magazine. July 21-27 (1975): 9.

Lalonde, Christine. Inuit Sculpture Now. Ottawa: National Gallery of Canada, 2005.

Leroux, Odette, Marion E. Jackson and Minnie Aodla Freeman, eds. Inuit Women Artists. Toronto: Douglas and McIntyre, 1994.

Legends in Stone. CBC film, 1995.

Lionnet, Françoise and Shu-mei Shih, eds. Minor Transnationalisms. Durham and London: Duke University Press, 2005.

Macdonald, Dwight. "A Theory of Mass Culture," in Cultural Theory and Popular Culture, ed. John Storey, 22-36. Athens, Georgia: The University of Georgia Press, 1998.

Marcus, George E. and Fred R. Myers, eds. The Traffic in Culture: Refiguring Art and Anthropology. Berkeley and Los Angeles, California: University of California Press, 1995. 
Mitchell, Marybelle. From Talking Chiefs to A Native Corporate Elite. Montreal and Kingston: McGill-Queen's University Press, 1996.

Mullin, Molly. "The Patronage of Difference," in The Traffic in Culture, ed. Fred R. Myers and George E. Marcus, 166-198. Berkeley and Los Angeles: University of California Press, 1995.

Myers, Fred. "Representing Culture," in The Traffic in Culture, ed. Fred R. Myers and George E. Marcus. Berkeley and Los Angeles: University of California Press, 1995.

New Sun Conference on Aboriginal Arts. Transforming Traditions. Carleton University: February 28, 2004.

Nicks, Trudy. "Partnerships in Developing Cultural Resources: Lessons from the Task Force on Museums and First Peoples." Culture vol. 12, no. 1 (1992): 87-94.

Paine, Robert, ed. Patrons and Brokers in the East Arctic. Memorial University of Newfoundland Social and Economic Papers 2. Toronto: University of Toronto Press: 1971.

Paulatuk Album: People of the 30s. Tusaayaksat, June, 1986.

Pearlstone, Zena. The Wheelwright Museum of the American Indian, Past Exhibitions, About Face: Self-Portraits by Native American, First Nations, and Inuit Artists, November 13, 2005 - April 23, 2006. http://www.wheelwright.org/exhibitions/AboutFace/aboutface.html. Accessed 12 October 2007.

Phillips, Ruth B. "Re-placing Objects: Historical Practices for the Second Museum Age," Canadian Historical Review vol. 86, no. 1 (March 2005): 83-170.

Phillips, Ruth B and Christopher B. Steiner. "Art Authenticity and the Baggage of Cultural Encounter." In Unpacking Culture: Art and Commodity in Colonial and Postcolonial Worlds, ed. Ruth B. Phillips and Christopher B. Steiner, 3-19. Berkeley: University of California Press, 1999.

Pratt, Mary Louise. Imperial Eyes: Travel Writing and Transculturation. New York: Routledge, 1992.

Press, Irwin. "Ambiguity and Innovation: Implications for the Genesis of the Culture Broker," American Anthropologist vol. 71, no. 2 (April 1969): 205-217. 
Prince of Wales Northern Heritage Centre Paulatuk: Mythology in Stone and

Photographs. David Ruben Piqtoukun and Tom Skudra. Yellowknife, N.W.T.:

Prince of Wales Northern Heritage Centre, 1987.

"Provocative Inuksuk Installed in Government Building," Inuit Art Quarterly vol. 22, no.3 (Fall 2007): 33.

Potter, Kristin K. "James Houston, Armchair Tourism, and the Marketing of Inuit Art." In Native American Art in the Twentieth Century, ed. Rusthing III, W. Jackson, 39-56. New York, NY: Routledge, 1999.

Routledge, Marie and Marion E. Jackson, Pudlo: Thirty Years of Drawing. Ottawa: National Gallery of Canada, 1990.

Ruben Piqtoukun, David. "A Journey to the Ivory Coast." About Arts and Crafts. vol. 5, no. 3 (1982): 1-8.

- "Inuit Sculpture Arts and China Changchun International Sculpture

Symposium," in Sculpturing Brilliance, Changchun Publishing House, 136-138.

. "Piqtoukun, David Ruben." Interview by John Ayre. Inuit Art Quarterly vol. 9, no. 3 (Fall 1994): 17-22.

. Sharing the Good Food, 1999, in cybermuse.

http://gallery.ca/cybermuse/search/artwork e.jsp?mkey=97186. Accessed 13 October 2007.

. “Trip to Abidjan, Ivory Coast, Africa." Inuktitut. (January1983):19-32.

Ryan, Allan and Zena Pearlstone, curators. About Face: Native American, First Nations and Inuit Self-Portraits. Santa Fe, New Mexico: Wheelwright Museum of the American Indian, 2006.

Said, Edward. The World The Text and The Critic. Cambridge, Massachusetts: The Harvard University Press, 1983.

Simpson, Bennett. "Pushing an Open Door: the Artist as Culture Broker," in The Americans. New Art, curated by Mark Sladen. London: Booth-Clibborn Editions, 2001 .

Sinclair, James. "David Ruben Piqtoukun Between Two Worlds." Inuit Art Quarterly. vol. 19, no. 3 and 4 (Fall/Winter 2004): 24-30. 
Speak, Dorothy. "Pudlo: Thirty Years of Drawing: The First Solo exhibition of an Inuit artist's work at the National Gallery of Canada, July 6 to September 3, 1990," IAQ, special issue, 1991.

Spiegler, Marc. "Do Contemporary Dealers still Need Galleries?," The Art Newspaper no. 148 (June 2004): 26, 28.

Steiner, Christopher B. African Art in Transit. Cambridge: Cambridge University Press, 1994.

Storey, John. "Introduction: The Study of Popular Culture and Cultural Studies" in Cultural Theory and Popular Culture, ed. John Storey, x-xviii. Athens, Georgia: The University of Georgia Press, 1998.

"Part One Introduction," in Cultural Theory and Popular Culture, ed. John Storey, 3-6. Athens, Georgia: The University of Georgia Press, 1998.

"Part Three Introduction," in Cultural Theory and Popular Culture, ed. John Storey, 93-98. Athens, Georgia: The University of Georgia Press, 1998.

Sutherland, David. "Paulatuk: Mythology in Stone and Photographs." Inuit Art Quarterly, vol. 2, no. 4 (Fall, 1987):13.

Swinton, George. "The Inuit Imagination at the Winnipeg Art Gallery." Inuit Art Quarterly. vol. 9, no. 2 (Summer 1994): 32-35.

. "Out of Tradition, Abraham Anghik and David Ruben Piqoukun at the Winnipeg Art Gallery." Inuit Art Quarterly. vol. 4, no. 3 (Summer 1989): 2325.

Symbols of Survival. Toronto: Paulatuk Fine Art, 1987.

Szasz, Margaret Connel, ed. Between Indian and White Worlds: The Cultural Broker. Norman: University of Oklahoma Press, 1994.

Thomas, Nicholas. Possessions: Indigenous Art/Colonial Culture. London: Thames and Hudson, 1999.

"Turning the Page: Forging New Partnerships Between Museums and First Peoples." A Report jointly sponsored by the Assembly of First Nations and the Canadian Museums Association, Ottawa, 1992.

Wight, Darlene. Between Two Worlds: Sculpture by David Ruben Piqtoukun. Winnipeg: Winnipeg Art Gallery, 1996. 
Interview by author. 27 April 2007. Audio recording. Carleton University, Ottawa.

. Out of Tradition: Abraham Anghik / David Ruben Piqtoukun: a retrospective exhibition. Winnipeg: Winnipeg Art Gallery, 1989.

Williams, Raymond. "The Analysis of Culture," in Cultural Theory and Popular Culture, ed. John Storey, 48-56. Athens, Georgia: The University of Georgia Press, 1998.

Wolf, Eric R. Anthropology. Englewood Cliffs, New Jersey: Prentice-Hall, 1964.

. "Aspects of Group Relations in a Complex Society: Mexico," American Anthropologist vol. 58, no. 6 (December 1956): 1065-1078. 